\title{
A HOME IN THIS WORLD: THE REPRESENTATION OF LOCATION AND IDENTITY IN THE PROSE FICTION TEXTS OF KATHERINE MANSFIELD, ROBIN HYDE AND JANET FRAME.
}

\section{by}

\author{
Stephanie Alison Pride
}

\begin{abstract}
A thesis
sub mitted to the Victoria University of Wellington in fulfilment of the requirements for the degree of Doctor of Philosophy
\end{abstract}

Victoria University of Wellington 1993 
There is no home in this world for colonising peoples, but the desire for a place or a state to call home permeates their literature. The act of colonising is an act of dispossession, not only for the autochthonous peoples, but for the colonising peoples too. The colonising peoples can never regain their relationship of autochthonicity to their imperial nation, but neither can they ever gain a truly autochthonous relationship to the colonised land, because the founding act of dispossession stands in their way. The loss of autochthonous identity and location is one which can never be fulfilled. There is no longer a home to go to.

The anxiety about identity and location which this loss produces is a basic condition of coloniality which cannot be escaped. This anxiety about identity and location can be tracked through the prose fiction writings of Katherine Mansfield, Robin Hyde and Janet Frame. Although the founding loss of autochthonicity cannot be undone or supplemented, it can be displaced, denied, disavowed or seized and interrogated.

Although this condition of coloniality is produced by a founding moment in history, the way in which that condition is manifested in the texts is not fixed and transhistorical. Coloniality is displayed differently in each of the three groups of texts examined here.

The dynamics of disavowal characterise the texts of both Mansfield and Hyde, but the products of this disavowal differ. Whilst the texts of Mansfield produce the colonising subject as a discriminated subject, the texts of Hyde produce the colonised subject as a discriminated subject. Frame's text interrogates its coloniality rather than disavowing it and attempts to articulate the foundering moments of individual and national identity rather than their founding moments. Under the hegemony of multinational consumer capital, the permanent nostalgia, which is the condition of coloniality, has become, also, the condition of the world. 


\section{ACKNOWLEDGEMENTS}

Firstly, my thanks go to John for his patient and scrupulous supervision.

I also appreciated the warm welcome I was given in the English Department at Victoria, when I arrived there as a complete stranger. I value highly the friendships that have developed in my time here.

I am grateful for the assistance I have received in the various libraries I have needed to use in the course of my research. The manuscripts staff at the Auckland University and Public Libraries have been particularly helpful, as have the staff in the reference department at Victoria University Library (especially Justin Cargill!).

The feminist theory reading group which thrived in the department for a short while was a great source of support and encouragement, for which I thank the other women involved.

Thank you Judith, Francine and Dave for the proof-reading.

And above all, my thanks to Diane Cooper for her continual support and her generosity of self, without which neither I, nor this thesis, would be here. 
TABLE OF CONTENTS

INTRODUCTION

1

CHAPTER $1:$ THE IMPORTANCE OF BEING AUTOCHTHONOUS.

CHAPTER 2 : THE BULL IN THE METROPOLIS.

CHAPTER 3 : EPILOGUE I: OLD LACE, TURKISH BATHS 96 AND BARBAROUS PINEAPPLES. CONFLICTED SUBJECT POSITIONS IN MANSFIELD'S STORIES.

CHAPTER 4 : CONCERNING GODWITS.

CHAPTER 5 : THE DOMEST ICATED ANGEL:

HYDE'S TEXTS AND THE PROBLEMS OF ESSENTIALISM.

CHAPTER 6 : EPILOGUE II: L'ENTENTE CORDIALE?

TRACES OF RACISM.

CHAPTER 7 : RETHINKING THE BLUE FURY.

CONCLUSION: PERMANENT NOSTALGIA

OR

THE CONCLUSION IN WHICH NOTHING

262 IS CONCLUDED.

BIBLIOGRAPHY

266

ILLUSTRATIONS

FIGURE 5.1 'BEING A GIRL'

170

FARMER'S UNION ADVOCATE 29 JULY 1922

FIGURE 6.1 'THE RETORT COURTEOUS'

NEE ZEALAND ARTISTS' ANNUAL, 1931206 


\section{INTRODUCTION}

There is no home in this world for colonising peoples, but the desire for a place or a state to call home permeates their literature. The act of colonising is an act of dispossession, not only for the autochthonous peoples, but for the colonising peoples too.1 The colonising peoples can never regain their relationship of autochthonicity to their imperial nation, but neither can they ever gain a truly autochthonous relationship to the colonised land, because the founding act of dispossession stands in their way. The loss of autochthonous identity and location is one which can never be fulfilled. There is no longer a home to go to.

The anxiety about identity and location which this loss produces is a basic condition of coloniality which cannot be escaped. This anxiety about identity and location can be tracked through the prose fiction writings of Katherine Mansfield, Robin Hyde and Janet Frame. Although the founding loss of autochthonicity cannot be undone or supplemented, it can be displaced, denied, disavowed or seized and interrogated.

I Simon During uses the term 'postcolonising' to identify 'those communities and individuals who profit from and identify themselves as heirs to the work of colonising, and 'postcolonised' to identify 'those who have been dispossessed by that work and who identify with themselves as heirs to a more or less undone culture' ('Postmodernism or Postcolonialism?' Landfall 155 (1985) pp.369-70. The terms 'colonising,' 'postcolonising,' 'colonised' and 'postcolonised' will be used where appropriate in this thesis to make the distinction which During outlines. 
In some of Mansfield's texts there is a strenuous attempt to disavow coloniality by adopting a position of European autochthonicity, but the very strenuousness of this attempt reveals the coloniality of the texts. The relationship between gender identity and colonial identity is unstable and fraught with ambivalences in these texts.

In Hyde's texts there is some explicit consideration of the problems of colonial identity, where it figures as displacement and dislocation. When these texts participate in the production of a notion of New Zealand national identity, the anxieties and the disavowals on which the claims to national identity are founded return to undermine the texts in other places.

Frame's texts interrogate the very notions of sense of place and identity. In doing this they engage explicitly with the anxieties of coloniality, the loss of autochthonous identity and location, has not been cured, it has become, not just the condition of the colonising peoples, but the condition of the nation state too. There is no resolution of the problems of location and identity, but now there is no home, quite literally, in the world.

I was first introduced to the prose fiction writing of Katherine Mansfield at the age of fourteen in an English class, in an English school, where we read 'Daughters of the Late Colonel.' The story was in an anthology of twentieth-century English short stories. It was only when, appetite whetted, I borrowed the Complete Works from the local library, that I began to develop a suspicion that Mansfield was not just an English writer. Re-reading Mansfield's stories in my first year at university (again under the zgis of twentieth-century English 
literature), I became aware that Mansfield's texts 'had been (mis)read in the light of what was understood to be English or British literature, international modernism, [and] the plight of humankind in the twentieth century.'2 Mansfield's œuvre was positioned as either peripheral to the Bloomsbury group and the development of modernist short fiction or the sentimental and thinly veiled autobiographical reminiscences of the banker's daughter from Karori.

What struck me was the lack of attention to coloniality in Mansfield's fiction and the excess of attention to her life. Her New Zealand life was documented, relentlessly, and her New Zealand life was discussed, relentlessly, as the source for the settings and characters of her fiction. The specificity of its coloniality went, by and large, unremarked. When her fiction was discussed in relation to the development of European modernism, her coloniality was only registered as a deracination which helped her to enter the modernist condition more fully. Literary criticism in New Zealand, obviously, has been more concerned with the question of coloniality, but until the mid 1980s, the main critical impetuses still seemed to be either biographical or part of an attempt to identify a particular New Zealand essence in Mansfield's texts. The majority of critical commentary on Robin Hyde and Janet Frame has also been governed by a similar motivation. In the last two decades there has been a body of feminist writing produced which investigates the significance of Mansfield,

2 Seamus Deane, introduction. Terry Eagleton. Frederic Jameson, and Edward Said, Nationalism, Colonialism and Literature (Minneapolis: Minnesota UP, 1990), p.11. Further references to Deane in the text. Deane's comments are made in respect of the colonial appropriation of Yeats and Joyce, but they seem to me to be equally applicable to the types of critical attention given to Mansfield. particularly in Britain, up to the beginning of the 1980 s. 
Hyde and Frame as women writers, but this, too, by and large investigates the relationship between the writers and their works.

This thesis resolutely refuses to engage in biographical criticism because for all three writers whom I consider here, the attention given to their lives and to the relationships between their lives and their texts has far outweighed the attention paid to their literary texts, to the relationship between their literary texts and other literary texts, and to the relationship between their texts and the wider economical, social and political context. I feel this is a balance which requires substantial redressing. I do not attempt to answer questions about whether Kathleen Mansfield Beauchamp, Iris Wilkinson or Janet Frame Clutha felt or feel at home in New Zealand. That is not within the ambit of this thesis. This thesis is concerned specifically with analysing textual representations.

The absence of attention to coloniality that struck me as an undergraduate reading Mansfield's fiction is one that this thesis attempts to fill, not only for the fiction of Mansfield, but for that of Robin Hyde and Janet Frame too. It examines the way in which the loss of autochthonicity (the loss of a home in this world) is registered in the three bodies of writing. These bodies of writing were all produced at different periods in colonial history. Within each body of writing this thesis examines the specific ways in which colonial identity is registered.

Given that identity and location are abstract concepts which are in danger of spreading until they are so ineffably vague and diffuse that they are unworkable, the discussion of each body of writing starts with a consideration of sense of place. In order to do this it adopts a 
schema from Stephen Gray's keynote address to the 1982 Macquarie University Conference on the Sense of Place in the New Literatures in English and applies this to each body of writing in turn. Gray's main contention is that particular notions of identity can be read off from particular representations of place. In the process of applying Gray's schema to each group of texts in turn, two things become clear. One is the differences in the particular representation of colonial identity between the bodies of writing, and the other is the problems inherent in Gray's analysis itself. The problems which Gray's analysis raises (often by foreclosing on them) are then turned back upon the texts in a further examination of their representations of coloniality and its intersection with the representation of other components of identity. 


\title{
CHAPTER ONE \\ The importance of \\ being autochthonous
}

\begin{abstract}
autochthon, n. Original, earliest known inhabitants; ... [Gk, = sprung from that land itself] (Concise Oxford Dictionary).
\end{abstract}

\section{Introduction.}

This section provides a discussion of the usefulness of Stephen Gray's analysis of sense of place in South African literature. This discussion will be drawn on in the rest of the thesis. I start by setting out some of the basic terms which will be used in the ensuing discussion. I then outline Gray's analysis of sense of place in South African literature and suggest some modifications to his terminology. Following on from that I mark out the possibilities for applying Gray's analysis to New Zealand texts. I then discuss some of the internal inconsistencies in Gray's argument and the issues which they raise, the main one of which is that the underlying dynamics of Gray's argument work toward establishing a state of cultural autochthonicity for the white settler. These dynamics are repeated in some of the New Zealand texts to be discussed. I conclude by suggesting that Janet Frame's later fiction undermines the premises on which Gray bases his argument. 


\section{Basic terms.}

This thesis defines 'home' as the satisfactory resolution of the problems of location and identity. This definition gives the term much wider ramifications than its primary dictionary definition of a dwelling place or the fixed residence of a family or household would allow. ${ }^{3}$ At the same time, articulating this broader definition raises questions about the relationship between the two terms 'identity' and 'location'. The definition is not intended to suggest that what is signified by 'home' can be neatly carved up into the two discrete concepts. Identity and location here are presumed to be ineluctably contingent.

In this thesis identity is taken to be the product of a 'constellation' of externally determined locations in relation to the material, social, political, cultural and ideological structures within which the subject exists. $^{4}$ Clearly, this statement in turn suggests that there are a number of specific structures whose geography (literal or metaphorical) can be mapped out, and in relation to which the specific locations which constitute a particular formation of identity can be discussed. Again this is not to suggest the division of structures into material, social, political, cultural and ideological is absolute or exclusive. These distinctions are arbitrary, and because of this they are, like identity and location, contingent. However, making these

3 The Compact Edition of the Oxford English Dictionary (Glasgow: Oxford University Press, 1971), I, p.1322.

4 The term 'constellation' is taken from Toril Moi. In summarising a model of the self derived from psychoanalysis, Moi writes of a multiplicity of structures [which] ... intersect to produce that unstable constellation the liberal humanists call the 'self". These structures encompass not only unconscious sexual desires, fears and phobias, but also a host of conflicting material, social, political and ideological factors of which we are equally unaware.' Sexual/Textual Politics: Feminist Literary Theory (London: Methuen, 1988), p.10. The notion of identity operating in this thesis is the antithesis of the Cartesian notion of the self. 
distinctions makes it possible to isolate individual aspects of the subject's location around which to organise the discussion of the satisfactory resolution of the problems of location and identity in the prose texts of Katherine Mansfield, Robin Hyde and Janet Frame.

As this discussion is a discussion of literary texts, it will be concerned with examining the representations produced in these texts, and the way in which these representations signify. Obviously, in accordance with post-Saussurean literary theory, it is presumed that these representations are governed by material, social, political, cultural and ideological structures, signifying in terms of them as well as participating in producing the above mentioned structures.

All these structures are affected by the dynamics of colonialism and post-colonialism, and if identity is defined as the product of a constellation of externally determined locations in relation to these structures, then the dynamics of colonialism clearly have a role in the structuring of identity as well.

\section{An Outline of Gray's Analysis of Sense of Place.}

The sense of physical place or location and the way in which its representations are structured would appear to be the most concrete and therefore perhaps the most accessible starting point. Stephen Gray suggests a useful schema for discussing physical location in relation to colonial literatures. 5 He proposes a rough division into four phases, giving a historical overview of the perception of place.

5 Stephen Gray. 'A Sense of Place in the New Literatures in English. Particularly South African,' in A Sense of Place in the New Literatures in English ed. Peggy Nightingale (St Lucia: U of Queensland Press, 1986), pp.5-12. Further references in the main text. (Although the term with which Gray initiates his discussion is 'New Literatures in English' and he focuses on South 
According to his division, place in the first phase is used as overseas exotica, 'a tourist phase, eloquently descriptive, heavily italicised and footnoted, influential in image-making' (Gray, p.8). 'It is powerful because it insists on unalikeness, on measuring the life out there against the nor ms of back home' (Gray, p.7).

Phase two is marked by a shift in perspective 'when the colonized writer sees the overseas landscape from the point of view of his or her belonging to it rather than to the motherland,' and Gray relates the emergence of this phase not only to a 'sufficiently strong sense of the viability and coherence of the life overseas, and to a sense that phase one literature is 'demeaning or clouded with a mythological haze that [makes it] unworkable,' but also to the effects of politicisation, predominantly in the form of nationalism, which he claims manifests itself in textual terms by centering on the uniqueness of the new sense of place (Gray, p.8).

Gray suggests that the third phase only arises where a culture has:

its own self-referring use of language, its mutual understanding of a set of infolded norms and values, its own context of myth about the past and the present. . . Phase two writers use place flamboyantly and assertively to proclaim their literary rights; they use the landscape as a battlefield on which to claim their stake [sic]. Phase three writers value an autochthonous readership first, for whom the advertisement of colourful landscapes is simply ludicrous. Somehow the familiar is never strange. The sense of place in phase three writing is back where it should be, merely part of a shared, felt milieu, a familiar and meaningful backdrop (Gray, p.9).

African writers, with some modifications his general analysis of colonial and postcolonial sense of place can be applied to an examination of the changes in representation of place observable in New Zealand literature.) 
He sees the fourth phase as pluralistic and synthetic, environmentally specific and yet open-ended. Obviously these divisions are rough and in some senses arbitrary but this description of a pattern of development has correspondences to that displayed in New Zealand literature. Sense of place, as a component of location, is certainly manifested differently in the writing of Mansfield, Hyde and Frame and this is related to their chronological separation. The chronological separation of the three bodies of writing situates them in different periods of colonial and literary history.

Gray argues that 'sense of place' in South African literature changes in direct relation to changes in the history of colonisation and that the way in which 'sense of place' is represented is revealing about the way in which sense of colonial identity is constructed. These are the two main points which I wish to extract from Gray's argument and apply to an analysis of New Zealand literature. If, as stated above, identity is a product of location in relation to material, social, political, cultural and ideological structures, and the way in which these structures are represented is affected by the dynamics of colonialism and postcolonialism, then the nature of colonial identity is readable from the way in which place is represented.

\section{Modification of Gray's Terminology.}

However Gray's analysis needs to be modified to fit the New Zealand context because the model of colonisation which he outlines conflates the position of the colonising and the colonised. This leaves no space for an indication of the ambivalences inherent in the position of the colonial which arise from the difference between these two in New Zealand literature. 
Gray's model suggests an essentially bipartite structure rather than a tripartite one. His schema implies that, although there are four phases, there are only two positions between which identity shifts in those phases; one can either identify with the colonizing country, the 'motherland' of phase one, or with the colonised country in the subsequent phases. There is no discussion in that schema of a distinction between the European, the colonising, and the colonised, or of the ambivalences inherent in any of those positions. It is particularly significant that in a country colonised substantially by the antagonistic exertion of force rather than primarily by the operations of commerce and negotiation (however coercive that in itself may have been) the position of the colonised is occluded in his analysis until it emerges rewritten as a bastardised figure in the synthetic fourth phase.

For the first part of the ensuing discussion, the following terms will be used in the following way: 'European' will be used here as a term which indicates an indentification with northern hemisphere, 'Old World' values; obviously, this includes the English literary tradition, but as I want to imply slightly more that this, the term European is being used rather than simply 'English'6 The terms 'colonial,

6 I am thinking here of the resonances the term 'Old World' has from Mansfield's use of it in her journal entry of 22 January 1916 where she expresses a desire' to make our undiscovered country leap into the eyes of the 0ld World, to Alan Mulgan's employment of the term in his Great Days in New Zealand Writing: 'When a New Zealander or an Australian goes to the Old World, and especially Britain, to seek his artistic fortune, in ninety per cent of cases or more he means London: Although this second quotation might initially appear to be in conflict with my use of the term, in that it suggests that 'Old World' mostly means London, it is the other ten percent, that extra which requires that Britain needs to be specified which I am intending to invoke in my use of the appellation European. Later on in my discussion of Mansfield's European stories I will distinguish further between European and English. References: Journal of Katherine Mansfield 22 January 1916, ed. J. M. Murry (London: Constable (1927), 1929), p.42 
'colonising' and 'white settler' will be used to identify a position which although it has racial and cultural origins in what is European, no longer has any autochthonous relation to the European and is involved in continuing the process of colonising. Lastly 'colonised' will be used to register the position of autochthonous inhabitants of a land that has been colonised. These distinctions, and the instabilities inherent in them, need to be kept in mind when extrapolating from Gray's schema to produce a discussion of the representation of physical location and its significance in terms of colonial identity in the New Zealand texts under examination.

\section{The Application of Gray's Model to New Zealand Texts}

When applying Gray's categories to New Zealand texts, not only is there a tripartite structure of Europeans, 'white settlers' and 'colonised' to consider rather than a bipartite structure of a European coloniser and autochthonous colonised, but also rather than fitting unproblematically into the first three phases, the writing of the three authors to be discussed, in each case, seems to mark a transition between one phase and the next. So in the writings of Mansfield there is definitely a sense, at times, of presenting New Zealand as exotic, unfamiliar and dangerous, and presenting it in this way specifically for a European audience. This is most obvious in the relatively early stories which deal explicitly with New Zealand subject matter, for example 'The Woman at the Store', 'Ole Underwood' and 'Millie', where the unfamiliar is displayed as exotic by the manner in which it is

(further references to Journal in the main text); Great Days in New Zealand Writing (Wellington: Reed, 1962), p.65. 
narrated.7 A well known, but extremely problematic passage from 'The Woman at the Store' illustrates this point:

There is no twilight to our New Zealand days, but a curious half-hour when everything appears grotesque - it frightens as though the savage spirit of the country walked abroad and sneered at what it saw (Stories, p.112). ${ }^{8}$

This sentence is marked by ambivalence. Here the place is clearly being offered up to a European gaze and identified in terms of its difference from a western European cultural norm; 'savagery' is only relevant in terms of the distance it marks from 'civilization'. Yet at the same time there appears to be a narratorial claiming of and identification with the place under scrutiny indicated by the possessive pronoun attributed to the name of the country. This suggests a position closer to Gray's second phase than his first. The narration both aligns itself with the European gaze which marks New Zealand as the object of that gaze, and locates itself, through the use of the first person plural, in a New Zealand national identity and thereby defines the narrator as colonial in line with the characteristics of phase two writing.

Hyde's texts can similarly be seen as straddling the divide between phases. Much of Hyde's writing is overtly concerned with her perception of the transitional nature of the social, cultural and political conditions of her time. Whilst the insistence on the specificity of the descriptions of the New Zealand landscape in Hyde's texts would seem

7 Katherine Mansfield, The Stories of Katherine Mansfield ed. Antony Alpers (Auckland: Oxford University Press, 1984), pp.109-17, 131-33 and 133-37 respectively. Further references to Stories in the text.

8 This is a sentence to which I will return several times during the course of my discussion. 
to locate them in the second phase of Gray's schema, the way in which sense of place is never strange, in which the familiar is related in terms which confirm its familiarity, would locate her texts in Gray's third phase. In fact what represents the unfamiliar, the exotic, the dangerous in Hyde's texts is the landscape of Australia. It is either construed as mythic, as in the visit to the distant relatives in The Godwits Fly or as alien and inhospitable, as in Nor The Years Condemn, where it is Australia which crystallises the notion of Starkie's cultural rejection. In the latter part of The Godwits Fly Eliza's journey to Australia provides a marking of cultural separation, and Eliza's desire to return 'home' is presented in terms of her desire for the familiar elements of the natural landscape9. Australia as a physical location is represented as the unfamiliar and unknown to New Zealand's known and familiar.

Frame's texts are the most difficult of the three to position with regard to Gray's schema, not least because they were produced over a chronological span three times that which the work of Mansfield or Hyde covers. This means the cultural conditions in which Frame's texts are produced are even more heterogeneous than those surrounding the texts of Mansfield or Hyde. Not only this but Frame also engages with and destabilises the very criteria on which Gray bases his divisions.

\section{Some Inherent Contradictions in Gray's Premises.}

9 Robin Hyde, The Godwits Fly (Auckland: Auckland UP, (1970), Nor The Years Condemn (Auckland: New Women's Press, 1986). Subsequent references in the text. 
His description of the fourth phase, although it engages in metaphors of physicality (he says 'our view of place ... should become three dimensional'), moves away from a purely geographical or landscapebased notion of sense of place:

sense of place is no longer a geographical condition, or a classificatory principle. It is located at the heart of a writer's society, his or her class, and culture, and his or her very being. important only insofar as it relates to the region before the whole (Gray, p.11).

In Gray's sketching out of what the fourth phase might be, this statement raises problems in relation to this last category and the previous three categories. By saying sense of place is no longer a geographical condition or a classificatory principle but is located at 'the heart of a writer's society, his or her class, and culture, Gray cuts the ground from under his own feet. He does not attempt to explain this discontinuity of premises within his own argument.

Up until this point, he has been making connections between representations of place and the nature of the society which represents place in that specific way. The way in which sense of place is represented is seen as a marker or signifier of the way in which a society perceives itself in terms of colonial identity. The representation of place is used in these instances specifically as a classificatory principle. His final statement about the fourth phase suggests that sense of place can now no longer function as a classificatory principle because sense of place is now somehow beyond representation. It implies that previously sense of place was mere representation, that it was somehow chimerical, that it was divorced from 'the heart of a writer's society, ... class and culture, ... or ... 
very being' in the earlier phases (which is in direct conflict to the implications of his argument previous to this point), and that somehow in this fourth phase, sense of place is no longer representation but truth, and that this 'truth' is a product of '[the] metaphysical ability to synthesise.'

Bastardized writers like Fugard and Sepamla are interesting not only for their English usage, but for the quantities of nonEnglish material they incorporate into their semantic frameworks. In the future, perhaps, the very pluralism of the influences upon them, and their metaphysical ability to synthesize, will be accounted their greatest strengths( Gray, p.12).

Whilst paying lip service to plurality, what Gray reasserts or privileges is the ability to synthesise and to elicit a single stable meaning from a coherent culture, some one thing which is at the heart of a writer's society.

Our view of place, then ... should become three dimensional, in terms not of the way our world has been, but in terms of the place it is likely to become. A sense of place in that fourth phase is, accordingly, going to have another special meaning of its own. in that new configuration, when we have at last made it our own. (emphasis added, Gray, p.12).

However, if in the previous three stages the nature of literary representations of the physical environment revealed something about the constitution of the culture by which they were produced, then this must be true also for representations which come after the third phase. Gray's metaphors give an indication of what might be at stake in his definition of the fourth phase. He talks about sense of place in terms of ownership, which when linked to his metaphors of mothering. legitimacy and bastardization, suggest that the synthesis which he so applauds is a way of legitimising the claim to the ownership of place 
through legitimising the right to representation of sense of place. This is in fact contained implicitly within the model which he initially outlines. 10

\section{The Importance of Being Autochthonous}

What is implicit in his schema is a particular relationship between cultural autochthonicity and the transparency of language. By its initial silence on the subject, Gray's article implies that the function of language is not brought into question in any way where there is a legitimate claim to both the motherland and the mother language, that it possesses an apparent transparency. In situations of cultural autochthonicity, rather than being seen to be influential in image making, language is regarded as a neutral medium for the recording of experience, so what can be deduced from this is that the apparent transparency of language functions as a signifier of legitimate ownership.

His article charts the difficulty which arises from attempting to represent exotic lands with the mother language, difficulties which result in recognition of the production of influential images and

10 I am thinking of the argument and tenor of Gray's whole article, but the extract which follows gives an indication of the grounds for my critique 'The mother language is no longer entirely in the mouth of the mother, and what the mother gets fed back from all the corners of the post-colonial world is a tongue which bears some similarity to the language which was taught by her, but Ah! we say, it is different, it is filled with the spirit of new places. Very well, says the mother, insofar as she's interested at all in such upstarts, the places sound new to me, but the tune is a very old one indeed; don't call them New Literatures, call them Old Literatures in New Places. And then we say back, Well then, Old Literatures in New Places, but they are in English at least. And she, if she can bother to reply at all, says, Call that English ? And we persist, saying. All right, Old Literatures in a kind of New English they may be, but we sure do have a great sense of place. ... and the immeasurably great thing about our place is that, even if it's unacculturated it is emphatically ours; so keep away' (emphasis added, Gray, pp.5-7). 
chimerical hazes. It then proceeds to outline the way in which a new 'vernacular' which synthesises the language of the colonised land with that of its mother-language is developed. The article presumes that this hybrid or bastardised or synthetic language can portray the synthetic culture accurately and unproblematically, and in so doing, implies that once more language becomes a neutral medium for the recording of experience (and is thereby absolved from involvement in the business of image making). Since the apparent transparency of language functions in Gray's text as a signifier of legitimate ownership, the claim to ownership of place is thus implicitly established through the re-established transparency of language in his schema. ${ }^{11}$

We'll keep your language, thank you, even though it wasn't made for our environment, but we're turning it round to mean exactly what we do mean and we're making it as dynamic as possible as a result. And we love our places, too (emphasis added, Gray, p.7).

The slip in Gray's argument between truth on the one hand and possession and representation on the other suggests a continuing anxiety about language, ownership and identity. ${ }^{12}$ One of the places where this slip occurs is the very term 'sense of place', which allows the distinction between representation of place and empirical experience of place to be blurred. In phases one, two and three, representation is what seems to be under discussion, but in the outline of the fourth phase experience seems to be privileged over representation. There is, of course, a vested interest for the post-

11 Whereas, according to Homi Bhabha's model the very metaphor of bastardization or the condition of hybridity described declares the operations of colonial domination which are otherwise neutralized in Gray's text. See discussion in $\mathrm{Ch} .2$ below.

12 In the extract above, this anxiety is marked by the paratactical collocation of the appropriation of language and the desire for (possession of) place. 
colonisation critic in this empirical position because it is the knowledge gained through unmediated experience by the colonial, which is the grounds of his claim to ownership and identity in the face of the spectre of the autochthonous European and the autochthonous inhabitants of the colonised land. The transparency of this new synthetic (bastardised and assimilated) language is what simultaneously guarantees cultural autochthonicity to the post-colonial critic and effaces the colonial appropriation of the past.

Gray's analysis can thus be seen to revolve around the importance of being autochthonous. Constructing a position of 'colonial autochthonicity' is a way of attempting to banish the ambivalences inherent in the position of colonial and in doing so, to guarantee the insecure position of colonial with a salvific unity and coherence. ${ }^{13}$ The desire for a position of cultural autochthonicity can be seen in the New Zealand texts to be discussed.

\section{Frame's Texts Interrogate the Grounds of Gray's Analysis.}

All Frame's texts interrogate the function of language and the later texts examine its complicity in the process of colonisation, raise questions about possession and ownership and destabilise the notion of identity. The linguistic play of Frame's texts interrupts the apparent transparency of language. Thus they call into question the grounds of the assumptions which are present in Gray's schema and this places them somewhere different from the position which Gray identifies for his fourth phase.

13 The inverted commas around the phrase 'colonial autochthonicity' are intended to indicate that it is an in herently oxymoronic construction. 
For example, as outlined above, what Gray's model also does not allow is any more complicated relationship than a binary one in terms of cultural identification. What Gray's model does is implicitly set up a binary opposition of known and exotic, and what he implies is that the exotic place has become so thoroughly known by its inhabitants that it in its turn becomes the known. What he terms the Colony's Revenge marks the point of reversal of this binary opposition, where the known is transposed into the exotic. ${ }^{14}$ However, in Janet Frame's texts there is a progression from dealing exclusively and emphatically in binary oppositions (as in Owls Do Cry), to the undermining and deconstructing of those binary oppositions. Living in the Maniototo for example grapples precisely with this problem of representations which cannot be binarily classified as original and replica, known and exotic. ${ }^{15}$ That text destabilises the idea of origin and the idea of empirical knowledge.

In Living in the Maniototo sense of place is always demonstrated as a discursive construction. The reader is forced to engage with an interrogation of the conventions which constitute the familiar and the unfamiliar. The narrative takes up multiple, shifting perspectives, which undermine the notion of unitary identity and emphasise the relative nature of every conception of place.

14 '. . there is a variant in the novel of phase two I've discovered in South Africa, but it surely exists elsewhere, which one might label the "Colony's Revenge" - the novel about the upstart colonial visiting London and finding it abnormal, aberrant, different, filled with the quaintest sense of place' (Gray, p.9).

15 Janet Frame, Living in the Maniototo (London: The Women's Press, 1981). Further references to Maniototo in the text. 


\title{
CHAPTER TWO The Bull in the Metropolis.
}

\begin{abstract}
it must be the rarest thing to be chased by a wild bull up and down Harley Street, Wimpole Street, Welbeck Street, Queen Anne, round and round Cavendish Square' (Katherine Mansfield, Journal).
\end{abstract}

\section{Introduction.}

From the previous discussion it is clear that Gray's schema is useful as a starting point for reading representations of place as indicators of particular notions of colonial identity. However, what an application of his schema to these New Zealand terts indicates is, in fact, the ambivalence inherent in these texts with regard to colonial identity. In all the texts under discussion, the representation of place and what it implies about colonial identity complicate the categories of Gray's schema. The following examination of specific texts will show that in the interstices of Gray's divisions sense of place is unstable, identity is unfixed and divided against itself.

I contend that what is at issue in the Mansfield texts examined in this section is the disavowal of coloniality and the construction of a position of European cultural autochthonicity. I argue that this textual dynamic in 'The Woman at the Store' coupled with the hybridity of the text itself is what marks the text as colonial. I argue that the text 
simultaneously produces the New Zealand landscape as exotic for the European reader and demonstrates a local knowledge of local place. Because of this, subscribing to the established critical division of 'European' stories and 'colonial stories' in Mansfield'soeure produces a reductive reading of the (inaptly named) 'colonial' texts. I suggest that the category of 'colonial' must be seen not as coherent and discrete, but as fractured and fraught with ambivalence in order to produce a less foreclosed reading of 'The Woman at the Store.' I utilise Homi Bhabha's theories of hybridity and disavowal to pursue my reading of the text.

I explore several examples of the assertion of an autochthonously European narrative identity in Mansfield's texts: in each case that position is produced by a disavowal of coloniality, and is registered by the production of stereotypes. I take the narrative of the bull in the metropolis as the paradigmatic example of this process. Finally I argue that in 'The Woman at the Store, the colonising subject is produced in the form of a stereotype in order that the narrator can establish an autochthonously European narrative identity, but that the process of disavowal is threatened and undermined by distressing signs of contiguity with the identity of the colonised subject. In "The Woman at the Store, the only means of recuperation from the contiguity with the colonial is to dismiss the whole locus in which that identity was threatened.

Finally I argue that a similar dynamic can be seen in a series of stories set in Europe. Here there is an attempt to claim a position of high European culture. To this end, other European figures are produced as stereotypical, and so displaced from a position of high cultural autochthonicity. The coloniality of the texts is revealed by 
their very anxiety to display their high European cultural autochthonicity. 


\section{The Landscape Represented as Erotic.}

'The Woman at the Store' does not fit easily into just one of the categories of Gray's schema. It displays characteristics of both first phase and second phase writing. I will discuss the presence of phase one characteristics first (and their coincidence with a particular European literary fashion), then address the co-presence of phase two characteristics and following that I will discuss the implications of the presence of these contradictory characteristics in this text.

As I discussed above, in phase one writing, the cultural identification is still with the colonising country and its representations are structured accordingly. In this story the opening paragraph clearly works to establish the unfamiliarity of the landscape in which the story is set. The landscape is represented as hostile and inhospitable.

All that day the heat was terrible. The wind blew close to the ground - it rooted among the tussock grass - slithered along the road, so that the white pumice dust swirled in our faces settled and sifted over us and was like a dry-skin itching for growth on our bodies. The horses stumbled along, coughing and chuffing. The pack horse was sick - with a big, open sore rubbed under the belly. Now and again she stopped short, threw back her head, looked at us as though she were going to cry, and whinnied. Hundreds of larks shrilled - the sky was slate colour, and the sound of the larks reminded me of slate pencils scraping over its surface. There was nothing to be seen but wave after wave of tussock grass - patched with purple orchids and manuka bushes covered with thick spider webs (Stories p.109).

The unfamiliarity of the landscape is emphasised in several ways. Both the inclusion of features which would be unfamiliar to a European audience (the pumice dust, the manuka bushes), and the unfamiliar 
conjunction of familiar elements (larks in their hundreds, purple orchids and thick spider webs), serve to signal difference. Similarly the re-positioning of familiar literary tropes in an unfamiliar context works to emphasise distance and difference. There is, for example, an immense gap between the quintessentially English blithe spirit that from heaven pours out its full heart in profuse strains of unpremeditated art and the larks here whose numbers seem threatening and whichsymbolise dissonance; they 'shrill' and are linked with the oppressive heat of summer rather than plots of beechen green, or roses embroidered in green leaves. The repositioning of this literary trope serves as an 'insistence on unalikeness', precisely as an instance of 'measuring the life out there against the norms of back home' (Gray, p.7). So, the norms of 'back home' which allow the text to produce its exotic effects are the norms of the northern hemisphere. The particular way in which the text displays familiarity and difference renders the exoticism available to a specifically European audience.

The text has a European audience in mind. It was written for the English periodical Rhythm and replaced a fairy tale which had been rejected as unsuitable for that magazine's tessatura. ${ }^{16}$ "The Woman at the Store' then, is clearly a calculated response to the literary imperatives of that publication. In its first issue under the heading of 'Aims and Ideals' Rhythm contained the slogan, adopted from Synge, 'Before art can be human again it must learn to be brutal', stated that its intention was to provide art which was 'vigorous' and 'determined', and concluded with the maxim that 'what is exalted and tender in art

16 Information cited in Antony Alpers, The Life of Katherine Mansfield (Oxford: Oxford UP, 1982 ), p.135. Further references to Life in the main text. 
is not made of feeble blood'.17

The literary demand of Rhythm that art become brutal before it can become human again is to a large extent commensurate with the presence of characteristics by which Gray identifies phase one writing. Adopting (albeit new) European literary practices is coadunate with adopting the Eurocentric positioning of the gaze. It is in these ways that the story is addressed to European readers from a European perspective ${ }^{18}$ The demand for brutality is fully compatible with a representation of landscape as foreign, alien and inhospitable by virtue of its difference from traditional representations of English landscape. The binary oppositions between known and unknown, human and inhuman, familiar and exotic are all clearly brought into play in this passage.

The demand for nouveau brutalité also goes hand in hand with influential image-making. The wind is characterised by the verbs 'rooting' and 'slithering' as a devouring and dangerous ophidian creature whilst the domestic packhorse is humanised and driven to tears by the inhospitable conditions and its ruptured body ('The pack horse was sick - with a big, open sore rubbed under the belly. Now and again she stopped short, threw back her head, looked at us as

17 Rhythm 1.1 (1911): p.36. In Life p.134, Alpers notes that the slogan is adopted from Synge.

18 In an unnumbered, two page, perforated subscription form following p. 36 of the first issue cited in note 14 above, Rhythm advertises itself as 'designed to give expression to new movements and new philosophies of the Arts' and indicates its intention to publish drawings from a list of continental, and predominantly French artists. The second attack by the New Age on Rhythm and 'The Woman at the Store' in particular heaped opprobrium on the 'Continental wash' of both story and periodical and suggested that Rhythm was 'the production of persons who were ... running after sensationalism'. These remarks occur in 'PresentDay Criticism, New Age 10.25 ns. (1912) : p.589. 
though she were going to cry'). Using the tropes of unfamiliarity, brutality, and exoticism simultaneously fulfils the demands of contemporary English writing as articulated by Rhythm and maintains the binary oppositional dynamic between known and unknown, subject and object, home and foreign where the narrative gaze is aligned with the known and presents the New Zealand landscape as foreign.

Producing a representation of the landscape as exotic within the terms of this binary opposition also works to remove any third term. Just as Gray's schema only allows two unambiguous possibilities, either identification with the colonising country in phase one, or identification with the colonised country in the following three phases, and this forecloses on a whole area of colonial problematics, so the use of the binary opposition of known and exotic within the representational code of phase one writing cuts out a middle or indeterminate ground, which is the possibility of a partial familiarity. The alternatives for representation of place as only either exotic or familiar construct identities which are only either European or native. A specifically colonising narrative identity is a position ruled out by the exclusionary operation of the binary opposition. Engaging in these phase one identifications helps to construct a location for this narrative which declares itself as European rather than as the partial vision of the colonial. So the way in which place is represented in the opening paragraph of this story identifies address of the narrative as European, because of the sense of a familiarity and compliance with contemporary literary developments and because the landscape is viewed as exotic. 


\section{The presence of phase two characteristics in 'The Woman}

at the Store.

Two of the characteristics of phase two which Gray identifies are that the colonized writer sees the overseas landscape from the point of view of his or her belonging to it rather than to the motherland, and that the writing emphasises 'uniqueness of the new sense of place' (Gray, p.8). The phrase from 'The Woman at the Store' which was discussed earlier comes to mind as clearly having these characteristics, There is no twilight to our New Zealand days, but a curious half-hour when everything appears grotesque... ' (Stories p.112). As mentioned above, the possessive pronoun indicates a sense of belonging and the content of the phrase as a whole can certainly be read as an attempt to register the (albeit disquieting) uniqueness of the new sense of place. There is one moment in the narrative where place is not represented as inhospitable and brutalising.

I went to the end of the paddock where the willows grew and bathed in the creek. The water was clear and soft as oil. Along the edges held by the grass and rushes, white foam tumbled and bubbled. I lay in the water and looked up at the trees that were still a moment, then quivered lightly, and again were still. The air smelt of rain. I forgot about the woman and the kid until I came back to the tent (Stories p.113).

Although the specifically colonial terms 'paddock' and 'creek' are used, their use at this particular point, which describes a moment of pastoral idyll, works to construct the uniqueness of the new sense of place, without invoking the brutality present in the opening paragraph of the narrative. It is clearly marked in the text that this moment is one from which the colonial characters are excluded.

So 'The Woman at the Store' betrays evidence of phase two 
characteristics as well as displaying characteristics of phase one writing. It is sited across the border of Gray's divisions. I would suggest that the coloniality of texts is marked as much by the simultaneous presence of these characteristics as by the registering of the 'uniqueness of the new sense of place ' which characterises phase two writing. However, as I will go on to argue, the coloniality of the text is marked by its display of hybridity in the sense of internal dislocation as well as in its display of hybridity in the co-presence of phase one and phase two characteristics. 


\section{The problem of taronomy.}

In this section I discuss the way in which the Mansfield textswhich deal with New Zealand subject matter have been assigned to fixed categories. The stories have generally been divided into colonial tales, European stories and mature fiction, all categories which are not particularly rational. I examine the results of categorising the tales of colonising subjects in this way and conclude that the rigid divisions between the categories do not allow for the hybridity of the terts, and because of this the coloniality of these tales has been under-read.

In her article 'How Kathleen Beauchamp was Kidnapped', Lydia Wevers suggests that Mansfield's 'colonial stories' (which she defines as 'The Woman at the Store', 'Millie', and 'How Pearl Button was Kidnapped') signal what Mansfield's writing might have been like 'had she stayed in colonial dress, and resisted appropriation by Europe'.19 This statement presumes that European influence is wholly absent from these stories, that these stories are purely colonial products and that European influence only appears in stories which post-date the ones mentioned above. All of these presumptions seem problematic to me, as they work to exclude any consideration of coloniality as a position of hybridity, both implicated in and distanced from European culture.

Certainly, as discussed above, these stories contain markers of regional specificity, but the context in which these markers (such as foreign plant names, intemperate conditions, unexpected conjunctions)

19 Lydia Wevers, 'How Kathleen Beauchamp Was Kidnapped,' Women's Studies Journal 4.2 (1988): p.6. Further references to Wevers in the main text. 
are placed means that they work here more as tropes of unfamiliarity than markers of regional specificity; the same sorts of configurations reappear again and again and are the stock in trade of phase one writing. In terms of their production of exoticism, I am not suggesting that these stories are exactly kin with a phase one text like The Travels of Hildebrand Bowman. Esquire, which describes the inhabitants of New Zealand as 'savages with eyes of moles and with the faces (and tails) of pigs', but the way in which the colonial characters are metaphorically and similaically connected to animals in Mansfield's stories are traces of the tropes which are explicit in Hildebrand Bowman. ${ }^{20}$ In both texts the production of these tropes is linked to a specifically European site of address. (Here it is useful to keep in mind the correspondences between Gray's phase one writing and what is being designated by the term European, and the similarities between his phase two writing and what is being identified as colonial.)

In both these cases the question of audience or the demesne of the circulation of these texts is as important in making distinctions as is the location of the action. Wevers' article begins with a discussion of the colonial short story drawing on publications in New Zealand at the turn of the century. She cites stories and critical comments from the New Zealand Illustrated Magazine and Zelandia and then proceeds to discuss 'The Woman at the Store' in this context. Although Wevers makes valuable points about the nature of the colonial short story,

20 The quotation is from 'Hildebrand Bowman in New Zealand' (Islands 3.2 (1974) : p.215.) in which Garry J. Tee gives an account of events of the 1778 text The Travels of Hildebrand Bowman. Esquire. In 'Ole Underwood' the main character is described as an 'ole swine', scuttling 'like a rat', and having an 'old claw' rather than a hand (Stories, p.132). 
there is an unarticulated presumption that 'The Woman at the Store' is colonial in the sense that the fiction which is discussed at the outset of her article is colonial, that is, that it participates in 'a literary community in [the] new landscape' (Gray, p.8). While this is clearly the case for the other stories discussed by Wevers, as they were all written and published in New Zealand, by New Zealanders for New Zealanders to read, this is not true for 'The Woman at the Store.' As I noted above, the marked area of circulation for that particular story was in fact completely divorced from the New Zealand contert.

'The Woman at the Store' was written in the northern hemisphere, for publication in a specific magazine there, by a writer who had already had three years of education in England and had also been in the northern hemisphere for the three years immediately prior to that story's publication and ${ }_{L}$ had also been publishing stories in the New Age in England for the previous two years. There can, therefore, be no question of her being appropriated by Europe subsequent to the production of 'The Woman at the Store,' 'Millie,' and 'How Pearl Button was Kidnapped.'

It seems to me that the labelling of these stories 'colonial' or European is problematic, and that this problem is related to the issue of their disposal within Gray's schema, and this disposal is, in turn, contingent on the way in which colonial identity is constructed.21 As with Gray's phases, characteristics of 'The Woman at the Store' would have to be ignored to fit it unproblematically into phase one or phase two, so to classify the story as either colonial (in the sense of belonging

21 Suggesting that 'The Woman at the Store' conforms to some European conventions and that the site of its address is European is not to argue that it can be labelled unproblematically as European. 
purely to a New Zealand context) or European means the refusal to consider on the one hand the place of address and circulation of the story and the particular nature of the representation of place, or on the other hand of the subject matter of the story. Further to this, the categories of European and colonial are themselves problematic. As mentioned above, in Gray's schema there are only two alternatives, identifying with the originating culture or identifying with the colonising culture. These positions are binarily structured and therefore mutually exclusive. The categories 'colonial' and 'European' are also structured as mutually exclusive binary opposites. I will argue below that thinking of these categories as discrete and mutually exclusive is problematic for reading 'The Woman at the Store.' 


\section{The Pure Colonial.}

The implicit assumption in Wever's phrase about Mansfield's appropriation by Europe is of a pure coloniality which is then eroded. This assumption is consonant with the construction of the concept of colonial in the writing of other critics on this story. Coloniality is registered as a discrete entity, separate from European, which works towards denying both the European aegis, which is a cultural condition of the colony, and the dependence of the concept 'European' for its existence on the differentiating power of the concept of 'colonial'. The construction of colonial as a pure and autonomous category invests colonial 'identity' with the appearance of essentiality and thus aids the claim to establishing cultural autochthonicity, just as in Gray's schema the presumption of the transparency of language invests representation with the aura of essentiality and similarly aids the claim to establishing cultural autochthonicity.

Antony Alpers' discussion of colonial identity in The Life of Katherine Mansfield displays the operation of the category of colonial as pure, as a discrete entity.

The creative temperament obviously had a difficult time in New Zealand before a cultural humus had begun to form, and it never has been easy to describe the causes, since paradox pervades them. Smallness, newness and rawness, remoteness from Europe, all must have played their part. In social and political terms these had positive effects, since they favoured experiment, but in the arts they became enemies of promise. The writer who would in Pound's phrase 'make it new' needs tradition to join him to past and future, and the act of emigration broke that precious chain. Those who left England in the 1840 s were either, like Arthur Beauchamp, cheerfully ready to sacrifice their cultural roots, or mistaken in supposing that they would transplant easily in a land that had not known man or even mammal in the time of Christ. They unloaded 
their pianos from the sailing ships and had them tuned again in wooden houses filled with comforting things from home, but the old songs never did sound the same again.

Coleridge, in Table Talk, says it is not the sod under their feet that makes men of one country, but identity in language, religion, laws, government, blood. . . . . [N] [ew mythologies must needs evolve. Identity in the things which Coleridge mentions cannot help the creative artist until several generations have shaped them again in one place - in organic relation to that place. When Christmas falls at summer's height and the Feast of the Resurrection occurs in the fall religion's roots are upside-down, and the human spirit must start again. (In a story called At the Bay, it does just that) (Life pp.43-44).

Despite the passing reference to paradox and the allusion to displacement in the form of the installation of a European signifier of bourgeois culture which no longer signifies in the same way because of the different context of signification (the piano which doesn't sound quite the same), the dominant figure in the passage is that of rupture: 'the act of emigration broke that precious chain', 'ready to sacrifice their cultural roots', 'mistaken in supposing that they would transplant', 'the human spirit must start again'. The passage suggests that the social, political, cultural and historical formation of the individual in European culture is somehow effaced or wiped out in the journey from the northern hemisphere. The 'identity in "language, religion, laws, government, blood." ' to which Coleridge refers is not dislocated or problematised in Alpers' account, but apparently completely erased. Vaughan Yarwood takes a view of the construction of New Zealand culture which is completely opposite to the one articulated by Alpers. He suggests that

[t]he immediate origin of New Zealand colonial culture was ... Victorian England. This had two related effects: firstly, seminal ideas reflected, and even now echo, the tensions of a European rather than an Oceanic perspective. Secondly, attention was diverted from the process of intellectually inhabiting the new 
land to fabricating an appropriate Victorian 'response' ... Victorian novels ... and ... poetry constituted a continuous channel for the transmission of cultural mores. ${ }^{22}$

The effect of structuring of the arrival of the colonial as rupture, as a breaking from European culture, rather than occurring in the context of the pervasive cultural continuum which Yarwood outlines, is to create a gap, a vacuum to be filled in: 'a land that had not known man or even mammal in the time of Christ'. This gap provides a space for the installation of the autochthonous New Zealand writer. Although it is initially suggested in Alpers' passage that culture must slowly accrete in the new land, that it is a matter of generations before an organic relation to the new place can be established, the conclusion of the passage 'the human spirit must start again. (In a story called At the Bay, it does just that)' suggests that it is the founding text of an autochthonous New Zealand literature which appears on the other side of the rupture. The figure of the rupture is part of an originary myth which seeks to deny a linking or complicity with the shaping processes of the past and thereby establishes colonial as a pure category rather than a hybrid one. The implicit establishment of this myth means that the New Zealand writer can then spring from the New Zealand soil secure in an autochthonous identity. ${ }^{23}$ In his Katherine Mansfield Alpers actually states that 'Millie', 'Ole Underwood', and 'The Woman at the Store' were 'early examples of an authentic New Zealand ఏterature. ${ }^{24}$ The admission of European culture as one of constitutive

22 Vaughan Yarwood, The Use of Paradigm: Classical Models of Empire in Early New Zealand Writing', in the Journal of New Zealand Literature 4 (1986): p.10.

23 I am thinking of the literal meaning of autochthonous here 'sprung from the soil' The Compact Edition of the Oxford English Dictionary (Glasgow: Oxford University Press, 1971), I, p.144.

24 Antony Alpers, Katherine Mansfield (London: Cape, 1954), p.193. Emphasis 
elements of colonial literature then threatens this position of the culturally autochthonous New Zealand writer and, in order to maintain that position intact, requires that a complete split between the categories of 'colonial' and 'European' be maintained.

The exclusiveness of the categories thus constructed plays a part in the construction and perpetuation of a division between the stories which use New Zealand material and the remaining short stories which are often labelled European at this point of distinction. For example, Anne Holden Ronning suggests that 'if we read the New Zealand stories edited by $\mathrm{I}$. Gordon as a piece of continuous prose, we realize that a definite distinction should be made between her New Zealand and her

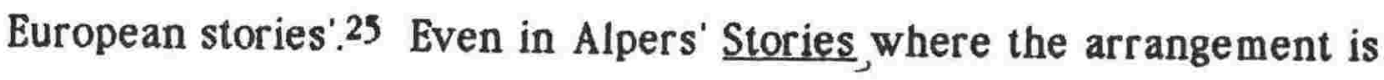
chronological rather than thematic, the placing of 'Millie' before 'Pension Seguin', 'Epilogue II' and 'Bains Turcs' and the exclusion of 'Old Tar' also produces a separation between pieces with New Zealand settings and pieces with European settings. 26

Maintaining the installation of the autochthonous New Zealand writer also results in the production of a demarcation within Mansfield's New Zealand stories: a number of the early stories within

added.

25 Anne Holden Ranning. 'Katherine Mansfield, British or New Zealander - The Influence of Setting on Narrative Structure and Theme', in The Fine Instrument, ed. Paulette Michel and Michel Dupuis (Sydney: Dangaroo Press, 1989), p127. Further references to Fine Instrument in the text.

26 Stories, pp.133-37, 137-41, 141-46 and 146-150 respectively. Alpers gives the rationale for his arrangement in the 'Commentary' to the Stories on p.553. 'Believing that Millie may have been written somewhat earlier, I have placed it beside Ole Underwood and in front of the Epilogues, so as to keep the latter as a set.' Unfortunately Alpers does not give any indication of the grounds for his belief. Whilst I have no grounds for believing that 'Millie' was written after the 'Epilogues' (they all appeared in the same edition of the Blue Review in June 1913). what is interesting to me here is the desire to keep these European stories as a set, and (by inference) to also keep the colonial stories as a set. 
this New Zealand group are separated off and labelled colonial. For example, in Undiscovered Country a collection of Mansfield's writing which is set in New Zealand, Ian Gordon divides the contents thematically and arranges them in five sections. ${ }^{27}$ The first four sections are named according to seasonal thematics, 'Spring', 'Summer', 'Summer's End' and 'Winter' and are thereby invested with a notion of coherence and unity, whilst the fifth section, which contains 'Old Tar', 'Ole Underwood', 'Millie' and 'The Woman at the Store', is labelled 'Scenes from Colonial Life', thus separating them from the other New Zealand pieces and implying by default that those other pieces are not 'Colonial', that there are no colonial politics to be read in the texts of the other New Zealand stories, and that the 'Scenes from Colonial Life' are authentically colonial in a way that the other New Zealand stories are not.

In In the Glass Case: Essays on New Zealand Literature C. K. Stead makes a comment similar to the one made by Wevers about appropriation in that it draws a firm demarcation between 'colonial' and 'European' stories:

One brief experiment consists of three stories which are interesting because they indicate a whole line of development [Mansfield] denied herself by becoming a European writer. 'Millie', 'Ole Underwood', and 'The Woman at the Store', are New Zealand stories quite different from the evocation of a middle-class childhood for which she is best known (emphasis added). 28

Again this comment implies that writing about colonial material and

27 Ed., Ian A. Gordon, Undiscovered Country: The New Zealand Stories of Katherine Mansfield (London: Longman, 1974). Further references in the text.

28 C. K. Stead, In the Glass Case: Essays on New Zealand Literature (Auckland: Auckland UP, 1981), p.32. Further references in the text. 
being a European writer are mutually exclusive. It is ahistorical in that it implies that Mansfield 'became' a European writer some time after the production of these stories and, in line with this failure to pay attention to the conditions of the production of these stories, it represents their production as a 'brief experiment' rather than a response to particular material circumstances. The disregard for the chronology of these stories again is a participation in the production of the notion of a pure colonial writer who subsequently becomes Europeanised which precludes the consideration of colonial as a hybrid category. Stead's comment also limits his designation of the 'colonial' stories to 'Millie', 'Ole Underwood' and 'The Woman at the Store',whereas Wevers selects 'How Pearl Button was Kidnapped' rather than 'Ole Underwood'. Just the variation in the constitution of the group of stories from critic to critic undermines the coherency of 'colonial' as a productive category when it is defined in antithesis to 'European'.

Bridget Orr comments on this passage that Stead's marking of a distinction between colonial and European texts allows him to define these stories as early, realist and proleptic and, by virtue of this, define Mansfield's later texts which deal with New Zealand material as non-realist and therefore not culturally specific. She suggests that this allows Stead to clear a space for Sargeson as the true father of New Zealand letters.29 Although Lawrence Jones suggests that it is Mansfield who occupies this position,

... it could even be said that both Ithe realist tradition of 'barbed wire and cowpats' . . . and the 'other' tradition of

29 Bridget Orr, 'Reading with the faint of the pioneer: Katherine Mansfield and settler criticism.' , Landfall, 172, 43.4 (1989). pp.448-450. Further references in the text. 
'mirrors and interiors'] begin with Mansfield, since 'The Woman at the Store', 'Millie' and 'Ole Underwood' anticipate the provincial realists, while 'Prelude', 'At the Bay' and the other more famous stories initiate the interior tradition. ${ }^{30}$

what is still at stake is the construction of the position of an originary source for New Zealand writing. Since 'How Pearl Button was Kidnapped' and 'Old Tar' are not plotted tales in the sense that 'The Woman at the Store' and 'Millie' are, but both come from the same period as these two and 'Ole Underwood', 31 the exclusion of 'How Pearl Button was Kidnapped' and 'Old Tar' from Stead's list can be seen, then, as a product of the desire to conflate the two categories of colonial and realist. This conflation is problematic in that it means that coloniality then can be read only in the realistic representation of a New Zealand setting, and cannot be registered as textual hybridity or internal dislocation.

Alpers similarly wants to remove 'The Woman at the Store' as well as 'Ole Underwood' and 'Millie' from their European context of circulation and confine them completely to a New Zealand context.

Far from representing any 'Continental' perversion of aesthetic principles... ['The Woman at the Store', 'Ole Underwood' and 'Millie' ] were something that only a New Zealander could have written at that time. They succeeded (and only seventy-five years after settlement) in relating character to environment in a land of 'no tradition' (Life. p.155).

Again the insistence on the colony as a land without a tradition produces the gap in which to install the autochthonous New Zealand

30 Lawrence Jones, Barbed Wire and Mirrors:Essays on New Zealand Prose (Dunedin: U of Otago Press, 1987), p.6.

31 All five stories appeared in Rhythm or its successor the Blue Review during 1912 and 1913 and all deal with New Zealand material. 
writer. However, having disallowed the possibility of the influence of the notion that art must learn to be brutal before it can be human again in the construction of these stories by their confinement to a purely New Zealand context, Alpers reads "The Woman at the Store' as somewhat unconvincing colonial realism. Whilst I agree that it is important to recognise the colonial specificity in these stories, to do this at the expense of denying the European context of their circulation and the ambiguity of the category of colonial forecloses on some possible readings of the stories, as in the following comment of Alpers'.

Although there is much in the story that is unconvincing, including the narrator, who is evidently meant to be a woman, it displays sharp insight into New Zealand backblocks life and atmosphere. . . . Nevertheless it belongs among her achievements, at least in the literature of her homeland (Stories. p.551)

The result of confining 'The Woman at the Store' to a context of colonial realism is to produce a text whose realism is unconvincing and to implicitly label the ambiguities of the text (particularly those concerning the narrator) as failures. I am not suggesting that The Woman at the Store' does not engage with the specificity of colonial life, but that paying attention exclusively to the 'mimetic and expressive dimensions' of the text takes place within a pre-existing framework of the presumptions of phase two writing, so it both registers phase one characteristics as 'unconvincing' and rules out the possibility of reading the coloniality of the text in its hybridity or internal dislocation ${ }^{32}$.

32 The phrase 'mimetic and expressive dimensions' is taken from Robert Weimann, 'Past Significance and Present Meaning in Literary History', in New Directions in Literary History ed. Ralph Cohen (London: 1974), p.59, cited in Nelson Wattie, 'Geographical, Historical and Cultural Distance in the Reception of Literary Works', in The History and Historiography of Commonwealth Literature ed. Dieter Riemenschneider (Tubingen, Germany: Gunter Narr Verlag, 1983),p.41. 
Whether trying to place the text within the categories of Gray's schema or the broader but contingent categories of either European or colonial, the assignment to a particular category which is constructed as homogeneous and unproblematic results in suppression of particular textual features. This is, of course, the case with the assignment of any text to a particular generic category, but it seems to me that the issue is of particular relevance here because the text of 'The Woman at the Store' has been under-read as a result of being so unequivocally assigned as realist and colonial. If reading the text as realist and colonial, that is as an example of phase two writing, occludes the possibility of recognising its production of exoticism and European site of address and reading the text as phase one European writing means not paying attention to the text's colonial specificity, it is necessary to produce another method of reading the text, of reading off its construction of identity from its representations without invoking the occlusionary operation of binary dynamics.

A reading within this framework also presumes the transparency of language which, as noted above, corroborates in the production of a position of colonial
autochthonicity. 


\section{The Notion of Hybridity as a Tool for Reading The Woman at the Store.}

My response to the taxonomic problems raised above is to argue that colonial cannot be constituted as a pure, discrete category in opposition to the category of European, that the category of colonial itself is a hybrid one. I have noted earlier that in my use of the terms 'hybridity' and 'mimicry', I have been mindful of Homi Bhabha's employment of these terms in his writing on colonial discourse. I would like to discuss the specific use of these terms in Bhabha's arguments briefly as I intend to draw on these arguments in my following discussion of 'The Woman at the Store' as well as the subsequent discussion of the Hyde texts. In his discussions of colonial discourse, Bhabha suggests that

Hybridity is the sign of the productivity of colonial power, its shifting forces and fixities; it is the name for the strategic reversal of the process of domination through disavowal (i.e. the production of discriminatory identities that secure the 'pure' and original identity of authority). ${ }^{33}$

It is this type of hybridity by which I would like to suggest that The Woman at the Store' is marked: this type of hybridity produces those other marks of coloniality in this text. Disavowal is the process of denying something that is known to oneself by projecting it onto something which is outside. The process of domination through disavowal is the process of producing a series of 'discriminated subjects:

33 Homi K. Bhabha, 'Signs Taken for Wonders: Questions of Ambivalence and Authority Under a Tree Outside Delhi, May 1817', in Europe and its others: volume one Proceedings of the Essex Conference on the Sociology of Literature. July 1984 eds. Francis Barker, Peter Hulme, Margaret Iversen and Diana Loxley (Colchester: Uof Essex, 1985), p.97. Further reference to 'Wonders' in the text. 
Produced through the strategy of disavowal, the reference of discrimination is always to a process of splitting as the condition of subjection; a discrimination between the Mother culture and its bastards, the self and its doubles, where the trace of what is disavowed is not repressed, but repeated as something different - a mutation, a hybrid ('Wonders', p.9697). 34

These 'subject[s] of a difference that is almost the same but not quite', which secure the identity of the colonising subject, Bhabha names mimic men. ${ }^{35}$ He suggests that these colonial subjects are constructed as partial presences (both incomplete and virtual) and cites the difference between English and Anglicised as an example of the distinction between the construction of the subject position of coloniser and the construction of the partial subject position of the colonised ('Mimicry', pp. 235-6, p.23). In Bhabha's writings the terms 'hybridity' and 'mimicry' are linked. He suggests that 'mimicry emerges as the representation of a difference that is itself the product of disavowal' and he suggests that it is this process by which colonial stereotypes are produced ('Mimicry', p. 235, p.237).

Bhabha's notion of stereotype is not simply the idea of a crude or not particularly progressive presentation of the image of the colonial, but is more or less synonymous with his notion of a partial presence or mimic man. It is a product of the attempt by the colonising subject to fix the other, the colonised subject in a position defined by difference (a difference though, that is the product of disavowal). This fixity

34 Following this model one can in fact read Gray's text as itself marked by coloniality, with its metaphors of bastard offspring coming from the mother language.

35 Homi K. BhaBha [sic], 'Of Mimicry and Man: The Ambivalence of Colonial Discourse', October no 28, Spring 1984, rpt. in Modern Literary Theory. A Reader eds., Philip Rice and Patricia Waugh (London: Edward Arnold, 1989), p.235. Further references to 'Mimicry' in the text. 
allows the colonising subject to maintain surveillance of and authority over the colonised subject. However, the production of fixed others is always under threat from excesses and slippages because the discourse which produces these colonial stereotypes is itself constructed around an ambivalence. Bhabha suggests that it is the force of ambivalence that gives the colonial stereotype its currency: ensures its repeatability in changing historical and discursive conjectures' 36 The nature of the ambivalence within colonial discourse which gives the stereotype its currency Bhabha identifies as being a split in the foundations of colonial discourse itself. He suggests there are

...two disproportionate sites of colonial discourse and power: the colonial scene as the intervention of historicity, mastery, mimesis or as the 'other scene' of Enstellung, displacement, phantasy, psychic defence and an 'open' textuality (Wonders p.94).

So colonial discourse is the site of learning, knowledge and the accumulation of facts and at the same time it is the site of fantasy and myth. It is this ambivalence which provides the possibility for the 'strategic reversal of the process of domination through disavowal. The very proliferation of discriminated subjects which are 'almost the same but not quite', in order to secure the identity of the colonising subject has the potential to turn mimicry into menace. 'If discriminatory effects enable the authorities to keep an eye on them, their proliferating difference evades that eye, escapes that surveillance' (Wonders, p.97). Bhabha suggests that the

36 Homi K. Bhabha.'The other question: difference, discrimination and the discourse of colonialism' in Literature, Politics and Theory: Papers from the Essez Conference 1976-84 eds., Francis Barker, Peter Hulme, Margaret Iversen and Diana Loxley (London: Methuen, 1986), p.148. 
ambivalence of colonial authority repeatedly turns from mimicry - a difference that is almost nothing but not quite - to menace - a difference that is almost total but not quite ('Mimicry', p.241)

This is the point where the strategic reversal of the process of domination by disavowal occurs, the point where the look of surveillance returns as the displacing gaze of the disciplined, where the observer becomes the observed and 'partial' representation rearticulates the whole notion of identity and alienates it from essence' ('Mimicry's p.238).

Hybridity, then, is simultaneously the sign of the productivity of colonial power and the site where that power is reversed. Although Bhabha's analyses of colonial discourse pay particular attention to racial difference, the models which he describes, by which the effect of the purity and originality of authority is produced, are equally applicable to the difference between autochthonous European subjects and those subjects of European extraction who have no claim to European autochthonicity, i.e. white colonials. 


\section{Camping in Colonial Dress.}

It is within this paradigm that I wish to attempt to construct a reading of 'The Woman at the Store' which occludes neither its European location of address nor its colonial specificity but takes account of the text's ambiguities. What is at stake in the narrative of 'The Woman at the Store' is the construction of a position of European autochthonicity. There is an attempt to construct this position through the use of colonial material. It was written in Europe with a northern hemisphere audience firmly in mind, but exploits the cachet of New Zealand exoticism. Rather than Mansfield being subsequently appropriated by Europe, Mansfield's use of this form can be seen as an appropriation of the colonial short story. Rather than representing an experimental attempt at regionalism by a writer not yet contaminated by the ways and knowledge of the metropolis, this story represents an attempt to construct an autochthonously European narrative position through the mastery of colonial material. I would argue that one of the process at work in it is (to inflect Wevers' sartorial metaphor) one of dressing up, perhaps even 'camping' in colonial dress, actually following the dictates of European literary fashion by masquerading as colonial. So we have a metropolitan European tale masquerading as a colonial tale, but this colonial tale nevertheless bears the marks of another registering of coloniality apart from its use of setting. This is not to suggest that there is a true colonial essence behind the European masquerade, but that the ambivalences in the tale itself are the product of a specifically colonial siting. The attempt to construct an autochthonously European narrative position then is undermined by ambivalences, and it is in these ambivalences that the coloniality of the text can be read. 
The hybridity of 'The Woman at the Store' as a product of colonial discourse is registered in several ways. There are uneasy slippages in the tone of the story which attest to this mimicry. In the bid to construct a position which is autochthonously European, the narrative has simultaneously to produce knowledge of, and distance from the colonial subject which is the subject matter of the story.

The Bull in the Metropolis: The struggle for Autochthonicity.

The dynamics which I suggest are operating in "The Woman at the Store' are in some respects similar to those which are in operation in a passage from the Journal of Katherine Mansfield which starts by describing the Principal at Queens College, Harley Street:

They told us he was a very learned man, but I could not help seeing him in a double-breasted frock-coat, a large pseudoclerical pith helmet, a large white handkerchief falling over the back of his neck, standing and pointing out with an umbrella a probable site of a probable encampment of some wandering tribe, to his wife, an elderly lady with a threatening heart who had to go everywhere in a basket-chair arranged on the back of a donkey, and his two daughters, in thread gloves and sand shoes - smelling faintly of some anti-mosquito mixture.

As he lectured I used to sit, building his house, peopling it filling it with Americans, ebony and heavy furniture cupboards like tiny domes and tables with elephants' legs presented to him by grateful missionary friends. . . I never came into contact with him but once, when he asked any young lady in the room to hold up her hand if she had been chased by a wild bull, and as nobody else did I held up mine (though of course I hadn't). 'Ah,' he said, 'I am afraid you do not count. You are a little savage from New Zealand' - which was a trifle exacting for it must be the rarest thing to be 
chased by a wild bull up and down Harley Street, Wimpole Street, Welbeck Street, Queen Anne, round and round Cavendish Square ... ' (Journal p.55).37

In this passage, there is the articulation of a double desire. In addition there are two sites of address for this desire within the narrative: there is the address to the occupants of the classroom and the address to the retrospective reader. There is the desire to occupy the position of autochthonous Europeanness. What is primarily at stake is the securing of the pure and original identity of the author as autochthonously European, but there is also the desire to benefit from the cachet of New Zealand exoticism. In terms of the address to the occupants of the classroom the dynamics of colonialism operate in the following way: in response to the invitation to display exoticism, Mansfield performs the role of the exotic, but rather than being marked as unique and exotic, the difference from autochthonous Englishness which she signals by the bid for exoticism is construed as something other. The inherent verbal violence of the Principal's response to the claiming of the exotic experience appears excessive in the narrative. In the context of colonial dynamics this excessive reaction can be read as a response to the presence of menace. In the Principal's initial question, there is an inherent presumption of a commonality to the limits of experience and knowledge. When this commonality is undermined by the obtrusion of knowledge and experience beyond those limits, the limits of authority and control are threatened too. The move by the Principal to re-exert authority is then characterised by the production of stereotypes. The narrator's identity is simultaneously fixed in terms of a stereotype and erased as an autochthonous English subject. The question is addressed to any 
young lady', but the constitution of a respondent as a 'young lady' is dependent on a negative reply. A reply in the affirmative initiates the erasure of the subject (the young lady) and its substitution by a stereotype. The stereotype ('You are a little savage from New Zealand'), which is an articulation of fantasy as much as it is of knowledge, in that it conflates the condition of savagery with the condition of coloniality and precedes both terms with a diminutive, is a sign of the productivity of colonial power which here secures the identity of the author of the phrase within the narrative as himself autochthonously English. This marginalising phrase stands synonymously in the text with 'you do not count', which is a phrase ordaining colonial exclusion from the position of autochthonous English subjectivity.

So the bid for autochthonous English subjectivity is lost in the realm of the address to the occupants of the classroom, but it is recuperated in the narrative address to the retrospective reader. In neither address is the location of the experience of being chased by a bull made specific, but within the metropolitan context of the Principal it clearly represents an experience of such exoticism that it is metonymically connected with colonial experience. In the address to the retrospective reader there are several moves of displacement and denial and some marked indeterminacy. The claim to the experience of being chased by a bull, which becomes the signifier of colonial difference in the address to the occupants of the classroom, is denied by the narrator in the address to the retrospective reader by the intimate aside though of course I hadn't'. At the same time there is a marked indeterminacy in the retrospective consideration of the status of that signifier: 'it must be the rarest thing to be chased by a wild bull up and down Harley Street, Wimpole Street Welbeck Street, Queen Anne, round and round 
Cavendish Square .... The shift into the conditional and the way in which the phrases trail off into an ellipsis serve to intensify this indeterminacy and provide two mutually exclusive but undecidable readings of the sentence.

On the one hand, it is possible to read the sentence as a retaliatory counter to the narrator's exclusion by means of the display of colonial difference. In this case the superlative would delineate the paucity of metropolitan experience ('it must be the rarest thing ... . ') and the sentence would work towards an inversion of the signifier of exclusion. On the other hand, since the construction of the sentence leaves open the question of the location of the fantasised experience, it can be read as containing the implication that the narrator is here claiming an exotic experience within the metropolis (when the stress would be on the superlative as a condition of its possibility rather than its impossibility). This would serve to reinstate the figure of exoticism within the metropolitan context, emptying out its function as a signifier of colonial difference and thus enabling the narrator to occupy that position of exoticism safely without threat to the desired subject position of English autochthonicity.

The irritation about being constructed as a discriminated subject through the production of colonial difference appears to be marked only by a trace in the assertion that the event 'was a trifle exacting'. Yet a few pages later on in the Journal, a similar expression is used in a litotical fashion to express the intolerability of the contiguity of other classes and other races.

But it was a little trying to have one's own washerwoman living next door who would persist in attempting to talk to Mother over the fence, and then, just beyond her 'hovel' as Mother called it, there lived an old man who burned leather in 
his back yard whenever the wind blew our way. And further along there lived an endless family of halfcastes who appeared to have planted their garden with empty jam tins and old saucepans and black iron kettles without lids (Journal, p.57).

The security of the identity of the narrator as purely white and middle class is threatened by this contiguity and results in the production of the stereotypic figure of the lower class washerwoman and the hybrid figure of the halfcaste. The similarity of construction of the phrases 'a trifle exacting' and 'a little trying' in contexts where cultural identity is under question suggest that in the address to the retrospective reader 'a little trying' litotically registers the intolerability of being constructed as a discriminated subject through the production of colonial difference.

Perhaps the most noticeable move by which the desired position of English autochthonicity is recuperated in the retrospective narrative is in the displacement figured in the narrative prior to the recounting of the bull in a metropolis incident. Here we have a displacement of the authoritative (English, male, Principal) figure into a discriminated subject, a caricature identity for which the narrator constructs a context of marginalising exoticism. The stereotypic and ridiculous figure of a colonial missionary is consigned to the realm of partial presence.

They told us he was a very learned man, but I could not help seeing him in a double-breasted frock-coat, a large pseudoclerical pith helmet, a large white handkerchief falling over the back of his neck, standing and pointing out with an umbrella a probable site of a probable encampment of some wandering tribe (emphasis added, p.55).

This displacement is the move by which the narrator is retrospectively able to gain mastery. This figure, who had previously 
asserted his autochthonous identity by displacing her because of and by virtue of her colonial identity, himself becomes the subject of a colonial difference. By a movement of disavowal, namely the projection of colonial difference onto the principal figure of English autochthonicity, the narrator recuperates that position of English autochthonicity as her own.

The attempt to assert an autochthonously European identity whilst being marked by the cachet of exoticism or the attempt to inscribe the marker of difference within the security of a metropolitan siting is also displayed in the 'story' which Alpers relates that Mansfield told to Floryan Sobieniowski. She told him that 'she was of "Irish" origin, and had talked of her adventures among the Maori savages'38 The claiming of an Irish origin in this tale has similarities to the displacement of an autochthonously Irish presence from another narrative followed by the installation of the narrator in that position of European autochthonicity. In 'About Pat', which was published in the Queen's College Magazine the tale of childhood reminiscence is framed by the present day observations of the narrator. ${ }^{39}$ In the section of childhood reminiscence. Pat the Irish gardener is introduced and his reminiscences of Ireland discussed in the narrative: He used to . . . recount long tales of the Dukes of Ireland whom he had seen and even conversed with' (Stories, p.6). But in the last sentence of the story, the Irish born figure who has 'rubbed shoulders with Ireland's aristocracy' is relegated by the narrator to colonial status:

I should dearly love to show him the sights of London, and take him to the 'Carlton' for a slice of German sausage and a

38 Cited in Life, p. 100.

39 Stories pp.5-8. 
bath bun, and see once again the way in which the Dukes of Ireland balanced their salt on their knives (Stories p.8).40

In a movement of disavowal and displacement, the narrative voice here announces itself as clearly in possession of London's cultural capital and displays Pat as foreign to London. The power and ownership which is displayed in the use of the verbs 'take' and 'show', dispossess the older, male, northern hemisphere figure and installs the narrator in a secure familiarity with the metropolis.

40 The retrospective narratorial frame is present in the text of the Alpers Stories, but in Ian Gordon's Undiscovered Country pp.27-9 and The Scrapbook of Katherine Mansfield ed. J Middleton Murry (New York: Fertig, 1974), pp.3-8. the text starts with the childhood reminiscence 'In the days of our childhood. and ends with the sentence immediately preceding the one quoted above. 'From that day to this I have never heard of him.

As well as the colonial dynamics which I outline, class distinction is also clearly in operation in this display of superiority. 


\section{European Autochthonicity in the 'Colonial' Tale.}

Less blatant assertions of European autochthonicity are present in the story 'How Pearl Button was Kidnapped. In this story, there is a difference marked between the representation of the colonial and the representation of the indigenous people. In 'How Pearl Button was Kidnapped' the whanau to which the little girl is taken is akin to a Rousseauvian idyll:

All the people were fat and laughing, with little naked babies holding on to them or rolling about in the gardens like puppies. ... There was a girl there with two pieces of black hair down to her feet. She was setting the dinner on the floor. . . She [Pearl] ate meat and vegetables and fruit and the woman gave her milk... 41

In this story there is an emphasis on noble savagery; nakedness is connected to innocence (naked being a term applied to the babies or innocents), animality is represented as a positive quality ('She nestled closer in the big lap. The woman was as warm as a cat and she moved up and down when she breathed, just like purring') and sensuality is divorced from a context of sexual and moral prescription:

The woman who had carried Pearl took off her hair ribbon and shook her curls loose. There was a cry from the other women and they crowded close and some of them ran a finger through Pearl's yellow curls, very gently, and one of them, a young one lifted all Pearl's hair and kissed the back of her little white neck. Pearl felt shy but happy at the same time (Stories, p.119). 42

41 Stories pp.119-20. Although I go on to make the point that Mansfield's colonial stories use the colonial as an oppositionary term against which to construct Europe as civilised, the cultural primitivism implicit in 'Pearl Button' also defines Europe as civilised in opposition to the 'state of nature' outlined in that story.

42 Stories, p.118. 
The peach and the pear which Pearl is given to eat are the antithesis of the fruit of knowledge; in the Rousseauvian idyll there is no forbidden fruit, and the eating of the fruit and the spilling of juice on clothing all serve to emphasise the notion of a lapse into innocence. The fruit in this story is part of a seductive dream of autochthonicity, of being indigenously native. The rules, restrictions and moral codes of the colonial society do not apply. The nakedness which is such an important trope of noble savagery is placed in contrast to the restriction of the colonial's clothing - the fussy pinafore frill which fills and gags Pearl Button's mouth, the imprisonment of 'ironing-[clotheslbecause-its [sic]-Tuesday ' and the disciplining 'men in blue coats'. In the same way the foods in the idyll - meat, vegetables, fruit and milk which are mentioned by their generic names, and thus represented as natural, stand in contrast to the adulteration and destruction of food which is identified with the colonial like when mother peppered her fish and the top of the pepper pot came off.'

In this story the white settlers get a bad press. All the comparisons mentioned above operate to the detriment of the white settler. The narrator has a vested interest in disassociation from the 'colonial' position in order to identify as metropolitan, and because of this, the story has a vested interest in privileging autochthonicity as a legitimising power. The desire to be identified as indigenous European produces the desire to privilege indigenous culture. The relationship between the colonial and the Maori is used to discredit the colonial, here by the assertion of the moral and aesthetic superiority of the natural Maori way of life. However, the representation of Maori in this story is in fact a culturally specific, stereotypic representation of Maori-as-noble-savage. The notion of noble savagery is a product of a 
society which perceives itself not only corrupt in relation to the unspoilt Pacific idyll which it regards, but also, implicit in this regard, as civilised, sophisticated and metropolitan by virtue of the 'natural' which it locates as its antithesis. So what is again located implicitly but ultimately as superior in this story is the panoptic gaze of the European, surveying, delineating and categorising the objects of its gaze, be they indigenous native or white settler.43 What is at stake here, again, more than anything else, is a narratorial identification with a Eurocentric positioning of the gaze, an implicit assertion of autochthonous European identity. The privileging of Maori over colonial has several effects; by deprivileging the colonial, it creates distance between the colonial and the narratorial position, imputes value to autochthonous culture, but also ultimately asserts the cultural superiority of the autochthonous European.

43 In his book Orientalism (Harmondsworth: Penguin, 1978), Edward Said suggests that the orientalist attempts 'to survey the Orient from above, with the aim of getting hold of the whole sprawling panorama before him', and that to do so 'he must see every detail through a set of reductive categories which are primarily schematic and efficient. This in conjunction with an assumption that no Oriental can know himself as well as an Orientalist can know him means that any vision of the Orient ultimately comes to rely for its coherence and force on the person, institution, or discourse whose property it is. Any comprehensive vision is fundamentally conservative. . . Orientalism is staked upon the permanence of the whole Orient, for without "the Orient" there can be no consistent, intelligible, and articulated knowledge called "Orientalism." Thus the Orient belongs to Orientalism... I have called [it] vision because it presumes that the whole Orient can be seen panoptically... pp.239-240. I would suggest that there is a similar process at work in the 'colonial' stories under discussion, that the categories of 'colonial' and 'Maori' here are reductive, schematic and efficient in producing apparently fixed stereotypes which appear to help to fix the position of the regarding subject. I include the qualifiers because, as Bhabha suggests, and as I go on to discuss in relation to Mansfield's stories, rather than producing the desired firity, stereotypes are in fact the location of a destabilising ambiguity. 


\section{The Construction of European Autochthonicity in 'The Woman at the Store'.}

I would argue that a similar set of dynamics are at work in "The Woman at the Store' as in the narratives discussed above. The production of a position of European autochthonicity is a governing force. In this narrative the colonial or white settler is constructed as a discriminated subject, a stereotype which is given its currency by the force of ambiguity. As discussed earlier, the opening paragraph invokes the familiar binarisms of phase one fiction, which allow the unambiguous construction of a European narrative position. Setting up a binary opposition between familiar and exotic and aligning these two oppositional terms with Europe and New Zealand respectively is a strategy which works in terms of the representation of the landscape to secure a European identification. Place is initially represented as unknown, inhuman and exotic. This landscape is inhospitably hot, inhospitably stormy, vast and empty, (the image of the slate pencil scraping over the surface of the slate rather than writing on it which is linked to a description of the sky as slate coloured even suggests a landscape which resists inscription, resists being written on or about).

Just as Gray's schema operates on the assumption that a particular construction of identity can be read off from the particular nature of the representation of place, so, according to Bhabha's schema, the anxiety about identity can be read off from the function of stereotypes in colonial discourses.

In 'The Woman at the Store' there is a whole structure of discrimination in place. It is a discrimination which works to secure the pure and authoritative and autochthonous identity of the narrator by 
marking the difference between the narrator and the colonial subjects which are the subject of the narrative. The effect of this production of difference, which is a product of disavowal, is to display these colonial subjects as stereotypes. Perhaps one of the answers to the question of why Alpers does not find the narrator of 'The Woman at the Store' convincing when reading it as a colonial tale (and therefore within the framework of expectations of phase two literature) is because of the distance which is continually marked between the narrator and the stereotypically colonial characters. There is no sense in this narrative of a colonial speaking among colonials as there is, for example, between Archie, the narrator of the inset tale in Henry Lapham's 'A Member of the Force' and the other characters in that tale.

... just as we were starting [Lily] called me back, and shutting the door, says in a soft voice, "Archie, do you think Jim is very badly hurt ?"

' "I do, indeed, as bad as can be almost."

" "Oh, poor fellow, poor fellow," she said, with her sweet voice all a tremble and her eyes quite dim; "you'll tell him Archie, I am so very sorry, please," and she looked so tender and pitiful, that I just felt like taking her in my arms and giving her a good kiss there and then.'

'And may be you didn't do it too?' said one of the listeners in a suggestive voice.

'Never you mind,' retorted Archie, 'that's got nothing to do with the yarn. ${ }^{44}$

In Lapham's narrative, Archie is shown to participate in colonial life and to share the values of the other characters. A commonality is displayed both between Archie and those mentioned in his inset tale (sexual liaison with Lily is marked as desirable), and between him and the characters with whom he is drinking in the pub, who identify the

44 Henry Lapham. 'A Member of the Force', in New Zealand Short Stories (Oxford: Oxford UP, 1953), p.71-72. 
same figure as an object of desire. Although the tale deals with a suspected murder attempt and a tragic drowning, it does not sensationalise these narrative events, nor does it display as exotic the landscape in which they occur. Although the level of diction is neither formal nor elaborate, and whilst colloquialisms are occasionally used, there is no attempt to indicate a colonial specificity through the use of orthographical irregularities. Above all there is no signalled attempt to construct a European position of address.

In contrast, in 'The Woman at the Store' there are a set of textual loci where the unnamed narrator is differentiated from the other colonial characters. The narrator is orthographically differentiated, distinguished by class, as well as behaviourally and physiologically separated from the woman and child at the store and from Jo. In each locus of difference the characteristics by which the colonial subjects are marked is stereotypical.

One of the ways in which this discrimination is marked is in the non-standard direct speech of the colonial characters, contained within the standard orthography of the surrounding narrative. The standard speech of the narrator and Hin is contrasted markedly with the utterances of the other characters.

A difference is clearly marked between the speech of jo and the speech of Hin; the contrast is particularly evident as Jo's vulgar colonial colloquialisms and his orthographically debased rendering of Hin's direct speech are immediately followed by Hin's authentic and undebased direct speech.

'My stomach feels like the crop of a hen. ... Now then, Hin, you're the bright boy of the party - where's this 'ere store you kep' on talking about. "Oh, yes," you says, "I know a fine store, 
with a paddock for the horses an' a creek runnin' through, owned by a friend of mine who'll give yer a bottle of whisky before 'e shakes hands with yer." I'd like ter see that place merely as a matter of curiosity - not that I'd ever doubt yer word - as yer know very well - but....'

Hin laughed. 'Don't forget there's a woman too, Jo, with blue eyes and yellow hair, who'll promise you something else before she shakes hands with you' (Stories, p.109-10).45

Distance is marked between Hin and Jo by the presence, in Jo's direct speech, of apocope, the dropping of aspirates, agrammaticisms, pseudo-phonetic spelling and general vulgarity of expression, and the absence of all these features from Hin's direct speech, and this distance is emphasised by the orthographically incorrect reproduction of Hin's direct speech within Jo's direct speech. Similarly, distance between the narrator and the woman at the store is orthographically marked. The type of direct speech that is given to the white settler characters in 'The Woman at the Store' re urs in 'Millie', 'Ole Underwood' and 'Old Tar'. In 'Old Tar' the density of the orthographical irregularities at points becomes extreme.

'It's a durn fine place ... it's a place to shake yer lungs out in yer know, boy, my Pap bought this from the Maoris-he did. Ye-es! Got it off Ole Puhui for a "suit of clothes an' a lookin'glass of yer Granmaw's." My stars! He had an eye! Larst thing the ole man says to me was - "James," 'e says, "don't you be muckin' about with that bit of land top of Makra Hill. Don't you sell it. 'And it on," 'e says, "to you an' yours" ' (Undiscovered Country, p.299)

Gillian Boddy suggests that the [humour] and the phonetic spelling of 'Tar's speech' is used 'to create realistic dialogue'. 46 I would suggest that the excessive degree to which consonants are omitted here serves

45 Ellipsis in Mansfield text.

46 Gillian Boddy, Katherine Mansfield: The Woman and the Writer (Ringwood, Victoria: Penguin, 1988), p.157. 
not as an attempt at an accurate representation of the speech of a particular class in a particular location at a particular time, that is, not as an attempt at regional realism, but as a trope of colonial difference. In Lady Barker's 'Christmas Day in New Zealand' the same process is at work as that identified in 'Old Tar' and 'The Woman at the Store' above, that is, the representation of colonial difference by the disjunction between the standard grammar and spelling of the narrator of 'Christmas Day in New Zealand' and the peculiarly non-standard direct speech of individuals whom the European narrator marks as 'colonial'. The European narrator represents herself as being in a foreign land, distant from the metropolis and, in insisting on the difference between London and the colonies, attests to her familiarity and identification with that metropolis:

I am afraid there were no presents exchanged that morning, for we were fifty miles away from the nearest shop, and had not been down to Christchurch for months. However, we received and returned many hearty good wishes; and in that foreign land it is something to be among friends on Christmas Day, even if there are no presents going about . 47

This metropolitan identification is further emphasised by the slip in the use of the pronoun. In a narrative which has been located in New Zealand and addresses London from that distance, 'that foreign land' attests to the desire of the narrator to locate herself in London. Cut off from the commerce and material exchanges of the metropolis (the nearest shop is fifty miles away, and there are subsequently no gifts to exchange), what becomes currency is language, verbal expression. Thus speech is the medium in which the narrator can signal her metropolitan identity against, and by virtue of the colonial speech of

47 Lady Barker, A Christmas Cake in Four Ouarters, (London: Macmillan, 1872), p.259. Further references to Barker in the main text. 
the subjects of her narrative.

'Dear me, how can you both wear the same clothes ?' I inquired. 'M'Pherson is such a giant, and you are not very tall, M'Nab.'

'Well, mem, we made them our ainsells, and we cut them on a between size, you see, so they fit baith, fine. The trews were hard to manage, but 'Phairson wears 'em with gaiters, and I rolls 'em up; so though they're a deal too short for him and too lang for me, we manage first class,' said M'Nab, relapsing into colonial phraseology (emphasis added, Barker, p. 259).

In Lady Barker's text the location of this colonial difference in the narrative strategy is made explicit by drawing attention to the different phraseology. It is interesting that the narrator here chooses to emphasise the colonial difference, in preference to the specifically Scottish regionalism which appears to be displayed in the orthography (M'Pherson and M'Nab, ainsells, baith, trews) or the class difference which requires $\mathrm{M}$ 'Nab to address the narrator as 'mem'. Here the emphasis on colonial difference in speech is a product of disavowal. The insistence on verbal expression as a means of differentiating between colonial and European discloses a hidden (i.e. disavowed) acknowledgement of the (danger of the) possibility of being identified as the same, of being classed as colonial by virtue of her colonial physical location. It is at this point that a similarity which is almost but not quite has to be denied and fired as difference. The dynamics of the relationship of the narrator in 'The Woman at the Store' to the other colonial characters has far more in common with the narratorial dynamics in Lady Barker's tale than those in Lapham's tale. The space which the narrator of 'The Woman at the Store' occupies is constructed in opposition to that occupied by the colonial characters, thus occupying that position which is clearly identified as 'European' in Lady Barker's narrative. 
Lapham's narrator is a worker amongst fellow workers whereas the narrator of 'Christmas Day in New Zealand' is an employer addressing employees. The occupation of the narrator of 'The Woman at the Store' is not indicated, but she is marked as possessing leisure time rather than a habitual form of work. In addition to this, the inset dream at the beginning of the narrative signals the class status of the narrator in terms of a prosperous middle class childhood.

I half fell asleep and had a sort of uneasy dream that the horses were not moving forward at all - then that I was on a rocking-horse, and my old mother was scolding me for raising such a fearful dust from the drawing-room carpet. 'You've entirely worn off the pattern of the carpet,' I heard her saying, and she gave the reins a tug (Stories, p.110).

In contrast with rocking horses and drawing room carpets, the squalor of the woman's house, from the garden which smells of dishwater to the broken chairs and the flies buzzing in circles round the ceiling, is relentlessly detailed. The colonial characters in Mansfield's stories are marked out by their occupations as working class: the woman at the store is an ex-barmaid, her husband a storekeeper, Old Tar is a shopkeeper, Millie is a farmer's wife and Ole Underwood a sailor.

In 'The Woman at the Store' the narrator is behaviourally separated from the violence and insanity of the woman and the child. The verbs which describe the narrator's actions, whilst not registering complete passivity, all indicate a degree of moderation and decorum: 'half fell asleep', 'walked', 'lay in the water', and the one vigorous action which the narrator contemplates is censored 'I wanted to shout 'Buck up,' but I kept silent.' By contrast the verbs describing the woman relate to violent activity: 'made frantic gestures', 'screamed', blinked rapidly 
screwing up her face', 'shouted violently', 'kicked', 'stamping', 'banging her fists', 'clutched her head' 'rushed from the table' 'beat the child's head'. These figures of violence are attached to other colonial characters too. Although Jo is depicted more as vulgar than violent, he is marked out in the narrative as a stereotypical colonial and surrounded by images of violence. Not only does the sentence 'A white handkerchief, spotted with red - it looked as though his nose had been bleeding on it - knotted round his throat ' contain a simile that is excessive, redolent of violence in the mention of blood, designed to provoke disgust and mark difference from refined manners or civilization, but also the ambiguity produced by the absence of an auxiliary verb here implies that Jo's handkerchief has a life of its own and murderous intentions (Stories, p.109).

Violence and murderous intentions run through 'Ole Underwood' and 'Millie'. In both narratives a murder has already been committed at the outset, Ole Underwood has murdered his wife, and in 'Millie' there is a graphic description of the murder scene.

There was blood all over the barn. And Willie Cox said he was that knocked out he picked a cigarette up out of the blood and smoked it. My word! he must have been half dotty. (Stories. p.134)

Both stories end with another murder about to be committed, one a lynching and one a strangulation. The colonial figures in these stories are represented as murderous and mad. Millie is overcome by blood lust, 'a strange mad joy smothered everything else. She rushed into the road - she laughed and shrieked and danced in the dust' (Stories, p.137). Even in 'Old Tar' although there is no murder committed the eponymous character is represented as desiring his father's death, and as mad. 
Old Tar, after one day's burst of excitement, kept his grim joy to himself. But he was mad inside, so hot that he felt all the hard years in him melting away. ... His feet seemed to freeze into the cold grass of the hill, and dark thoughts flew across his mind, like clouds, never quiet, never breaking (Undiscovered Country p.301, p.303).

Despite the fact that this piece is classified as a 'Scene from Colonial Life' in Gordon's collection, suggesting the reportorial accuracy of journalism or a sketch, the method by which the main character's internal derangement is registered is classically symbolist, the concrete image of the clouds standing in for the intangible psychological derangement.

In 'The Woman at the Store' it is the narrator who defines both the woman and the child as insane. Although the description of this story in the New Age is designed to be disparaging, 'murderous hags and degenerate children' does not fall so very short of the terminology of the story itself. ${ }^{48}$ The child is described by the narrator as a 'mean, undersized brat with whitish hair, and weak eyes' and further on in the narrative the child's drawings lead the narrator to comment that they are 'the creations of a lunatic with a lunatic's cleverness. There was no doubt about it, the kid's mind was diseased' (Stories, p.113. p.116). It is revealed in the narration that the woman has murdered her husband, she has threatened to kill her own child, and there is an implication at the end that Jo is also a potential murder victim. She is described by the narrator as 'a figure of fun':

Certainly her eyes were blue, and what hair she had was yellow, but ugly. She was a figure of fun. . . her front teeth were knocked out, she had red pulpy hands. . (Stories, p.111).

48 'Present-Day Criticism' New Age 10.25 ns. (1912) : p.589. 


\section{No Sympathy for the Colonial Woman?}

Several critics read this story as a sympathetic and proto-feminist analysis of the position of women in the backblocks. Sylvia Berkman suggests that one of Mansfield's overriding themes is 'the painful nature of all sexual relationships,' and that 'The Woman at the Store' is a story about

[a] woman, taken from the busy life of a coastal public house to the unsettled bush country, neglected by her roving husband, [who] is driven in her hatred to kill her husband and conceal the crime... 49

C. $K$ Stead locates the same area as being the one of primary importance. He describes the story as one which portrays the woman as 'ruined by neglect, maltreatment, and the strain of outback life,' and suggests that it has at its heart 'Katherine Mansfield's central preoccupation - female sexual involvement and the destruction she seems to feel goes inevitably with it'(Glass Case p.33). Cherry Hankin's reading of the story is similar to that of Stead and Berkman. She suggests that the association of sexuality with violence is a recurrent the me in Mansfield's writing, and that it appears in 'The Woman at the Store' as 'outrage at the biological helplessness of women. ${ }^{50}$ Hankin suggests that sympathy is created for the woman.

An important difference between the two works ['Millie' and 'The Woman at the Store'], however, is the extent to which the reader's sympathies are manipulated and directed. While we are not asked to condone the woman at the store's murder of

49 Sylvia Berkman, Katherine Mansfield: A Critical Study (London: Geoffrey Cumberlege, Oxford University Press, 1952), p.48. Further references to Berkman in the tert.

50 C. A. Hankin, Katherine Mansfield and Her Confessional Stories (London: Macmillan, 1983, rpt.1984), p.32. Further references to Hankin in the text. 
her husband, our pity is aroused by Jo's cynical exploitation of her, the woman's bitter story about her married life, and the narrator's own sympathy (Hankin, p.52).

These commentators all mark out gender interaction and the resultant oppression of women as the primary focus of the narrative. However, there is not the same consensus over the narrative angle from which these matters are presented. Hankin claims that the narrator of the story is sympathetic (though she does not cite any part of the text in support of her claim), whereas Berkman's view is that the narrative is presented objectively.

The narrative is given with scrupulous objectivity. The scene is set, the figures move and speak, the plot unfolds without a word of comment (Berkman, p.48).

Claire Tomalin's isolation of the crucial elements of the story and her perception of its presentation are similar to Berkman's:

the woman at the centre, once a pretty barmaid with 125 ways of kissing, has been broken by marriage, childbearing, solitude, and responded with violence. The story is left coolly at that, neither characters nor author passing judgement. 51

Certainly there is no overt statement of judgement by the first person narrator as there is in 'The Advanced Lady' or The Modern Soul' nor is there a final maxim attached to the text as there is in "The Tiredness of Rosabel' , 'In a Café or 'The Baron', but the absence of these features from the narrative of 'The Woman at the Store' does not mean judgement is absent or that presentation is objective.52 judgement is insistently invoked throughout the narrative.

51 Claire Tomalin, Katherine Mansfield: A Secret Life (London: Penguin, 1988), p.96.

52 'The Advanced Lady' (Stories p.80), 'The Modern Soul' (Stories p.73), 'The Tiredness of Rosabel' (Stories p.21), 'In a Cafe'(Stories p.11), 'The Baron' (Stories p.34). 

In both cases the question is asked in the context of marriage, sex and childbirth, and in both stories marriage, sex and childbirth are associated with pain, violence and loss. The narrative of 'Frau Brechenmacher' works constantly to engage the sympathies of the reader for the Frau, by the continual gap between Herr Brechenmacher's aggressive and overbearing treatment and Frau Brechenmacher's gentle and obedient response, by the difference between the vindictive comments of the other women in the Festsaal and mildness of the Frau's comment 'Girls have a lot to learn', and by the repeated image of Frau Brechenmacher as a vulnerable child. However, in 'The Woman at the Store' the woman's long speech where she asks 'wot for' is the only section of narrative where sympathy is actively engaged for her. Otherwise the woman is represented by a whole series of negative images, and despite Hankin's comment I can detect no sisterly sympathy from the female narrator. As mentioned above, the narrator stifles her only impulse to cheer and console ('I wanted to shout 'Buck up,' but I kept silent'), and the narrator's comment " "Good Lord, what a life!" I thought. ". . mad, of course she's madl" ' (Stories p.112), is marked more by disdain and matter of fact acceptance than righteous anger at the plight of a similarly gendered sufferer. When their common gender is considered, there is in fact a very marked gap between the position of the narrator, from whom signs of sexual desire and fertility appear to be completely absent, and that of the woman whose body is ravaged beyond recognition, whose spirit is broken and looks spoiled by childbearing and miscarriage, but who nevertheless registers a lust which responds to Jo's display of sexual interest. In the text there is the suggestion in the woman's history that sexual desire has left her defenceless, at the mercy of both 
the exploitative husband's sexual desires and the resulting pregnancies.

"... 'e'd say ... "Come and give us a kiss." ... and if I took it all right, 'ed wait till 'e could twist me round is finger, then 'e'd say, "Well, so long, I'm off." ' (

This marital relationship is marked by lust as is the one with Jo, where the woman is represented by him as no more than female flesh'. It stands in contrast to the sanitised relationship between Hin and the narrator, where adult sexual desire is completely expunged: 'we behaved like two children let loose in the thick of an adventure' (Stories p.116). The difference which is marked here between the desirous and partially destroyed female and the androgynous narrator is the product of disavowal. Excitement, as adventure, is constructed as exterior to the body of the narrator, and adult female sexual desire, the burden of childbearing and the subsequent disfigurement is displaced from the person and body of the narrator onto the body of the woman at the store. The focus on the woman as the object of male abuse also reduces to a trace the verbal abuse which the female narrator is subjected to from both male travelling companions (" "Well of all the fools. Hin's slanging you. What have you been doing all the time?" ' Stories p.112.)

A similar process is at work in the attribution of animal images - the child is referred to as a 'rat' and the woman is referred to in a couple of animal images which signify very differently from the cat simile used to describe the Maori woman in 'How Pearl Button was Kidnapped'. In 'Pearl Button', the woman who purrs like a cat is a comforting and natural presence. In 'The Woman at the Store' these figures work as signs of colonial dehumanisation. The woman 
describes herself as a 'broody hen', and the simultaneous aptness and inaptness of the phrase is unsettling, (she has had five pregnancies in six years, but she has also threatened to kill her own child). The mention of her flared nostrils, register her as equine in contrast with the packhorse who is humanised earlier in the story. The woman's first words to the travelling party are that she has mistaken them for hawks, which is followed closely in the narration by the first animal simile with which the narrator describes her, 'like a hungry bird'. It both brings to mind the scavenging hawks just mentioned and again serves as a marker of disavowal. The narrator firmly displaces onto the woman the signs of colonial dehumanisation.

I do not wish simply to replace colonial difference by gender difference as the privileged criterion for analysis, but it seems to me that the textual features outlined above prevent a straightforward yoking of this story under the gender the matics which Berkman et al. invoke to provide a reading of the text. Bridget Orr suggests that accounts of Mansfield's oeuvre by recent metropolitan feminist critics occlude Mansfield's colonial difference (Orr, p.448). I would suggest that this occlusion does not only operate in specifically metropolitan and specifically feminist accounts of Mansfield. To see the woman in this story represented purely as a victim it is necessary to register coloniality only as setting and to be 'indifferent' to the colonial politics displayed elsewhere in the text. The claims for the objectivity of the narration and the absence of comment on the matter of the story are what signal this 'indifference' to the colonial politics of the text in the accounts outlined above. Although the position of the woman may be treated sympathetically at one point, she is a derided colonial figure at others, and these antagonistic colonial politics in the text have to be 
addressed. The text is fractured by colonial difference as much as gender difference.

Clare Hanson and Andrew Gurr note that the 'feminist element in "The Woman at the Store" . . combined with its attention to social setting and detail ... produces a degree of confusion and diffuseness of effect not found in the later "Ole Underwood" 54 Although they do not elaborate upon this observation, I would suggest that the 'confusion and diffuseness of effect' which they note is the product of conflict between the colonial politics of the text, which produce a division between the stereotypical colonial and non-colonial irrespective of gender, and the feminist politics of the text which mark an antagonist relation between male and female which cuts across the boundaries of colonial difference.

54 Clare Hanson and Andrew Gurr, Katherine Mansfield (London: Macmillan, 1981), p.40. 


\section{Alarming Contiguity and The Return of the Displaced Gaze.}

I have detailed above the way in which the text attempts to establish an unambiguously, autochthonously European position by the relentless production of difference between the colonial subject and the narrator, a production of difference which constructs the narrator as pure, seamless and unified by virtue of the difference from stereotypically colonial characteristics. I would further suggest that both the purity and the authority of the narrator are undermined, whilst the narrative has to be 'corrected' to keep it coherent. The distance and difference which have been continually marked are threatened by the return of contiguity. It is this undermining of authority, dislocation of coherence and return of contiguity which registers the coloniality of the text, both despite, and because of its attempt to construct an autochthonously European position.

As suggested above, the anxiety ${ }_{L}$ an autochthonously European identity, and in particular about the coherence and security of this identity, is manifested in the production of colonial stereotypes. These stereotypes are produced as hybrid figures. In Blanche Baughan's 'Pipi on the Prowl' for example, the old Maori woman Pipi is represented as both infantile and anile; mendacious and atavistic; full of 'native' cunning but projecting a front of native innocence. 55 The anxiety about colonial identity, about the hybridity of a position which is neither fully European nor fully New Zealand, is displaced into a stereotypical figure. The fractured colonial identity registers that hybridity as outside itself in a movement of disavowal.

55 B. E. Baughan, Brown Bread from a Colonial Oven (London and Christchurch: Whitcombe \& Tombs, 1912), pp.1-6. 
Similarly in Lady Barker's tale, the hybridity is registered in a textual slip, 'that foreign land', but is displaced onto a figure which is specifically registered as colonial, and which encodes hybridity, as two bodies occupy the same one set of clothes. In 'The Woman at the Store' the place where the narrator's identity is most threatened is strikingly registered in the problematic sentence discussed before.

There is no twilight to our New Zealand days, but a curious half-hour when everything appears grotesque - it frightens as though the savage spirit of the country walked abroad and sneered at what it saw (Stories, p.112).

As Bhabha suggests, the production of discriminatory others, the repetition of similarity as something different, reaches a point where it undermines the power by which the discriminatory others are produced. In 'The Woman at the Store,' the figure of the mad colonial woman is produced through exactly this process of disavowal. The narrator disavows incoherence and mental disturbance outside of herself into her surroundings, and by this move constructs herself as sane, coherent and non-colonial. But the ultimate product of disavowal is the return of the displaced gaze. In this narrative it can be seen as the savage spirit which sneers, it is the point where mimic turns to menace, where what has been projected outwards returns in threatening form, 'appears grotesque', 'it frightens'.56 So what can be seen as an attempt to secure an unproblematic narrative position, a tale on colonial subject matter addressed from a European perspective reveals identity as hybrid and under threat.

56 Just as later the control of the narrator is undermined by the displacing gaze of the child who has watched her while she was bathing, transposing the narrator from surveyor to surveyed. 
The coherence of the narrative is also undermined by a textual hybridity. In the version of the text printed in Rhythm the sentence 'He rode ahead of me' produces difficulties in distinguishing between Hin and Jo, and in particular in determining to whom the description 'white as a clown, his black eyes glittered, and he kept shooting out his tongue and moistening his lips 'refers. 57 Alpers notes in the commentary to the Stories that 'Murry . . corrected one confusing sentence' (p.551). Apart from Alpers' registering of Murry's alteration as a correction, the ambiguity between Hin and Jo which exists in the Rhythm version of the text is mirrored by a similarly ambiguous sentence towards the end of the text. The narrator's exclamation ' "One hundred and twenty-five different ways - alas! my poor brother!" ' (Stories, p.117), is clearly spoken to Hin, but it is Jo who is with the woman and experiencing the multifarious amorous addresses. The sentence suggests that either it is Jo who is the narrator's brother, or that Hin is the narrator's brother and she is sympathising with him for missing out on one hundred and twenty-five different ways of kissing, or that Hin is the narrator's brother and she is sympathising with him for having previously experienced one hundred and twenty-five different ways of kissing. The possibility of a sibling relationship

57 Rhythm, 1.4 (1912): p.7. It is in fact possible to make some sense of the Rhythm text as it stands, by presuming that 'He rode ahead of me' refers to a person (Hin) with whom the narrator has a special relationship (the opening line of the story assumes certain specifics which are known to the narrator and not the reader), as the description of a second set of clothes clearly belongs to a second person, although there would still be some ambiguity in the sentence. However, there certainly seems to be no need to change 'ahead of me' to 'beside $\mathrm{me}^{\prime}$. The narrator is describing the relative positioning of the riders. Jo in front, Hin ahead of her, and herself bringing up the rear. There are various other differences between the Rhythm text and that of Stories and Something Childish and Other Stories ed. Murry, ed. Murry (London: Constable, 1924), pp.58 -75. For example 'she's the dead spirit of me' in Rhythm, p.14 reads 'she's the dead spit of $m e^{\prime}$ in Stories (p.112), and SCVN (p.65). 
between Jo and the narrator is made unlikely by the distances marked between those two in the text, but the sentence remains ambiguous. What it does bring to mind is the 'confidential moment' mentioned earlier by Hin and implies a previous sexual liaison between the woman at the store and the brother of the narrator. So the state of the lustful, squalid, abused, fecund and deranged figure of the colonial woman from which the narrator has distanced herself returns with alarming familial contiguity. The brother is implicated with knowledge of the colonial land and its inhabitants which contaminates the narrator's position of distance. It is in this context that Jo's naming of Hin as a 'cuckoo' has particular significance, he brings back within the family that which is marked as other and disavowed and displayed as difference.

Hin is, in fact, contaminated by those signs of violence which are textually associated with the colonial landscape and the colonial inhabitants. He 'snatches' the embrocation from the narrator, smiles maliciously at her and threatens to beat the child, ' "I'll give you a bor on the ear if you don't," said Hin savagely' (Stories p.114). The narrator is implicated in the positions which she denies.

Hin is identified with the narrator in terms of both diction and orthography as non-colonial, but marked by the characteristics of lust and violence which have been displayed as signifiers of coloniality. The absence of overt comment by the narrator at the conclusion of the tale, can be read in the context of the problematic relationship of Hin to the position of the colonial, and the therefore problematic relationship of the narrator to Hin. The concluding lines which Tomalin and Berkman read as objective and without comment, to me seem to construct a strategic absence which is a comment in itself. 
'I'll pick you up later,' he shouted.

$A$ bend in the road and the whole place disappeared (Stories. p.117).

The conclusion of the story enacts a similar dynamic to the recuperative strategies of the bull in the metropolis incident. Rather than signalling objective neutrality, the last sentence signals relief. The undermining of the position of autochthonicity is recuperated by the banishing of the whole locus, the 'whole place' is 'disappeared'. In this context all the violence and lust are displaced back onto the colonial characters, leaving the violent Jo to the violence of the woman. Rather than an absence of judgement, there is a total displacement in which the brutalised figure of the colonial woman and the vulgar colonial male absolve Hin and the narrator of all traces of coloniality, and it is with the relief of this absolution and the autochthonicity which it restores that the story concludes. 


\section{More Colonial Anxiety.}

\section{Displaying the Apricot Cosmopolitanism.}

Colonial dynamics and the desire for autochthonicity can be seen operating in a number of stories which do not have New Zealand settings and never overtly raise the question of colonial identity. Although there is no direct discussion of colonial identity, I will suggest that the problem of colonial identity underlies the dynamics of the stories to be discussed, just as it is present as a motivating force throughout the bull in the metropolis incident, even before the Principal's denunciation makes the specifically colonial nature of the interaction explicit. 'The Journey to Bruges', 'Being a Truthful Adventure' and the three 'Epilogues', 'Epilogue I: Pension Seguin', 'Epilogue II: Violet' and 'Epilogue III: Bains Turcs' are all set in northern Europe.58 However, to designate these stories simply 'European' is as problematic as consigning the early stories set in New Zealand to the category of 'colonial', and positioning these pieces of writing with respect to Gray's schema is no easier. In discussing the colonial stories I suggested that conflating the question of subject matter, address and area of circulation of those pieces in assigning them to a particular category forecloses on reading certain aspects of those texts. In particular the conflation forecloses on what might be signalled about colonial identity by reading the representation of place in those texts outside the framework of the category to which they are habitually assigned. I would suggest that the same criteria apply to a 
reading of these 'European' stories. They are European in that the settings which they use are European, and the area of their circulation is again an English periodical, but the textual features of the pieces display an anxiety about cultural autochthonicity which marks them as colonial.59 They are marked by a coloniality which is displayed in the same way as it is displayed in the bull in the metropolis incident and in 'The Woman at the Store', that is in the production of stereotypes and the figures of displacement and disavowal.

These pieces are not, however, examples of what Gray refers to as the " "Colony's Revenge" - the novel about the upstart colonial visiting London and finding it abnormal, aberrant, different, filled with the quaintest sense of place' (Gray, p.9). What is strenuously attempted in the representation of place in these texts is not to mark the experience of place as abnormal, aberrant, and different but as familiar, known and controlled. There is again the attempt to construct a position of autochthonicity in the narrative. However, the very excessive strenuousness of the attempt results in an overly flamboyant proclamation of literary rights which paradoxically reveals an insecurity about cultural siting which it is intended to conceal.

Comparatively little attention has been paid to the "The Journey to Bruges' and 'Being a 'Truthful Adventure'. What critical commentary

59 'The Journey to Bruges' appeared in the New Age, 24 August 1911 and 'Being a Truthful Adventure' appeared in 17 September 1911 issue of the same magazine. The three Epilogues appeared in the three issues of the Blue Review: 'Epilogue I: Pension Seguin' appeared in the May 1913 issue, 'Epilogue II' appeared in the June 1913 issue and 'Epilogue III: Bains Turcs' appeared in the July 1913 issue. For ease of reference and discrimination I will refer to the three epilogues as 'Pension Seguin','Violet' and 'Bains Turcs' in the following discussion. All five pieces were reprinted by Murry in SCVN where two of the titles are slightly altered. 'Being' is dropped from 'A Truthful Adventure' and 'Epilogue II' becomes 'Violet'. 
there is on these two pieces tends to be of a classificatory nature and derogatory tone, and reveals the framework within which the pieces are read to be an expressive realist and humanist one as the criticism takes the pieces to be an expression of the writer's feelings and values, an authorial position which is deeply feeling and ultimately humane. Saralyn Daly remarks that 'Being A Truthful Adventure' contains 'probably the worst sentence Miss Mansfield ever wrote'60 and then goes on to criticise the overly satirical eye of the narrator in the Epilogues, suggesting that they are redeemed by the narrator learning to laugh at herself in 'Violet', and by the moment of deep human insight at the end of 'Bains Turcs' (Daly, pp.48-51). Antony Alpers regards the two texts as autobiographical pieces and comments that the 'recuperative trip to Belgium had yielded two slight travel pieces, The Journey to Bruges and A Truthful Adventure' (Life p.127).

In the 'Commentary' to the Stories he dubs them 'a pair of lightly handled travel sketches set in Bruges - hardly fiction yet' (p.549). However, it seems to me that there are other possible readings of these stories which are precluded by an interpretation of them as pieces of autobiographical journal jotting, merely transposed in context. For instance, a concentration on the 'autobiographical' content of the pieces deflects attention from their formal characteristics. Granted that 'The Journey to Bruges' is not a plotted tale, nor is it the sudden illumination of a particular moment or state of mind, 2 hower ${ }^{\text {its absence of }}$ plot does not necessarily render it formless or unliterary, accidental

60 Saralyn R. Daly, Katherine Mansfield (New York: Twayne, 1\%5), p.38. Further references to Daly in the main text. The sentence to which Daly refers is the more or less indefensible ' 0 ne cannot expect to travel in upholstered boats with people who are enlightened enough to understand laughter that has its wellspring in sympathy' (Stories p.100). 
rather than incidental, as Alpers implies in his suggestion that it is not 'fiction'. The piece is organised by two sets of co-ordinates, one external and one internal, by the progression of the journey from the London railway station to the Grand' Place in Bruges and by the internal consciousness of the narrator. There is a constant play between the internal and the external in the piece which gives rise to a textual complexity which is belied by Alpers' designation of 'slight' 'travel sketch'.61 Alpers' designation of 'sketch' is perhaps worth taking a little more seriously than he does himself, and W. H. New's analysis of the development of the sketch form is particularly useful in supplementing the sense in which it is used by Alpers. New outlines the development of the sketch in Canada and New Zealand and suggests that the nature of the sketch changed between the beginning of the nineteenth century and the beginning of the twentieth century.

Throughout the history of the sketch, the central element the form has required is a sense of immediacy; the writer is (or the reader infers that the writer is) present as an observer. But what can the observer see, and how ? From observing scenery and types at the beginning of the nineteenth century, the writer is allowed by the end to observe characters and events. And as these narrative elements creep into the 'neutral' observer's form, neutrality disappears. 'Impression' takes over as the accompaniment to 'immediacy,' and the force of the observer/narrator's point of view comes to be felt in the nature of the communication that takes place. ${ }^{62}$

He also argues that in response to different social and cultural

61 I am not suggesting that these pieces have the density or textual complexity of 'Prelude' or 'Je ne parle pas français' for example, but that it is worthwhile to examine them as literary constructs rather than noting only their 'autobiographical content.'

62 W.H.New, Dreams of Speech and Violence: The Art of the Short Story in Canada and New Zealand (Toronto: U of Toronto P. 1987), p.22. Further references to Dreams in the text. 
contexts, it was not the vocabulary used for documentary sketches which changed but that much in the new society, though different from the Old, was renamed with the old words' and that this produced an alteration in 'the tonal modulation which carried the vocabulary and the formal shape it took', and he suggests that it was the resultant tension which made the documentary sketch no longer a 'static' form (pp.23-4):

. . the 'sketch' stopped being a 'static' form because it was charged with the tension between the observing mind and the documentary language of observation. The mistake of those critics who find the sketch merely static is to have mistaken an absence of narrative plot for a lack of narrative vitality; the vitality exists in another guise, in the tension held creatively between language and form (Dreams, p.24).

'Narrative vitality', 'immediacy' and 'impression' seen to me to be accurate descriptions of the most striking features of these two pieces. Events, places and characters are registered in a chronological progression as the narrator observes them in the course of the journey and they are registered both with a sense of immediacy (which is created by the thumb-nail sketches and the attention to particular detail as well as the swiftly changing scene and tone), and with the force of impression. The pieces are thus filled with a sense of the particularity of the narrator rather than the neutrality of the narrator. The sense of particularity is produced not so much by the overt recounting of the narrator's opinions but by the manner and tone of the depiction of the scenes and characters observed. Encoded in this particularity are specific representations of cultural, national and gender identity.

In these stories there is a repetition of caricature of national types and stereotypes. The caricatures are swiftly delineated sketches, 
indicating types by registering culturally delineated markers of identity. The English 'types' in 'The Journey to Bruges' are juxtaposed, the thumb-nail sketches not so much suggesting essential identities but featuring as markers of difference within a particular field. The piece begins with a representation of the crude vernacular of the English lower classes, " "You got three-quarters of an hour," said the porter. "You got an hour mostly. Put it in the cloak-room, lady." ' (Stories p.92.). The porter's speech with its agrammaticisms, omissions and verbal irregularities creates atmosphere, and colour but it also establishes distance between the narrator and the subject matter. In the same manner as distance is marked between 'colonial' and narrator in 'The Woman at the Store' the distance between narrator and lower class railway porter and railway clerk is clearly signalled by the ironic envelopment of the colloquialism by the voice of the narrator

'Wot are you putting it in here for ?'

I said, 'Because I've a long time to wait.'

He shouted, 'Train's in 2.20 . No good bringing it here. Hi, you there, lump it off !

My porter lumped it (Stories p.93).

It seems to me that class distinctions are clearly at issue here, but Alpers who labels these pieces as 'not fiction' at the same time denies the class specificity in them:

Insubstantial as ['The Journey to Bruges' and 'Being A Truthful Adventure'] are, they show the beginning of a new concern, to achieve that intricate delineation of the spaces between people which Katherine Mansfield later captured as the Impressionists had captured light.

In English fiction generally, the nuances of class had always performed this function, as they do in Jane Austen. For a Colonial writer, unattached to class, the viewpoint had to be somewhere else and somewhere insecure: it had to float; and it is evident that Katherine assumed it most readily in a context of travel and movement, among other deracinées (Life p.127). 
To say that Mansfield is a writer 'unattached to class', although pointing towards the ambiguous position of the colonial in British society, is to deny the firmly white and bourgeois nature of Mansfield's origins and to imply that it is possible for a writer to speak from somewhere outside 'culture': the 'myth' of deracination is myth precisely because it is predicated on an oppositionary relation to the normative culture from which an individual defines themself as deracinated. Alpers again implies the figure of rupture, suggesting that the class distinctions which mark English society were effaced in the transition to the colonies, rather than that the categories and their boundaries may have been subtly altered. Further to that he then privileges class as a determinant of identity, suggesting that without an attachment to class, the narrative viewpoint is freed to take up that floating position which he then characterises as deracination. This effectively rules out gender and coloniality as determinants of identity. In this passage Alpers 'cures' Mansfield of the marks of class by virtue of her coloniality, and then by substituting a general uprootedness for colonial specificity produces her as a universal literary Impressionist.

I would suggest that rather than a narrative position which 'floats' in these pieces, distance and difference are continually being invoked, and that the position of the narrator is established in relation to what it is being differentiated or distanced from. It becomes clear from the assumptions of social and cultural distance, that the piece takes up a specific class location. There is a shift from the humorous caricaturing of 'low life ' characters to a satiric rendering of the manners and mannerisms of the Edwardian upper classes. The dialogue spoken in the train by the two young Englishmen is marked by fashionable 'slang' ('Ripping', 'frightfully') and is mannered, affected and 
intellectually 'content-free'. Reading like a section from a P. G. Wodehouse novel, it serves to satirise a set of class and social values just as firmly as does the orthographical irregularity of the speech of the railway staff. Registered with similar economy are the 'homœpathic' young clergyman's class, religious fervour and potential for annoyance to the narrator.

The young clergyman, who had listened and remarked, smiled at me radiantly. 'The train is in,' he said, 'really in. You've only a few moments, you know.' My sensitiveness glimpsed a symbol in his eye. I ran to the book-stall (Stories, p.93).

The use of 'really' simultaneously denotes gentility and a euphoric engagement with religious symbolism inappropriate to the context, as does the radiant response to the mundane announcement of the arrival of a train. Again, the thumb-nail sketch depicts a type, but it simultaneously provides as much information about the narrator as it does about the subject. It is in the recorded observation of the narrator that religious sentiment is registered as excessive, an observation which is far from neutral in its dispersal of value judgements. Whilst the viewpoint of the narrator is clearly not neutral and free-floating, there is an implied complicity in a set of values between narrator and reader. In this instance, because the evangelical fervour of the clergyman has been made blatantly clear (and has been ridiculed), the narrator's self-ironisation in reference to her 'sensitiveness' about the matter unites the reader's view with that of the narrator rather than distancing the two.

Through these markings of difference the narrator is identified as upper middle class (neither common nor affected), cynical and worldly-wise, free from religious sentiment, perceptive and sensitive, but not exorbitantly sensitive, and literate (as she dashes to the 
bookshop for 'salvation' from the clergyman).

So, the narrator's position with regard to English culture is established by virtue of difference from other English types, the déclassé and the pretentious and vapid. A position of Englishness is also marked by the production of national stereotypes, both blatant and covert. There is a blatant caricaturing of national types in the scene on the boat:

All the beauty and artificial flower of France had removed their hats and bound their heads in veils . A number of young German men, displaying their national bulk in light-coloured suits cut in the pattern of pyjamas, promenaded (Stories, p.95).

Obviously there is a totalising depiction of nationalities here, but also the depiction of the comically common and 'airy' porter of the English railway station is very different from the depiction of the French porter, who is a 'villainous-looking creature' (p.96). The figures which people Europe in these stories are ridiculed: in 'Being A Truthful Adventure' there is a 'burly young Belgian' boatman who '[throws] out his chest and chant[s] the beauties of Bruges with the exultant abandon of a Latin lover' (p.99), and a servant described as a 'wall-eyed family treasure' (p.98). The servant in 'Pension Seguin' is represented as similarly grotesque:

Her round red face shone like freshly washed china. She had a pair of immense bare arms to match, and a quantity of mottled hair arranged in a sort of bow (Stories pp.137-8).

And the pension contains a baby which spends all day 'banging his little head against the floors and walls' (p.141). 'Violet' depicts an old man who coughs and shoots 'a jet of spittle' from the window into the street (p.143), and in 'Bains Turcs' the cashier is described as 'an overripe fungus bursting from a thick, black stem' (p.146). There is a 
constant return in these stories to a depiction of the Europeans as either gross, grotesque or false. There is a repeated association throughout the stories of foreign women with artificial flowers. In "The Journey to Bruges', the 'artificial flower of France' characterises the French women (p.95), Mademoiselle Amabatielos in 'Pension Seguin' has her 'high firm bust decorated with a spray of artificial roses' (p.141), and the saprophytic cashier of the Bains Turcs stands amongst 'artificial palms' (p.146). The implied authenticity of the narrator stands in contrast to these explicit associations with artificiality. The narration similarly presents the narrator as cynical about romance and male sensitivity by displaying romantic tenderness in the context of a man watching his beloved being sick over the side of a boat:

He looked at her with infinite tenderness. I decided never again to call men unsympathetic, and to believe in the allconquering power of love until I died - but never put it to the test. I went below to sleep (p.95).

The narrative ridicules both the figures and sentiments described through the hyperbolic reference to the omnipotence of love and the permanence of its duration followed by the bathetic effect of the narrator's actions.

As in the bull in the metropolis incident, the production of distantiating stereotypes is accompanied by moves of displacement, which help to install the narrator in a position of autochthonicity. In 'Being A Truthful Adventure' where the narrator meets Betty Sinclair, an old school fellow from New Zealand, Betty's claim to English autochthonicity which takes the form of an assertion of location ('We live in England now'), and a questioning of the narrator's presence there ('can you believe it? - It's Katherine, in Bruges of all places in the world!'), is carefully undercut (Stories p.101). The inauthentic 
language of guide books has already been undermined earlier in the narrative by passages in which the narrator quotes extensively from a guide book to Bruges which are closely followed by narrative events that demonstrate the non-correspondence between the rhetoric of the text and the experience of the narrator. The language which Betty speaks is a mixture of the inauthentic language of guide books and the fashionable slang of the type used by The Enthusiast in "The Journey to Bruges'.

Betty is 'frightfully keen on the Suffrage', thinks she remembers the narrator being 'frightfully keen' on the subject too, and wants the narrator to 'go about together' with her in order that they may 'thrash the whole subject out' (Stories pp.101-02). What is asserted is the narrator's wider experience, greater knowledge and cultural and aesthetic superiority. The narrator does not use fashionable slang, distances herself from fashionable causes, recognises the guidebook's participation in exotic image-making and rejects it in favour of an activity which displays true aesthetic sensitivity, that is 'watching the swifts wheel and dip in the bright air' (p.100). The dynamics in this story are similar to those in 'Violet' where another old acquaintance greets the narrator

as though I had been given up for lost times without number; as though I had been drowned in foreign seas, and burnt in American hotel fires, and buried in a hundred lonely graves. 'What on earth are you doing here?'(p.143).

The narrator's hyperbole describing the manner of Violet's greeting starts to undermine her character before she opens her mouth, so to speak, in the direct speech of the narrative. Violet's position of English authority is undermined. Her frank English gaze which is likened to 'sitting in the glare of a window at breakfast-time!' is turned aside by 
the narrator's questioning of Violet's presence in Bruges:

'What are you here for,' I said, smiling graciously to soften the glare. At that she turned and looked across the lawns, and fidgeted with her umbrella like a provincial actress about to make a confession (p.144).

Here Violet is displaced from the position of the metropolitan into the position of the 'provincial' and the inauthentic, the actress, and later in the narrative Violet makes the confession which demonstrates her to be naive and limited in comparison to the narrator's savant. At the end of the narrative, the narrator suggests that the disparity between expectation and fulfilment in Violet's narration means that the joke is at the narrator's own expense, but there is a double irony at work and the narrator's very suggestion turns the laughter back on Violet. Throughout the narrative there have been continual textual indications of the narrator's 'depths' in contrast not to Violet's heights, but Violet's surface beneath which there are no depths. In this way the narrator has already prepared the ground for the dénouement and the repeated image of the water half sly, half laughing is representative not of the folly of the narrator, but of the narrator's tone itself.

In both these stories the figures with the claim to English autochthonicity are displaced by the narrator. In particular it is being conversant with the objects of high culture which displays the narrator's superiority in 'Violet'. After Violet's cryptic relation to the narrator of her emotional heights and depths, (made even more ridiculous by her self-conscious allusions to her symbolism), the narrator's response to Violet is not immediate, but the reader is given the benefit of the narrator's comments and thought.

No young girl ever performs such gymnastic feats by herself. Yet in my experience I had always imagined that the depths 
followed the pinnacles. I ventured to suggest so.

'They do,' said Violet gloomily. 'You see them, if you look, before and after.'

'Like the people in Shelley's skylark,' said I.

Violet looked vague and I repented (Stories, p.145).

It is not just the narrator's sarcastic remark about gymnastic feats and the appeal to the value of her own experience which asserts her superiority to Violet. What marks the difference between them is the narrator's familiarity with Shelly's poem and Violet's complete ignorance of it. The narrator is thus shown to be conversant with 'high' culture in a way in which the supposedly English Violet is not. There is a presumption that 'we look before and after,/ And pine for what is not' will spring immediately to the mind of the reader, and it thus becomes an indicator of an English cultural commonality. The allusion to 'To A Skylark' here is different from the description of the larks in the hot, dusty, summer landscape in 'The Woman at the Store'. In that passage there is a repositioning of a literary trope to indicate difference and distance. Here we have not a repositioning of a trope, but an invocation of a proper name and a cultural sign as guarantors of cultural autochthonicity. The intellectual ownership of Shelley and his skylark marks the narrator as a possessor of an English cultural heritage.

Running through these stories along with the derogation of European types there is a claiming of European high culture. Stories are crammed with references which are more or less obtrusive. In 'The Journey to Bruges' whilst one of the Englishmen given to fashionable slang reads the unillustrious 'The Snark's Summer Annual', what the narrator notices is a poster for the Athenaeum: 'As we crept out of the station I saw a poster advertising the Athenaeum' (Stories p.94). That the 
poster is remarked upon suggests that it is culturally significant; that it is remarked on without further comment suggests that there is again a presumption of common cultural knowledge between narrator and reader. Rembrandt and Anatole France are mentioned as chance associations in the narrator's mind, and in 'Being a Truthful Adventure' Mendelssohn's Spring Song, the Place van Eyck and Verlaine are all mentioned. In 'Pension Seguin' the cultural artefacts include the 'First French Picture', Hamlet, the Appassionata Sonata and Gogol. In 'Violet' Russian novelists are invoked as well as the aforementioned Shelley. An importance is placed on the ability to read these cultural signs which suggest a particular location in relation to high culture. The obtrusiveness of the allusions in these stories is perhaps made clearer by comparison with the skilfully unobtrusive allusion to the standard texts of high culture elsewhere in Mansfield's texts.

In 'Pension Seguin' a reference to Hamlet is introduced appended to a piece of comical syntax, where the comedy is, of course, at the expense of a European. This is the reply to the narrator's requests $L_{L}$ a quiet room from Madame Seguin:

'I have a beautiful room to let, and quite unexpectedly. It has been occupied by a young gentleman from Buenos Ayres whose father died, unfortunately, and implored him to return home immediately. Quite natural indeed.' 'Oh, very!' said I, hoping that the Hamlet-like apparition was at rest again and would not invade my solitude to make certain of his son's obedience. 'If Madam will follow me.' Down a dark corridor, round a corner I felt my way. I wanted to ask Madame if this was where Buenos Ayres [sic] père appeared unto his son, but I did not dare to (Stories p.138-39).

Although this passage is amusing, the installation of the cultural sign is impossible not to note. It is not just that the Great Bard of English letters is juxtaposed with a foreigner's woefully ambiguous use 
of language, or that the narrator's erudition is displayed, but that an appreciation of the humour is dependant on a knowledge of the Shakespeare text. If the reader does know the Shakespeare text, then there is a reciprocal assurance of cultural autochthonicity between the reader and the Mansfield text. If the reader does not know the Shakespeare text, then the superior cultural autochthonicity of the Mansfield text is flaunted. (This is particularly the case where the signs of high culture are introduced by the use of the simile, as the reader is left with a blank instead of a term of comparison, as for instance with similaic allusion to the First French Picture at the opening of 'Pension Seguin'). By contrast the allusion to King Lear in 'The Stranger' does function as allusion rather than obtrusion. where John Hammond has just been told by his wife that another man has died in her arms on a voyage from which she has just returned, his thoughtsare registered in free indirect discourse:

And yet he died in Janey's arms. She - who'd never - never once in all these years - never on one single solitary occasion No; he mustn't think of it. Madness lay in thinking of it. No he wouldn't face it (Stories, p.373).

If the reader can make connections with the Shakespeare text, then their reading is enriched. However, if the reader does not know Lear's ' 0 , that way madness lies; let me shun that; / No more of that.' and its context of emotional desolation and profound psychological disturbance which is a result of the severing of the ties of familial duty and affection, it does not hamper an appreciation of the significance of the moment. ${ }^{63}$ The desolation and desperation of John Hammond are fully

63 Lear, III.iv. 21. 
registered in the Mansfield text and do not rely on the reader's intertextual knowledge to complete the reading.

The contrast between the subtlety of the allusion in 'The Stranger' and the obtrusion of extratextual reference in the European stories serves to highlight the process at work in these stories with European settings. The process is one of structuring of a position of European cultural autochthonicity through the displacement of other contenders to that position and a display of mastery of the signs of European high culture.

However, as the narrator's mistake with the mats in 'Pension Seguin' suggest, signs are available to a plurality of readings. In that piece, the narrator chooses to take a room at the eponymous pension because she sees in the salon of the pension an abundance of white crotchet mats and reads them as 'signs and tokens of virtue and sobriety':

'A woman with such sober passions,' thought $I$, 'is bound to be quiet and clean, with few babies and a much absent husband. Mats are not the sort of things that lend themselves in their making to cheerful singing. Mats are essentially the fruits of pious solitude (Stories, p.138).

The narrator then proceeds to expound upon appearances with an illustrative anecdote.

... the story of my one and only nurse, who, knowing my horror of gooseberry jam, spread a coating of apricot over the top of the jam jar. As long as I believed it apricot I was happy, and learning wisdom, I contrived to eat the apricot and leave the gooseberry behind(Stories p.139).

In 'Pension Seguin' it is revealed that the mats are made by the owner of another pension and the one which the narrator has selected 
is filled with children, music and talkative guests. It becomes apparent that a different reading of the signs from the one the narrator originally makes is possible. The display of cultural signs in the stories under discussion can be read as signifying cultural conversance, even of legitimate possession of a particular cultural language, but, as with the mats in the Pension Seguin, the display of cultural signs is open to another reading too. It can be seen as a flamboyant assertion of literary rights, as the strenuous attempt to establish a position of cultural autochthonicity, the very flamboyancy of which suggests that a claim is at stake, that there is in fact an anxiety about the legitimacy of the possession of these signs of European high culture, and anxiety about the autochthonicity which that possession should signal. Colonial identity is betrayed, not by finding a layer of true colonial gooseberry under the veneer of apricot cosmopolitanism, but by the degree of anxiety manifested to display the apricot cosmopolitanism. What is strenuously attempted in the representation of cultural location in these texts is the display of cultural autochthonicity which locates the narrative as culturally autochthonous. However, the very excessive strenuousness of the attempt results in an overly flamboyant proclamation of cultural and literary rights which paradoxically reveals an insecurity about cultural siting which it is intended to conceal. 


\section{CHAPTER THREE \\ Epilogue I: 01d Lace, Turkish Baths and Barbarous Pineapples. \\ Conflicted Subject Positions in Mansfield's Stories.}

\section{Introduction}

This section briefly explores some of the intersections between gender identity and colonial identity in Mansfield's texts. I suggest that there is no single coherent and consistent formulation of the relationship between gender identity and colonial identity in these texts. I argue that in 'The Journey to Bruges' and 'Epilogue III: Bains Turcs,' gender identity is destabilised whilst European high culture remains a fixed point of reference for cultural identity. In contrast, in 'A Pic-nic,' gender identity remains a fixed and secure point of reference, whilst the desirability of metropolitan identity over colonial identity is put into question.

Falling For Old Ladies on Trains Can Be Good For Your Cultural Autochthonicity.

In 'The Journey to Bruges,' the narrator expresses cynicism about conventional romance and conventional gender roles. Romance and desire is present in this text in another location. European figures who are exempt from the force of ridicule or depiction as stereotypes are 
ones whose gender identities are destabilised. In contrast to the desire to conform to the standards and measuring sticks of a dominant European high culture, there is a desire to undo and re-evaluite conventional gender roles. The mocking of the tenderness of the young man's sympathy for his seasick beloved is concluded in the hyperbolic phrase, 'I decided ... to believe in the all conquering power of love until I died' (Stories p.95), but this is followed in the narrative by another dream of love until death.

The unnamed old lady who is also travelling on the boat is one of the few figures who is exempted from the force of caricature.

She lay on a rose and white couch, a black shawl tucked round her, fanning herself with a black feather fan. Her grey hair was half covered with a lace cap and her face gleamed from the black drapings and rose pillows with charming old world dignity. There was about her a faint rustling and the scents of camphor and lavender. As I watched her, thinking of Rembrandt and, for some reason, Anatole France... (Stories, pp.94-5).

The old lady is represented as a source of visual, auditory and olfactory delight to the narrator, and her charm is specifically linked to her 'old world dignity.' Whilst the other European characters are marked off from the signs of high culture, the figure which arouses the narrator's desire is seen as an embodiment of those signs of European high culture. It is this old lady of whom the narrator dreams. After a conversation in which the old lady's voice is described as 'so fine it seemed to quaver on a thread of lace, 'the narrator has a dream vision:

I could not think why, but I had visions of myself perhaps travelling in the same railway carriage with her, wrapping her in the black shawl, of her falling in love with me and leaving 
me unlimited quantities of money and old lace.... (Stories p.96).64

Sexual and colonial identity intersect in the narrator's dream. In the earlier passage it is the narrator's desire for the old lady which is registered, but in her dream, the narrator imagines the old lady falling in love with her and sees herself taking up a role towards the old lady which hovers between the masculine and the filial. The result of this relationship would be the narrator's inheritance of the old lady's money and lace. Lace has already been specifically associated with high cultural autochthonicity. In this narrative it is the fantasied destabilisation of gender positions and the installation of desire in an economy other than the conventional heterosexual one which allows the narrator to inherit a position of cultural autochthonicity.

\section{Looking in the Turkish bath}

The brittle satirising of heterosexual courtship in these stories has been discussed. In contrast to this, the erotic relationships between women are represented by indirection and with the force of the concrete images of symbolist practice. In 'Bains Turcs' there is a suggestion of possibilities for desire other than the constricted roles apportioned by convention. (Again this is not to suggest that there are 'true' desires under the 'false' role playing, but that all subject positions are conflicted and constricted in one way or another.)

The female environment of the Turkish bath is fraught with representations of desire and disgust. Masculinity is represented

64 Ellipsis in Mansfield text. 
either as deformed and disgusting or distantiated and emasculated. The male attendant is a midget who sneezes and sniffs all over his cotton gloves, and the male explorer, whom the narrator imagines, is only fascinating when hedged round by conditions which circumscribe his imagined profession and the attributes of his maleness.

Yes, it might have been very fascinating to have married an explorer ... and lived in a jungle, as long as he didn't shoot anything or take anything captive. I detest performing beasts (Stories, p.147).

In the 'Warm Room' in 'Bains Turcs,' there are positive images of female communality, suggesting the freedom of a pre-oedipal state of interchange, before the intervention of the law of the father, but there is also a suggestion of mounting excitement.

Through the matchboard walls and from the corridor sounded cries and laughter and snatches of conversation. 'Are you ready?' 'Are you coming out now?' 'Wait till you see me!' 'Berthe - Berthe!' 'One moment! One moment! Immediately.' I undressed quickly and carelessly, feeling like one of a troupe of little schoolgirls let loose in a swimming bath (Stories. p.147).

But there is no simple revalorisation of binary oppositions here, of naming female as good and male as bad. Women are also described as 'hideous, lying back, red and moist, with dull eyes and lank hair,' and the narrator concurs with the opinion of the two blonde women that the other women look 'like beefsteaks in chemises' (p.148). It is not so much that the two blonde women are valorised by the positive terms in which they are described and the negative descriptions of the other women, but that the narrator and the two blonde women share not only a common language and a similar aesthetic of the female body, but they also share the same scopic economy. 
The power of the scopic economy is suggested by the way in which, although the narrator shares a linguistic economy with the Mackintosh Cap, this is shown to be an unwanted source of commonality and contiguity. The German woman here is specifically associated with low culture and with a prohibition on female desire which exhibits itself as a refusal to see. National identity is fixed and this allows the question of gender identity to be opened up.

The gendered scopic economy, which exists outside, momentarily ceases to function within the female environment of the bath house. The blonde women, who clearly make economic capital out of being the object of male desire, become the approved and desired object of the narrator's gaze. And the narrator's scopically registered and valorised desire is contrasted with the Mackintosh Cap's failure to take up a position of one who sees in that scopic economy:

'I cannot see,' she said, 'what men see in such women. No, a husband and children and a home to look after, that's what a woman needs' (Stories, p.149).

In doing so, she is refusing to take up a position other than that conventionally ascribed to women and in that refusal, she is rhetorically reiterating the conditions of women's oppression. She validates a version of femininity which confines women to a domestic and procreative role. She validates a model in which the possibility of female desire is replaced by the needs of a husband and children. In doing this, she defines herself as a 'proper' woman, in opposition to the impropriety of the blondes. Her constitution as 'proper' is founded on a specifically female scopic occlusion and the reattribution of the gaze of desire to the masculine. 
Where looking is synonymous with desiring, the German woman's marking of difference is fraught with the marks of disavowal.

'Are you going to take off your chemise in the vapour room?' asked she. 'Don't mind me, you know. Woman is woman, and besides, if you'd rather, I won't look at you. I know - I used to be like that. I wouldn't mind betting,' she went on savagely, 'those filthy women had a good look at each other' (Stories, p.149).

The disavowal occurs in the projection of the German woman's desire to look at the female body on to the blonde women. The vehemence with she articulates disgust ('filthy' is spoken 'savagely'), the gratuitousness of the accusation and the strenuous assertion that she will not look at the other woman all symptomise the disavowal of her own desire.

This implication is reproduced in the story's final concrete image, where the German woman 'stare[s] after [the two fresh beauties], her face all mouth and eyes, like the face of a hungry child before a forbidden table' (Stories p.150). Here both the desire of the German woman, and the prohibition under which it operates, is represented. The gaze of desire, its representation as consumption, 'all mouth and eyes', and the lack of fulfilment are registered along with the prohibition on fulfilment.

However, the representation of the German woman is not the only one in which disavowal and the traces of desire are registered. Signs of disgust are articulated by the German woman, but she is also the receptacle for the narrator's disgust at female flesh. The 'Mackintosh Cap' is 'a short stout little woman with flat, white feet,' she 'rub[s] her yellowish arms', she has a 'hideous German voice' and the narrator is 
filled with 'rage and disgust,' when the German woman 'sidle[s]' up to her and 'smile[s] meaningly.' But just as the German woman evinces disgust but cannot get the 'two fresh beauties' out of her mind, so too, the narrator who evinces disgust cannot get 'out of [her] mind the ugly, wretched figure of the little German with a good husband and four children' whilst she is being 'soaped and smacked and sprayed and thrown in a cold water tank' by a 'half naked' Berthe. The exchanges between the narrator and the other women are eroticised, but this is disavowed by the narrator's representation of her function as an observer rather than as a participator. As with the bull in the metropolis narrative, what is unacceptable is displaced, but returns to fracture the coherence of the narrator's account.

\section{Barbarous pineapples or poor little pole cats ?}

There is a very different intersection of gender identity and colonial identity displayed in 'A Pic-nic'.65

'A Pic-nic' is set in Wellington and Day's Bay, but since it is an experiment in dialogue, there are no passages of descriptive narrative where one would expect 'advertisement of landscape', so sense of place has to be read off from the representation of character. The colonial dynamics in the piece initially seem similar to those outlined in The Woman at the Store, where the colonised subject is stereotyped by virtue of difference from the metropolitan subject, and the coloniality

65 Stories pp.215-222. Apart from the addition of one comma and the omission of spacing between the scenes, the text is the same as that in the New Age 21.6 (1917): pp.136-38. 
of the piece is revealed in the strenuousness of the attempts to mark difference. But in 'A Pic-nic,' the desirability of the metropolitan position is undermined as the piece progresses. At the end of the piece, uncertainty about the relative value of colonial identity and metropolitan identity is side-stepped by a vigorous reinstatement of male and female gender positions.

The piece starts with a dialogue between Andrew Gold, a metropolitan artist, and Miranda Richmond, a middle-class, colonial wife. Because of an initial mutual attraction, Miranda invites Gold on a picnic to Day's Bay. In the scene of embarkation for the picnic, colonials are marked out as vulgar and commercial.

Mrs Hill: Who are we waiting for? Aren't we all here? Oh, your husband's not come yet, has he?

Miranda: No, he had to go to the office first. But he promised to be here in good time.

Mrs Hill: Oh, he does have to work hard - doesn't he! What a shame it is! My dear, why on earth has Mrs Barker brought her mother? She's such an old bore; she always wants to do what everybody else does. She actually bathed last year, my dear, in an immense chemise. And do you see what she's carrying over her arm? An air-cushion. Isn't she too disgusting!

Miranda: Dreadful....

Richmond: By Jove, that was a narrow shave. I couldn't manage to get away a moment before. Morning everybody! Grand day! (Shouts to Captain.) Let her go, Captain! (He feels triumphant; he feels like a King's messenger arriving.) Had to answer an important letter by this morning's mail. Just managed to get it off in time.

Old Mrs Barker: (with great relish): He'll catch his death of cold out on the water in that state of perspir-ation.... 
Hill ( to Richmond ): Just a world, ole man. (leads him away mysteriously): Have a nip of whiskey. I've got a drop of the very best. How's that - eh? (Stories, pp.217-8)

Vulgarity is registered by a concern with commerce, by the detailing of bodily functions (the perspiration and the air cushion), whiskey drinking on the sly and by orthographical debasement. Both the financial and the bodily concerns of the other characters mark them out as vulgar. In this way, lower class identity is conflated with colonial identity.

Colonial dislocation is registered in the text by the strange simile of the King's messenger. It suggests that Richmond is a representative of English rule in a distant land, not the original figure of power and authority, but a stand-in, a proxy thereof. That he has just sent off an important letter, emphasises the fact that however 'important' the colonial male or the colonial mail, he can only be a weak and distant representative of the original seat of power and knowledge which is located in the metropolis of the imperial nation. The oppositions between provincial and cosmopolitan, between vulgar and aesthetically sophisticated are reiterated:

Miranda: Oh, what am I doing among these vulgar people ? I never realised until to-day how far, far away I was from them. Why can't we simply disappear? I, too, feel that we've something to say to each other. He makes me feel so myself in the truest sense....

Mrs Hill: Will you butter, Mrs Richmond, while I mustard, or will you mustard, while I butter?

Miranda: Certainly, Mrs Hill. (p.219-220)

Here the word 'vulgar' is used specifically in conjunction with an assertion of cultural difference and an assertion of essential identity, 
which is linked to a desire for physical distance. (The articulation of that desire is ambiguous, however, as disappearing can also mean ceasing to exist.) In the eponymous pic-nic, the difference between the life of art and of the metropolis, and the life of commerce and of the colonial is again reiterated.

Richmond: Pass your glass along. Gold. I suppose you're accustomed to this kind of thing. Pic-nic every day of the year, if you want one - what. By Jove, you can't think what it means to a chap like me, who spends his life sweating in an office eh? Hill? (Stories, p.220).

Sweating and mercenary pursuit are what characterise the colonial male, and an avid interest in bodily functions and the production of food characterise the colonial female, and both are labelled vulgar. The metropolitan, on the other hand is characterised by an espousal of barbarity. It seems paradoxical that the provincials are seen as 'vulgar' by those characters who claim to appreciate barbarity, but in the text, conflating the two poles of the barbaric and the metropolitan creates a firm ground from which to repudiate the middle ground of the provincial or the colonial. Both barbarity and metropolitan sophistication are given the same aesthetic value. Miranda's interest in the pineapple is registered as primarily aesthetic.

MIRANDA: Yes, I love pineapples - don't you? Not only the taste, but the colour and shape of them - their solidity. They are so really barbaric - don't you think? (A pause.) The first painting I ever saw of yours was a dish of nectarines and black grapes. (miles.) I never forgot it (Stories p.216).

Here an appreciation of barbarity is linked to an appreciation of metropolitan art, and in the next extract, the difference between the 
culturally sophisticated Miranda and the vulgarity of the hoi poloi is registered explicitly by a transposition into a context of barbarism:

Gold: (fervently ): Until to-morrow. (Stands bareheaded until she disappears.) My God! She's a gorgeous woman. She's wonderful. And to think she's wasted on that ass of a Richmond. She's such an amazing type to find in a place like this. Awfully primitive. Extraordinarily barbaric. (He sees himself in a strange country. dressed as a hunter, striding back to the camp fire at evening. A woman crouches over the fireglow.)

Woman: Andrew!

Hunter: Miranda! (Stories pp.216-7).

Here an affinity with 'high culture' and modern art is registered paradoxically as 'awfully primitive.' Again connection of these two extremes would appear to be governed by a desire to establish distance from the central ground of the colonial.

When the difference between the metropolitan and the colonial is registered by the soi-disant cosmopolitan artist, however, something different is revealed.

Gold: How lovely she looks under that yellow umbrella. The Yellow Umbrella - portrait by Andrew Gold. One thousand guineas. And sold the day the exhibition opened.... What on earth have I been doing ever since I came to this rotten little town? I never seemed to see her until last night when she made that remark about the pineapple. She's utterly unlike all the women here. I must get her to myself for a bit. I must talk to her. Why can't we give these people the slip when we get off the boat.... Would she? (Stories, p.218).

'[R]otten little town, 'utterly unlike,' and 'these people,' all mark out the distance between the cosmopolitan artist and the colonial commoner, but at the same time Gold's own barbarity and vulgarity is revealed. His aesthetic and artistic vision of Miranda, '[h]ow lovely she looks under that yellow umbrella. The Yellow Umbrella - portrait by 
Andrew Gold, is translated into a vulgar vision of its commercial worth and his material success, 'lolne thousand guineas. And sold the day the exhibition opened.' Similarly, remembering Miranda's remark about the 'barbaric pineapples' - which is linked in the narrative with his vision of himself as a hunter - produces the barbarous, uncivilised desire for possession. The violence of the emotion is marked by the imperative of the modal verb, 'I must get her to myself for a bit.' The metropolitan is represented as culturally sophisticated but is also revealed as predatory and exploitative.

In this story, unlike the earlier ones dealing with colonial matter, although the colonial figures are ridiculed, so too are the cosmopolitan pretensions of the artist. Miranda's acceptance of her husband's protection - despite the ludicrousness of his tender appellation 'my poor little pole cat' ( $\mathrm{p} .221)$ - is presented in the narrative as a return to her senses as much as a cowardly retreat into bourgeois colonial security. In the phrase 'the past a dream,' the pretensions to metropolitan identity here are banished in much the same way that the threat to metropolitan identity is banished in "The Woman at the Store,' that is by the act of 'simply disappearing.' The support of the earlier despised colonial community is welcomed ('Miranda: Where is our Dickie? Richmond: Old mother Barker's got him. He's all right.') Most interestingly, the rejection of the metropolitan is also bound up with a reinscription of gender roles.

In this story the ambivalence about colonial identity is side-stepped by a vigorous reinstatement of binary oppositional gender stereotypes, of male protectiveness and dominance and female delicacy and vulnerability. Richmond becomes a 'big bear' whilst Miranda takes up the position of a 'poor little polecat' or a 'little woman.' At the same 
time, Gold is sidelined as implicitly effeminate, 'we're all married men, except Gold, and he's an artist, and don't count' (Stories p.219). In this text, gender as an organising feature of difference is privileged over colonial difference. The ambivalence surrounding Miranda's desire to be more herself by becoming metropolitan, and the ambivalence of the status of Richmond as a colonial figure is supervened by the security of the gendered positions of male and female.

The intersection of gender identity and colonial identity is polyvalent in Mansfield's texts, There is no one stable and coherent position maintained in terms of the representation of colonial identity, nor is there one stable and coherent position maintained in terms of the representation of gender identity, and neither is there a coherent relationship between these two parameters of identity. In each text, however, where one aspect of identity is explored and put into question, this is enabled by the implicit fixing of the other co-ordinates of identity. 


\title{
CHAPTER FOUR \\ Concerning Godwits
}

\begin{abstract}
All nationalisms have a metaphysical dimension, for they are all driven by an ambition to realize their intrinsic essence in some specific and tangible form (Seamus Deane, Nationalism, Colonialism and Literature).
\end{abstract}

\section{Introduction.}

The prose fiction texts of Robin Hyde represent place in ways that exhibit characteristics of both Gray's phase two writing and his phase three writing. As with the Mansfield texts discussed, it is not possible to consign Hyde's writing unproblematically to just one phase. Much of Hyde's writing is overtly concerned with the transitional nature of the social, cultural and political conditions of its time, and the representations of place in her texts signal a sense of colonial identity which is both problematic and transitional.

According to Gray's schema, phase two writing is characterised by 'seeling] the overseas landscape from the point of view of . . belonging to it' and by the flamboyant assertion of literary rights through the 'advertisement of colourful landscape' (Gray, pp.8-9). In Hyde's texts there seems to be a claiming of a stake, or a flamboyant assertion of literary rights which would locate them as belonging to the second 
phase. It is precisely the assertion of literary rights with which The Godwits Fly is concerned. One of the journeys which the text charts is a turning away from representations of things English to a deliberate representation of things New Zealand. The foreword to the text which is called 'Concerning Godwits' makes this transition explicit both in its content and in its rhetorical strategies. What is also clearly present in Hyde's texts, and what is not acknowledged in Gray's schema, is the problematic nature of the transition in national identity. Whereas Gray's schema suggests a simple switch in identification and hence identity, what Hyde's texts reveal is the way in which identification and identity are stricken by indeterminacy in the period of transition. In these texts, the problematic nature of colonial identity is foregrounded. Because anxiety about colonial identity is made explicit in some of Hyde's texts, those 'other marks of coloniality' which were discussed in relation to Mansfield's texts are much more accessible in the Hyde texts which are discussed below, as it is precisely the otherness of the colonising people itself which is the subject of these texts. In The Godwits Fly the other marks of coloniality can be found by reading with the text rather than by reading against the text, which was necessary with the Mansfield texts discussed.

One of the problems which is foregrounded is that in a colonising society which gains its identity as a colonising society from the way in which it accords cultural supremacy to the originating culture66, any moves to assert a national identity involve a rejection or denial of the

66 I am thinking here of the definition of 'colony' articulated by W. H. New. He suggests that a colony 'is not only dependent on another society's metropolitan centre but is presumed by definition to be incapable of developing metropolitan centres of its own' (Dreams p.17). 
founding culture, with the result that the emergent sense of national identity is founded on loss.

Gray suggests that the establishment of phase two writing is helped by the development of a sense of political nationalism. The development of a sense of political nationalism is charted in Hyde's texts both in their explicit concern with the question of national identity (for example in the chapter 'Bird of my Native Land' in The Godwits Fly and in 'That Night' in Nor the Years Condemn), and in the manner in which they represent New Zealand landscape and culture. In specific instances of representation of place, Hyde's texts themselves insist that a particular sense of place signals a particular sense of identity, so in some ways the founding premise of Gray's schema (that the nature of colonial identity can be read from the way in which place is represented) is made explicit. The overt sense of political nationalism in Hyde's texts indicates that they can be located as phase two writing in Gray's schema. However that phase two position is problematised in Hyde's texts where the national identification is seen as no less problematic than the colonial identification out of which it is constructed.

There is still in these texts a sense of a split in the address, but whereas the split in Mansfield's and Lady Barker's texts is in the location or identification of the addressor, in Hyde's texts the split is most visible in the identification of the addressee. The elucidatory nature of some passages suggests that a northern hemisphere audience is being addressed, but other passages are culturally specific without any of the accompanying explanations which would enable a reader not conversant with the culture to read a passage in the same manner as a reader who is conversant with the culture. The suggestions in the 
text of an address to an English audience indicates the enduring presence of a sense of English cultural domination and authority but also suggests a sense of a location somewhere different from that culture. The totalizing statements about New Zealand presented for the information of an overseas readership also paradoxically indicate a 'strong sense of the viability and coherence of the life overseas' (Gray, p.8).

However, as well as the presence of the features of phase two writing in Hyde's texts, there are also representations of place which conform to one of the criteria of Gray's phase three. Gray suggests that in phase three literature advertisement of colourful landscapes is ludicrous and that sense of place is characterised by its 'familiarity'. In Nor the Years Condemn and The Godwits Fly New Zealand is constructed as the known and familiar to Australia's unknown and unfamiliar. 


\section{Characteristics of Phase Two Writing in Hyde's Texts.}

It is perhaps easiest to see the way in which Hyde's texts exhibit the characteristics of phase two literature by examining their difference from phase one texts. One of the main distinctions which Gray makes between phase one and phase two writing is the way in which sense of place is characterised by the registering of 'exoticism' in phase one writing and by the registering of 'uniqueness' in phase two writing. In passport to Hell, there are representations of place which attempt to register the uniqueness of the sense of the new place without producing it as exotic:

The delightful moment arrived when [Starkie's] father daily commanded him to let the horses out of the stable for their morning drink at the dam. The mornings, hazy over wide yellow fields, broken only by silhouetted pines and a blue circle of the inevitable New Zealand hills far away, smelt sharply of frosty soil; little puddles in the stable-yard frozen over with ice that tasted cold and slippery like glass; horsedung trodden into the mire and yet gentled with the smell of warm straw. He let the big working horses out first, their breath wreathing blue as tobacco-smoke around their snorting velvet nostrils (Passport, pp.12-13).

In this description there is an insistence on the uniqueness of the sense of place which is registered by a specificity of detail. However the insistence on specificity does not mean that detail is presented in the reportorial manner of the documentary sketch or by the relentless cataloguing of botanical types. What is emphasised is the specific experience of place. The description makes its appeal to the visual sense with economy and without extravagance (the 'haze', the 'wide yellow fields' and the blue hills). The visual sense is not the only one to which there is an appeal in the passage of description. In the narration the tactile, offactory, aural and gustatory senses are all also 
invoked; the smell of the frosty soil, the taste of ice, the sound of the horses and the texture of their noses are all registered. So whilst it is not a long or laboriously detailed description, it manages to produce, with immediacy, a sense of a specific place. The description also moves from the particular to the general and back with ease, locating the specific evocation of place in a general New Zealand context. It is this collocation of the general and the specific, the display of the landscape in a context which is clearly signalled as a New Zealand context, which makes the above description clearly a part of a phase two literature which is asserting an identification with the land it is representing. The distinction between the simultaneously taxonomic and exoticising descriptions of phase one writing and this detailed and assertive display of identification is shown in a comparison of a passage from Jane Mander's The Story of a New Zealand River with a passage from Hyde's Wednesday's Children. In the opening chapter of The Story of a

New Zealand River there is a lavish description of the Northland bush:

From the mangrove banks to the sky a great variety of trees in fifty shades of evergreen covered every yard of space. There was a riotous spring colour in the forest, voluptuous gold and red in the clumps of yellow kowhai and the crimson rata, and there were masses of greeny white clematis and bowers of pale tree ferns to rest the satiated eye. Stiff laurel-like puriris stood beside the drooping fringe of the lacy rimu; hard blackish kahikateas brooded over the oak-like ti-koti [sic] with its lovely scarlet berry. ${ }^{67}$

67 Jane Mander, The Story of a New Zealand River (Christchurch: Whitcombe and Tombs, 1974), p.9. The passage quoted above is one which Katherine Mansfield picks out for particular comment in her review of Mander's text. Mansfield's comment is discussed below. Documentary elements in the representation of the landscape continue throughout Mander's novel (for example the the history of the gumfields in chapter XXVI and the description of weather in the 'southern latitudes' at the opening of chapter XXXIV). 
Although there may initially appear to be some similarities between the Mander passage and the Hyde passage quoted above (as well as the Hyde passage below), the differences between the descriptive prose of the two writers are precisely those differences marked out between Gray's phase one and phase two writing. The Mander passage imputes an exotic quality to the bush; it is 'riotous', 'voluptuous' and brooding. Furthermore, the terms of the description appeal exclusively to the sense of sight, producing the bush as something to be looked at rather than lived in and the gaze which looks at the bush in this way is located as an English gaze by the way it can only represent the New Zealand bush by its similes of similarity or difference from English points of reference ('laurel-like puriris', 'oak-like ti-koti' ).

In contrast, the Hyde passages in their multiple appeal to the senses construct a representation which implies a lived relationship to the environment. Although the Hyde extract below, taken from Wednesday's Children, also lists different types of flora, its comparisons are between the different types of native flora and not between New Zealand flora and English flora.

... the island ... had three kinds of grasses ... a tawny twitch grass over which bare feet could run in comfort, pussy-grass which was pale yellow and slender, furnished with a long catkin useful for tickling the neck of the person in front, and cutty grass [which] . . . was the nearest thing to an enemy that the island knew. ... Fringed against the sandy hillocks ... grew daisies with fleshy leaves and blind pink flowers, and very delicate fragile sea-convolvuli (WC 75).

There is clearly an attempt to display a very specific sense of place in the detailing of the flora, but again, although the account is detailed, it does not have the quality of a botanic catalogue. What is 
emphasised is sense of place gained through a sensual interaction with the place; running over twitch grass and tickling with pussy grass. Not only this but the listing of 'foreign' names in the Mander passage gives way to the local names given to the local habitation in the Hyde extract. If as Seamus Deane suggests 'naming or renaming ... is, like all acts of primordial nomination, an act of possession' then the acts of naming registered in the Hyde passage suggest the very definite claiming of a stake in the landscape.68

The differences between the two passages which are highlighted by reading the $m$ in the light of Gray's schema are also displayed in critical commentary on the two passages. The attempt to register the uniqueness rather than the exoticism of the sense of the new place in Wednesday's Children is recognised in Joan Stevens' 1961 commentary on the text in The New Zealand Novel:

You may not agree with the verdict that the book is her best, but you will agree that seldom has so vivid a picture been painted in our fiction of Auckland and its surroundings, of the harbour, the gulls, the sand dunes and convolvulus, the Bay hovels, the slum dwellers. 69

Here the attempt to register a distinct sense of place is recognised and welcomed (and in fact taken by Stevens as the main achievement of the text), whereas Katherine Mansfield's well known comment on the Mander passage, that in spite of the fact that there is frequent allusion to the magnificent scenery, it profiteth us nothing,' specifically highlights its participation in the production of exotic images. 70

68 Deane, p.18.

69 Joan Stevens, The New Zealand Novel 1860-1960 (Wellington: Reed, 1961), p.58. Further references to $\mathrm{NZ} \mathrm{Novel} \mathrm{in} \mathrm{the} \mathrm{text.}$

70 'First Novels', Athenaeum, 9 July 1920. 
By virtue of this comparison between the Hyde and the Mander texts, Hyde's writings can be seen to represent place in a way which conforms to the parameters of Gray's phase two writing. However the shift in the nature of identification and identity from phase one to phase two, from an identification with the 'mother land' to the colonised country, which seems unproblematic in Gray's schema is demonstrated as problematic in Hyde's writing. In 'Concerning Godwits', the 'Author's Foreword' to The Godwits Fly the text locates itself precisely in the transition between phase one and phase two. The passage discusses the question of colonial identity in terms of cultural location and sense of place. The rhetorical strategies of the foreword as much as the content suggest the problems and the processes involved in producing a sense of New Zealand national identity. The passage uses the metaphor of the godwits to suggest the cultural dominance of England:

most of us here are human godwits . . . our youth, our best, our intelligent, brave and beautiful, must make the long migration, under a compulsion they hardly understand; or else be dissatisfied all their lives long (Godwits p.IX).

The imperial myth of England as the true home of the colonising is shown to have the power and compulsion to shape the course of lives. However the status of this imperial myth is put into question in this passage: rather than a myth being a universally held cultural truth, myth is clearly revealed in the passage as a chimerical fantasy which is deceptive and disabling. Just as the child comes to learn later that the godwits do not fly to England, so the necessity for the cultural godwit to go to England is revealed by the text as a production of colonial dynamics, an internalised rather than an atavistic desire. 
The quotation from Seamus Deane in the epigraph suggests that nationalisms are 'driven by an ambition to realize their intrinsic essence in some specific and tangible form' (Nationalism, p.8). Deane goes on to argue that this 'essence' is itself a cultural construction. The historical occurrence of the journey of the colonising to 'Home' can be seen as the specific and tangible form in which the 'intrinsic essence' of colonial identity is recognised, and the form in which it marks its relationship to the imperialist nation from which it derives. Alan Mulgan's Home: A New Zealander's Adventure, with its initial assertion that 'it was as natural to talk of England and Ireland as "Home" as it was to call New Zealand a colony',71 can be seen to be a testament to the cultural functioning of the godwit myth. Mulgan's insistence on the naturalness of regarding England as a cultural home and of regarding New Zealand as peripheral and provincial can be seen as both a product and a repetition of a particular construction of colonial identity. It is this construction of colonial identity as natural, as an essential quality, which The Godwits Fly investigates and undermines.

71 Alan Mulgan, Home: A New Zealander's Adventure (London: Longmans, Green \& $\left.C_{0}, 1927\right)$, p. 3 . 


\section{Colonising cultural autochthonicity: the relationship}

between the godwit myth, colonial identity and the structure of the novel.

In The Godwits Fly it is the attempt to establish a position of New Zealand cultural autochthonicity which allows the imperial myth of the naturalness of the relations of cultural dominance and subservience to be revealed as myth. The transitional nature of the siting of the text is suggested by the way in which two alternative positions are set out paratactically in the text:

England is very beautiful, she [Eliza] thought, staring at a tree whose hair ... not properly flowers ... was the colour of fire. And this also is very beautiful (Godwits p.xI).

Here two sets of aesthetic criteria are placed side by side, hung in the balance as it were, as an acknowledgement that there is perhaps another possibility besides the cultural hegemony which is outlined in the preceding paragraph of the foreword, 'Concerning Godwits'. A way forward is suggested in both the content and the rhetorical strategies of the passage quoted below. The ubi sunt motif is a device enshrined in English literature from 'The Wanderer' onwards. ${ }^{72}$ But in Hyde's

72 The motif is present in centuries of northern hemisphere writing. The ubi sunt passage in 'The Wanderer' runs as follows:

Where has the horse gone? Where has the man gone?

Where has the treasure-giver gone?

Where has the feasting-place gone? Where are the joys of the hall?

Alas for the bright cup, alas for the corsleted warrior! Alas for the prince's glory! How that time has passed away,

Grown dark under night's shadow, as if it never was!

Old English text in An Old English Anthology ed. W. F. Bolton (London: Edward Arnold, 1963), p.81. (Translation mine.) 
text, the figure does not function simply to reaffirm the superiority of the English literary tradition and colonial subservience to that tradition. The ubi sunt of English history is juxtaposed to a specifically New Zealand ubi sunt:

'Where is Mowbray? Where is Mortimer?' whisper the old leaves of their history. 'Nay, and more than all these, where is Plantagenet?' But ours, darker, might cry, 'Where is Selwyn? Where is Rutherford? Where is Katherine, with weeds on her grave at Fontainebleau, when what she really wanted was the dark berry along our creeks? (Don't you remember? We call them Dead Man's Bread.) (Godwits p.XX).

The repetition here is repetition with a difference. The ubi sunt lament for New Zealand's golden lads and girls is positioned not just as an echo of that quintessentially English one, but as a reply and an accusation; an accusation in which the English cultural hegemony is located as responsible for New Zealand's cultural and personal loss. The passage starts with the dominant voice of English cultural history, invoking Mortimer and Mowbray, but ends - by quoting Katherine Mansfield - with the installation of a New Zealand born writer's representation of sense of place. The repetition of the ubi sunt motif then serves to announce a new and specifically local culture, but one whose origins are already founded in loss.

The conclusion of 'Concerning Godwits' implies that some form of what might be labelled 'cultural organicism' is the first step in maintaining a viable notion of national identity (whilst at the same time the passage reiterates the notion of empty land which allows a point of origin to be established):

We are old and can wait, said the untamed soil against which she pressed her fingers; although it, more than anything else, was awake and aware of its need to be a country . . . the integration of a country from the looseness of a soil. [ ... ] And, 
of course, there's something fine, a King of the Castle feeling, about having the place almost to oneself. Fine but lonely.... Only fools, said the sparse-ribbed rock, are ever lonely (Godwits, p.xxi). ${ }^{73}$

In this passage, the voice of the land replaces the voice of English history in age, authority and wisdom, but the text implies that the problem of accommodating the change has only just begun for the colonial subject. The cultural organicism of Hyde's text does not suggest that the problems of cultural identity or colonial location are solved. Rather it suggests that an affinity with the land can start to build a specifically local sense of human communality. ${ }^{74}$

$73 \mathrm{My}$ ellipsis is placed in square brackets to distinguish it from the others which are integral to Hyde's text.

74 In this representation of the relationship between sense of place and sense of identity, Hyde's text produces a very different notion of colonial identity and society from that in John Mulgan's Man Alone (Hamilton: Paul's Book Arcade Ltd., 1960). In Man Alone there is an implication that sense of communality (which is specifically male rather than specifically colonial) is produced in reaction to the hostility of the new land itself. 


\section{The issue of 'structural problems' in The Godwits Fly.}

The problems of cultural identity and colonial location are not only addressed explicitly in the subject matter of The Godwits Fly: these problems (and the absence of a solution to them) are also articulated in the structure of the novel. It seems to me that this has not been recognised by many critics who discuss Hyde's text. In the following discussion I will examine the ways in which the structure of Hyde's text has been found lacking by several critics and point to some of the presumptions on which the readings which are discussed are based. I will then go on to provide an interpretation of The Godwits Fly which reads its structural features not as flawed but as central to an attempt to articulate a sense of identity which is not coherent, secure or autonomous.

In her essay 'Robin Hyde and The Godwits Fly', Gloria Rawlinson starts by citing a letter in which Hyde articulates her attempt to 'do something nobody else has tried' in The Godwits Fly:

It has been miles harder to write than anything else, but then what it is trying to do is something nobody else has tried. ...

Although she at no time elaborated on what that something was that 'nobody else has tried', she was obviously referring to the style which she had evolved for herself ...75 (emphasis added).

75 Gloria Rawlinson. 'Robin Hyde and The Godwits Fly,' in Critical Essays on the New Zealand Novel, ed. Cherry Hankin (Auckland: Heinemann Educational Books, 1976), p.40, hereafter refered to as Critical Essays. Rawlinson refers the reader to p.xvi in the 'Introduction' to the Auckland UP edition of Godwits for the source of this letter. In that text the letter is identified as being addressed to the Rawlinsons and dated November 18, 1936. 
Rawlinson identifies the 'something different' which Hyde is attempting as being contained solely within Hyde's stylistic method, which allows her to identify the novel as stylistically 'brilliant' but structurally flawed. Despite initially making claims for the innovatory character of Robin Hyde's prose style in The Godwits Fly, Rawlinson goes on to demand a rousing conclusion to the novel and 'answers' to the questions and problems posed in the tert:

Unfortunately, a sense of anti-climax persists, and even increases as Robin Hyde battles for a satisfactory conclusion to her story. One begins to query gaps in the narrative, sometimes hastily filled as if by afterthought, sometimes bypassed altogether. And what has become of the godwit-dream ?... It becomes obvious that the weakness in these last chapters lies in the fact that arguments built up in The Godwits Fly are, in the end, so tentatively resolved. (Critical Essays, p.56).

Rawlinson seems to demand a 'dramatic' coherence to the structure of the plot, that is, she wants a 'direct confrontation' where the main conflicts in the texts are brought to crisis, followed by a firm resolution rather than the 'tentative' one she finds (though I find it hard to find even tentative resolution in the text). In insisting on a satisfactory conclusion' and by demanding to be presented with a sense of closure, Rawlinson herself closes down on the possibilities for reading 'something nobody else has tried' to do in other locations in the text. The 'structural breakdown' and the 'gaps in the narrative' which Rawlinson identifies as 'faults' in the novel can only be viewed as faults if a particular formulation of the constitutive conventions of the genre is already in place in the reader's mind, and if that particular formation is implicitly regarded as 'correct'. Although, as Barthes suggests, the constitutive conventions of a genre are what allow a 
reader to make sense of a text, a text can work either within or against those constitutive conventions. It seems to me that in working against some of the constitutive conventions of the novel, for example linear narrative development, coherence of narrative position and adequate closure, this text's 'something different' becomes something many critics had not counted on. As a result of this the text has suffered from a degree of critical misrecognition.

Frank Birbalsingh finds that 'the narrative seems aimless' and that 'the action ... appears either confused or insignificant' and concludes that 'because the plot lacks direction ... we are lulled into a response that is simply random and fragmentary. 76 I would suggest that rather than the text producing a response in the reader which is random and fragmentary, the text is carefully structured to portray an experience of randomness and fragmentation, and this is not necessarily ipso facto a fault of a text (one wonders what this critic's reaction to Joyce's Ulysses would be). M. H. Holcroft states with a critical absolutism which denies the flexibility of generic categories and their history of change that The Godwits Fly is not a very good novel. Robin Hyde lacks firmness in construction. 77 Then (having implicitly substituted her body for her texts), he proceeds to gender the qualities which he dislikes in her writing:

... she's inclined to write in a breathless and feminine way, as if for a woman's magazine. She doesn't have the masculine quality, the controlled strength, which one notices in exceptionally good novels by women (Holcroft, p.21).

76 Frank Birbalsingh, 'Robin Hyde,' Landfall 31 (1977): 365-66. Further references in the text.

77 M. H. Holcroft, Islands of Innocence (Wellington: Reed, 1964), p.21. 
It would have been interesting had Holcroft deigned to cite an example of this stylistic asphyxia or offer some rationale for designating it peculiarly feminine other than comparing it to the writing in 'women's magazines', as there is in fact a marked difference between Hyde's writing and that in women's magazines and women's pages in the newspapers of the 1930 s. $^{78}$ What Holcroft's comment does is to demonstrate that for him 'masculine' is a synonym for 'normative' and 'authoritative' and to help to make explicit for a reader in the 1990 s the phallocentric and culturally conservative grounds of his particular misrecognition. Holcroft's fixed notions of genre and of what constitutes good writing combined with firm belief that authority is essentially male render him unable to read textual difference as anything other than failure.

Joan Stevens complains that the 'several themes in the book' are 'not well fused' and that the godwit theme 'is not ... worked out in the terms of the novel' as its impact on Eliza's life is 'stated but not shown.' She labels this as 'a major weakness' and concludes that technically there is nothing new in this text (NZ Novel pp.59-60). Clearly Stevens also has particular expectations of the text which are not fulfilled. She summarises the text as follows:

... we have a brilliant rendering of a Wellington girlhood, which shades off into loneliness, unhappiness, disaster in love, the loss of a child, and final grey acceptance of what life has brought. The godwit, in this case, did not really fly; but we are not made to feel that Eliza would have been 'more herself' had she 'flown' to the other hemisphere, for the tragedy is in her

78 This denigration of 'women's magazines' also fails to take into account the serious journalism written for and by women, including Robin Hyde, in the Working Woman. 
own temperament. The godwit theme peters out, after a memorable opening (NZ Novel, p.60).

What does not enter Stevens' analysis is the possibility that the 'petering out' of the godwit theme might not be a structural flaw, but rather the central concern of the text. Certainly the text does not produce the impression that Eliza would have been 'more herself' having followed the path of the godwit, but that is not necessarily the structural failure which Stevens' comment suggests. I suggest that Hyde's text is concerned with the explicit 'demythologising' of the godwit myth. The text demonstrates that making the migration to England under the compulsion of a cultural myth, in which colonial experience is constructed as marginal and metropolitan experience is constructed as central, does nothing to help the colonial feel more herself or himself. Timothy, the character who makes the godwit journey, does not achieve any sense of a resolution of the problem of identity through doing so.

It is not so much that the text loses its way in abandoning the godwit theme, as that the abandonment of the godwit theme demonstrates that that particular way is lost. Although cultural godwitism is left behind by Eliza as no longer tenable, its loss is keenly marked by the absence of the structuring sense of direction and purpose it provided. Thus the sense of loss of direction which Stevens, Rawlinson and others criticise as a flaw is part of the text's articulation of the problem of colonial identity in a period of transition.

The process of misrecognition which causes the 'something different' of The Godwits Fly to be construed as lack is particularly obvious when the above commentaries on this text are compared to those on Mulgan's Man Alone. Paul Day announces with approval that 'lits 
structure is simplicity itself,' and Stevens finds it a 'well made book' signalling her approval of Mulgan's straightforward, linear narrative. ${ }^{79}$ It is interesting to note that whilst Hyde's text is criticised for a lack of straightforward, linear narrative and lack of structure, Peter Quatermaine criticises Jane Mander's Allen Adair for precisely the qualities which Stevens and Day find praiseworthy in Mulgan's text. Quatermaine's comment, 'Jane Mander's book has failings. The pattern is too neatly planned, could just as easily be applied to Mulgan's text ${ }^{80}$; that the criticism is not levelled at Man Alone suggests the gender bias inherent in some critical practice. ${ }^{81}$

The gender bias in Quatermaine's critical position becomes more obvious as he continues, 'the Allen/Dick relationship is as sentimental as perhaps only a woman could have made an all-male bond.' Pronounced notions of what constitutes men's and women's writing operate in all these accounts, though they are more explicitly

79 Paul Day, 'Mulgan's Man Alone,' in Critical Essays, p.63. Further references in the text. Stevens, NZ Novel, p.61.

80 Peter Quatermaine, 'Shorter Notices,' Journal of Commonwealth Literature, $11.1(1976): p .83$.

81 In the following discussion I do not propose that women's writing is qualitatively different from men's writing or that one is inherently better or worse than the other. I trace the way in which essentialist theories of gender are operating in the critical evaluation of Hyde's texts. I have no vendetta against Mulgan's text, and do not suggest that it should be expelled from the canon or even demoted in favour of Hyde's text. It is merely that it serves well as a case in point of the assertions of completeness (plenitude) in the commentary on that text in comparison to the imputations of lack in respect of Hyde's text.

Gloria Rawlinson cites a very telling example of a 1936 review of Robin Hyde's poems which presumes that Hyde is male. The reviewer refers to the boisterous pugnacity of Mr Robin Hyde' and continues 'He has the vigour and weight of a forward in a rugger scrum ... . From his poem 'Woman' I imagine Mr Hyde has played mixed rugger'. One could not move further away from Holcroft's 'breathless' and 'feminine'. Rawlinson's example is cited in Private Gardens: An Anthology of New Zealand Women Poets, ed. Riemke Ensing (Dunedin: Caveman Press, 1977): p. 141. 
articulated in some accounts than others. In common with the critics mentioned above, Quatermaine finds the depiction of 'individual sensibility' in The Godwits Fly more 'successful' than the 'godwit' image. What this criticism effectively does in emphasising the individual sensibility, which has been seen as the appropriate sphere of women's writing since the late eighteenth century, is to downplay the significance of colonial politics in Hyde's work.

Criticism of Hyde's texts in general has a tendency only to gesture to their concern with national events and colonial identity, and the criticism tends to comment on the attempt to address those matters and then to proceed to locate the successful parts of the texts as those engaged in representing the subjective experience of the individual. In contrast, Stevens is prepared to read in Man Alone

... the sense of modern man's isolation and losing private battle with forces he cannot control, economic, military and political, and the picture of a social structure in collapse. As the bits fly apart and cohesion is gone, so man becomes the solitary, the outlaw ... (NZ Novel, p.61).

Like Day, she is quite ready to read allegorical significance into the events of Mulgan's novel. Day suggests that:

... breadth, humanity, freedom, sense of community, civility, urbanity - these qualities are squeezed out of men in the pitiless fight to the death against the land - a fight which is externalised and dramatized in Johnson's epic journey through the Kaimanawas (Critical Essays, p.63).

He concludes that 'ii]n his deceptively offhand way Mulgan has managed a remarkably full and a completely truthful account lof the land]' (p.70). Stevens feels that '[bly the end of the novel, Johnson has turned into an almost mythical figure, the common man' (p.61). 
When one turns back to the text of Man Alone in search of this epic quality in the dramatization of Johnson's journey through the Kaimanawas there seems to be something of a gap between the expectations raised by that description and the words of the text:

He had to climb after that to get over the first heights of the range that ran up six thousand feet high, and he did this after two weeks of journeying, going up again to a country of bare rock and lichen and down again to a great valley beyond that fell steeply two thousand feet (Man Alone p139).

Presumably one is meant to infer the Herculean nature of the task from the lists of heights and distances. Similarly the fullness and complete truthfulness of the account which Day finds 'remarkable' seems remarkably absent in my reading unless one construes truth here as a relentless attention to facts and figures. The text is full of 'potted' history, most of which is part of the omniscient narration, so its simplistic analysis cannot be taken as a representation of the limitation or the lack of understanding of a character who represents the common man. The reader is told: 'Prices began to fall in 1931. Wool went first, it had been going down for two years, and butter followed it' (p.40). On the other hand, the reported thought of Johnson is occasionally completely incompatible with the unreflective and predominantly inarticulate character which is sketched elsewhere in the text. When we are told that '[1]istening, he considered the necessity which all men have of dramatising themselves,' it is obvious that neither that degree of analysis nor the aphoristic economy with which it is expressed is consonant with the representation of Johnson elsewhere in the text. 
It seems to me that what happens in Stevens' and Day's critical commentaries on Man Alone is that their readings supplement the 'lack'82 of Mulgan's text by insisting on an allegorical or mythic dimension to the text, which then restores it to a state of completeness, of copious plenitude, whereas the plenitude of Hyde's texts is suppressed in critical accounts in favour of a concentration on their lack (a lack which I suggest above is a product of a particular framework of reading and not inherent in the text).

If The Godwits Fly is read as a novel in terms of the constitutive conventions which shape Mulgan's Man Alone, it will, of course, be found to 'lack' precisely the linear narrative and the universalising resolution that Man Alone possesses. At the end of Mulgan's text, the central character, Johnson, finds a sense of community and brotherhood in the 'international' context of the Spanish Civil War. Day and Stevens both produce readings of Man Alone which claim that the central concern of the text is the problem of colonial identity. However, neither critic seems to aknowledge that the sense of resolution of the problems outlined in the text (the effect of closure, which they applaud), is achieved by a circumvention of the problems of colonial identity, by a removal of the protagonist from the colonial society. Mulgan's text implicitly indicates that the problems of finding a home, of resolving the problems of location and identity, are not possible in the structures of the colonial world which the text portrays.

82 In using the term 'lack,' I am not disparaging Mulgan's text. No text is ever all-encompassing. I am merely stresing the dynamics of these critical accounts, dynamics which are motivated by preconceptions about gender. 
But the obverse can also be stated. Man Alone can be seen to lack precisely that which Hyde's text possesses, namely a refusal to circumvent the problem of colonial identity. There is no transcendence of the problems of geographical or cultural location in Hyde's text (or of the further problem of the relative position of the female), because it is precisely these problems with which The Godwits Fly is concerned. With a change of subject pronoun Stevens' comment on Man Alone can be seen to be, if anything, more appropriate to The Godwits Fly. To paraphrase: the text demonstrates the sense of modern woman's isolation and the losing of a private battle with forces she cannot control, economic, medical and political, and presents the picture of a social structure in collapse. As the bits fly apart and cohesion is gone, so woman becomes the solitary, the outlaw. .83

Where the critical accounts suggest that Mulgan's text offers a solution to this bleak vision of social and personal disintegration and chaos, Hyde's text does not. Mulgan's commentators simultaneously make claims for the 'truth' of his realism and applaud the mythical dimension of Johnson as the man you can't kill. Yet, although Hyde's text depicts in detail the way in which war, the depression, poverty, illness and childbirth kill and maim people and deals in no mythic transcendence, it is only very recently that similar claims have been made for the 'truth' of its realism. ${ }^{84}$ Yet the portrayal of a social

83 The description also fits Nor the Years Condemn which deals with men's and women's experience of the depression in much more detail than does Man Alone.

84 In the Penguin History of New Zealand Literature (Auckland: Penguin, 1990) Patrick Evans suggests that '[Hyde] offered such a clear alternative to what we have come to think of as the Sargeson tradition' and continues:

... the change from Hyde's masculinist first novel to these fictions [The Godwits Fly and Nor the Years Condemn] made her seem unstable and irresponsible to some, and as if she had a narrow, 
structure is much more detailed, much more fully achieved in Hyde's texts. The way in which the narrative of the text shifts between third and first person narration and moves its focus from Eliza to Timothy, to Carly, to Augusta, to John, as well as embracing the position of many other minor characters in its progression, means that it articulates a much fuller and much more varied and complex version of colonial life than does Mulgan's text.

in ward vision seeking idiosyncratic expression when there was a healthy, natural realism available to her. There is a cruel irony in that charge, since much male writing of the Thirties and Forties was to have a narrower and more inward vision than hers, and she was capable of a far more generous realism than any male writer could achieve (p.138).

Although Evans is clearly acutely aware of the gender bias within which the critics discussed in the main text above are working, earlier in the same paragraph of his discussion he refers to the 'problems of tone and style' which he feels these two texts of Hyde's suffer from, without ever articulating the grounds on which his criticisms are based. 
The bits fly apart: towards a constructive reading of the structure of The Godwits Fly.

Hyde's remarks about attempting to do something nobody else has tried are strongly reminiscent of the remarks made by Mansfield in the Journal about wanting to write in something which is neither poetry nor prose but 'a kind of special prose ' (Journal, p.42). In the texts of both these writers there are attempts to break new ground. No one has suggested that the new ground which Mansfield breaks is confined to stylistic innovation. It is a commonplace of Mansfield criticism and modernist aesthetics that style, content and meaning are inextricably bound up together. Whilst it would be inaccurate to attribute to Hyde an impact on the New Zealand novel comparable to Mansfield's impact on the short story in English, it seems profitable to read the differences in Hyde's texts as attempts to break new ground in style, content and meaning, rather than confining the attempt to register something different to the realm of style, and reading the other differences as failures to succeed in attaining the goals of established literary conventions.

Hyde's text presents a society whose ideologies about colonial identity, national identity and gender identity are themselves riddled with contradictions and where the vicissitudes of the position of the colonial subject produced in this society have to be lived through and not evaded. That the resultant 'loss of cohesion' and the way in which 'the bits [fly] apart' is represented in the structure of Hyde's text as well as its thematics does not necessarily mean that as a novel the text is flawed. What the critics cited above register as the central flaws in 
Hyde's text - its tentativeness, its fragmentary nature, its lack of cohesion - can be read as its primary concerns.

Rawlinson's reading of the 'something' different in the text only as stylistic, and her reading of its fragmentation as failure in terms of the conventional novel, is echoed in her reading of the foreword 'Concerning Godwits'. She claims that 'to think of the real godwit is to become aware of a gap in metaphorical logic as it is worked out in the story' and suggests that the foreword is an attempt to cover over this flaw with a belated justification. It is because Rawlinson sees the petering out of the godwit metaphor as a failure that she feels that 'the foreword adds little to what is already woven into the text.'

Cherry Hankin's analysis is much more acute than Rawlinson's where she identifies the disintegration of the text without an implicit critical corollary that a successful novel should be fully integrated:

Those novels in which the quest ends with neither compromise nor some positive resolution are inevitably the bleakest. Where the possibility of finding some permanent and sustaining value is rejected, and where a sense of purpose is ultimately despaired of, there remains only the prospect of alienation or death. Structurally as well as thematically, there is a sense of disintegration towards the end of The Godwits Fly: and this parallels Eliza Hannay's virtual abandonment of the will to live (Critical Essays, p.xv).

Rawlinson's reading does not admit the possibility that the text could be making the point very forcefully that the myth of the godwit is both disabling and of limited relevance. The failure of the myth in the text suggests that it is of limited use in a colonial society undergoing a metamorphosis from a position of colonial dependence to a position where there is an attempt to define a specifically national identity. 
Patrick Sandbrook, on the other hand, does suggest that the abandonment of the godwit theme might be more than a failure to sustain an idea:

In a foreword entitled 'Concerning Godwits' [Hyde] explains that there are a number of apparent flaws in the symbol. . . . No resolution of these flaws is offered, which might seem to provide evidence for the critical view that the theme is clumsily handled and in fact 'peters out'. However, by drawing attention to these flaws, Hyde deliberately prompts the reader to look more deply [sic] into the implications of the symbol to discover exactly how it functions in the novel. 85

Sandbrook suggests that the godwit metaphor has more to do with the metaphorical journey involved in the growth and development of Eliza's mind than with the literal journey to England and that if 'the novel is read in the light of this suggestion it will be seen to be much more carefully constructed than is usually assumed' (Sandbrook, p.332). Whilst Sandbrook's reading is a more productive reading than those of critics who simply dismiss the text and the godwit metaphor as flawed, reading the text merely as a quest for Eliza's personal growth and artistic maturity also fails to pay attention to parts of the novel. In suggesting that the text's main move is towards a position of universalism, towards a 'recogniltion]' that 'the world of "man, woman and child" is the whole world; not just New Zealand, not just England,' Sandbrook de-emphasises the significance of the concern with colonial identity in the text, which is present right to the end, even though the godwit metaphor is not (Sandbrook, p.335).86

85 Patrick Sandbrook, 'Two Responses to Armstrong's Hyde,' Landfall 36.3 (1982). p.332. Further references in the text.

86 Susan Ash takes up a similar position to that of Sandbrook, stressing the Kunstlerroman aspects of the novel. "Hyde's novel "prepares" the reader for the final image of Eliza as an artist alone in the street observing. Each chapter is a 
My reading of the text will focus on the final four chapters of the text where the charges of failure are most specifically located. Of these four chapters it will examine chapter twenty-three 'Absalom, My Son' in most detail. The last four chapters have no dominant or connecting metaphor but, in the absence of the godwit metaphor, each one presents a different experience of dislocation and confusion in a colonial society where individual identity and the relationship of the individual to the society is shown to be problematic. It is this specifically colonial experience of dislocation and confusion that I would locate as one of the text's central concerns.

In the chapter 'No More of Me You Knew', although Eliza wants to 'go home' from Australia to New Zealand, the text suggests that in New Zealand there is no home for the mother of a dead illegitimate baby in any position recognised by that society, either as a wife (the father of the child has married), or as a lover (the man she loves is dead), or as a daughter (her mother's rejection of her is symbolised by a pair of gloves which 'burst', because the stitching that holds the fabric together is coming undone). There is no 'place on earth where you could lie still as long as you liked' (Godwits p.214). In 'Carly' the only viable place which Carly can find is in the imagined security of a past childhood, and in 'Absalom, My Son' not only is John represented as unable to reconcile himself to the structures of the society or the family in which he has to live, but the relationship between the

development of Eliza's growing alienation from family, friends and society until she is wholly alone. The narrated scenes thus prepare the reader for this image as the "only truly appropriate outcome" " ( Susan Ash, Narrating a Female (Subject)ivity in the Works of Katherine Mansfield, Robin Hyde, Janet Frame and Keri Hulme, diss., U of Otago, 1990), p.47, further references in the text. This reading again takes no account of the specific concern with colonial identity in these chapters and of the fact that they are not only concerned with Eliza but also with August, Carly and John. 
colonial product and the imperial product is brought sharply into focus by the fight between a shop assistant and John over the ranking and prominence of texts.

John keeps placing Eliza's volume of poems 'Stranger Face' (whose very title suggests alienation and dislocation) 'Irlight middle top ... and centre pages full spread, with Wordsworth on the one side and Tennyson on the other' as the shop assistant complains (Godwits, p.224). John's rearrangement of the texts is represented as a threat to the established order precisely because his intervention means that the curator of cultural distinctions is no longer in full possession of the power to maintain the separation of (metropolitan) English texts and local (colonial) texts - the assistant asks how he is to keep stock of [his] own counters if [he] can't arrange the books without the public stepping in and interfering' (Godwits, p.224).87 John's protest to the manager underlines the illogicality and unsuitability of these divisions which are maintained by force of 'tradition':

Mr Hansen [the manager] said gravely: 'This, sir, is a local production. I'm afraid local productions don't do us much good. The public won't look at them.' He swept wide, white hands, exonerating his shop, damning the public.

'Can't you tell poetry when you read it? Local production you're a local shop, aren't you? You live by local custom, don't you? Then what do you mean, letting snippets like him look down their noses? I suppose a poet's a poet, even if born in this country....' (Godwits, p.224).

It also suggests forcefully the need to produce in the place of traditional distinctions a set of codes which accommodate the lives of

87 That 'the public' pose a threat to the maintenance of hierarchical order on the bookshelves and in the canon is in keeping with the sympathy for socialist ideas present throughout the text, in that it defines the incipient New Zealand national identity which will challenge the imperialist hegemony as a specifically populist identity. 
those in the local society. The language of the text connects the rigorous maintenance of notions of canonical propriety in this society to the rigorous maintenance of the notions of moral propriety. John's reflection that it is not right that everything should be so 'shabby' and his determination that Eliza should get a 'fair deal' (p.226) apply as much to the illegitimate pregnancy and resultant moral censure as to the poor printing quality and partial concealment of the local poems. The hierarchy of privilege between colony and metropolis, between established orders and moral practices, are called into question.

Even though the manager responds to John's comment about local economic imperative by instructing the assistant to place 'Stanger Face' on the 'second top shelf' instead of replacing it on the lowest shelf from which it had come, the small difference which his individual protest has made is not enough to resolve any of the problems of identity or location by which he is beset. He is represented as outcast and dislocated, 'shambling along the pavements, his thin unkempt hair giving him his usual wild look, and although an atheist, he is shown paradoxically finding in biblical language an expression of his sense of loss and incompleteness: ' 0 Absalom, my son, my son. Would God that I had died for thee, my son Absalom.' (Godwits, p.226).88

'Various Goods' repeats the figures of dislocation, confusion and disintegration. Eliza is shown on the margins of cultural institutions, dislocated from them; she is the 'Sidebottom's girl,' not a daughter but a 'sleep out' maid, she lives in 'barren' lodgings. Rawlinson points out

88 The quatation in the Hyde text is from $2 \mathrm{Sam}$. 18:33. The words are spoken by King David at the news of the death of his son. The last chapters of the text are filled with dead chidren or damaged babies. Eliza's child is dead, Carly assists at the birth of a baby who 'isn't all right' ( $p .221$ ) and, as mentioned above, John's words also refer to the death of a son. 
that at the end of the text Eliza is going to be 'not the bride of popular "happy ever after" fiction, but a bridesmaid at her friend's wedding' (Critical Essays, p.57). The bridesmaid's dress is described as hanging 'like the stiff ghost of a woman at a dance' (emphasis added, p.229), a simile which suggests both the constriction of the female role in the society described and that it is a role that no longer accommodates the lives of those who live in that society. Even Simone (who, according to Rawlinson, is going to be the bride of 'happy ever after' fiction) will have a 'stranger face' in marriage (p.230). This reference provides a direct lexical link with the 'Stranger Face' volume of the preceding chapter, and the poem which is quoted from that volume is directly concerned with the colonial inheritance and the destruction of female beauty by 'menial needs and base' (p.225). In Eliza's reported thought her sense of identity and location is represented as disparate.

Where am I going? Into dreams, travel, fag-ends of love thrown down in gutters by those who did not want them, poetry, journalism, drink, drugs, the steep blue country of melancholy, where I have been before? Or down the road to the fishmonger's to buy Mrs Sidebottom's little fresh soles? It doesn't matter much (Godwits p.231).

Rejection and desire, career and personal life, larger philosophical questions and specific detail are mixed up together. Here the expression of confusion about direction and purpose, about a tenable place in the scheme of things and about the relative values of different activities are echoed in the mixture in tone and imagery. The colloquial 'fag-ends' of love contrasts with the more lyrical 'steep blue country' of melancholy, as do the large scale generalisations with the bathetic mention of 'little fresh soles'. 
The figures of colonial dislocation and disintegration can be seen to be represented both stylistically and structurally in this text, and the 'something different' in. Hyde's text can be read as an attempt to represent a version of colonial identity that had not been represented before in a way that had not been attempted before. It is a text which engages specifically with the problems which Gray's schema does not even allow for.

If The Godwits Fly is read in conjunction with a text like Living in the Maniototo which works against novelistic conventions much more

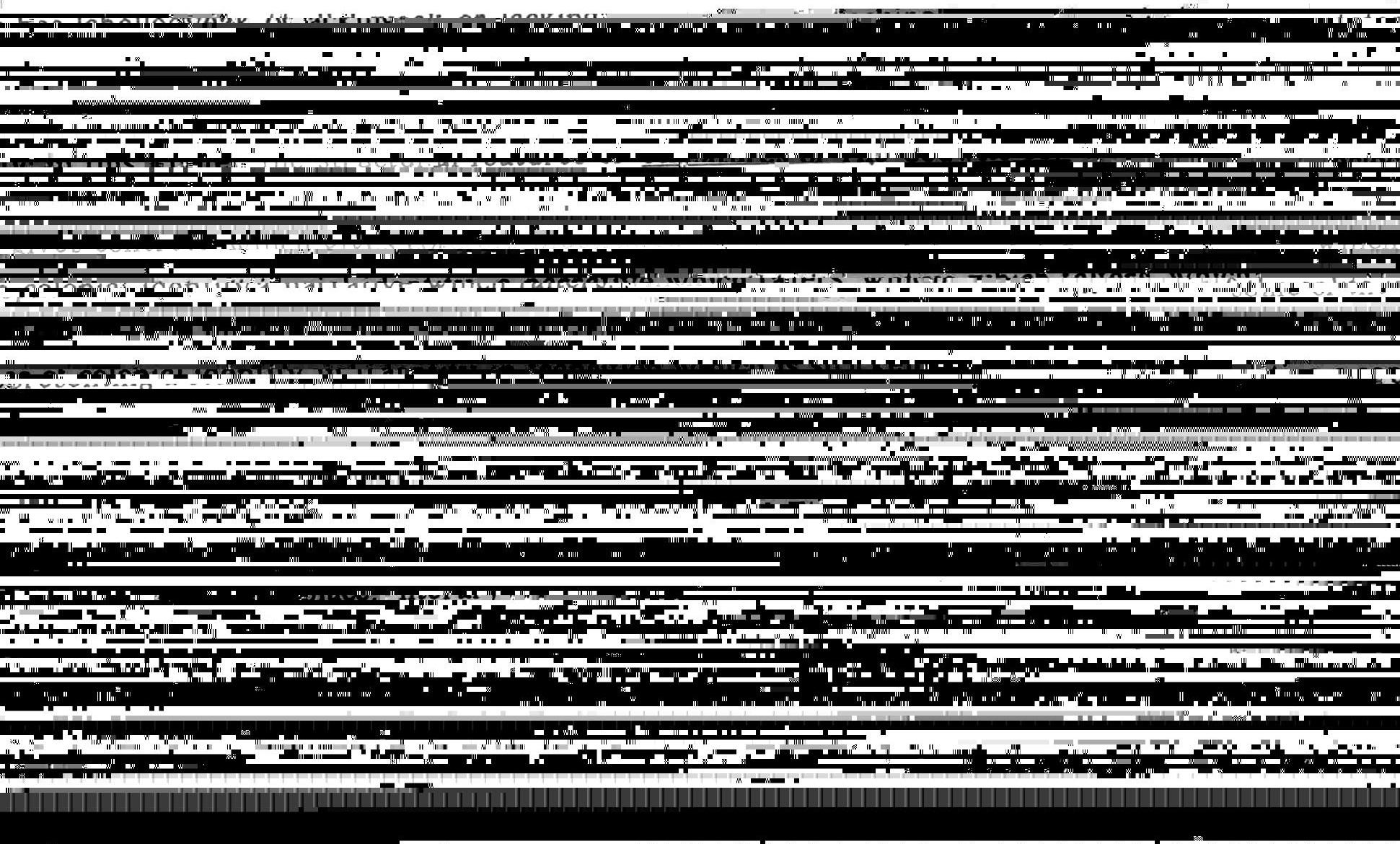

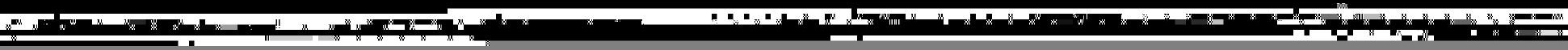


are made to sing on Arbor Day and it draws attention to the problems encountered in establishing a sense of identity caused by both the hegemony of literary representations of England and the myth-making of phase one literature:

Bird-of-my-native-land was supposed to be the tui, but none of the children had ever seen one, or a kauri tree either.... It was a lie to say that bird-of-my-native-land and the thin trees stuck in holes in the playground were sacred and beautiful.... Somewhere, far away in real wildness, it might be different; but here the native things looked only grey and sad, and covered all over with dust. And the cabbage-palms and tree-ferns people grew in their backyards - like beasts in a zoo - looked cowed and sick....

Something there had been, something delicate, wild and far away. But it was shut out behind the doors of yesterday, lost beyond the hills, and sticking a dead twig of it into a hole in the playground, or a rotten poem in the school journal, only made it sickly and unreal. You didn't really have to think about it - Maoris, godwits, bird-of-my-native-land. Attending to it at all was a duty call to a sick bed. History began slapbang in England. 'At the battle of Hastings, in 1066, William of Normandy defeated King Harold.' . . . You were English and not English. It took time to realize that England was far away. And you were brought up on bluebells and primroses and daffodils and robins in the snow - even the Christmas cards were always robins in the snow. One day, with a little shock of anger, you realized that there were no robins and no snow, and you felt cheated; nothing else was quite as pretty (Godwits, pp.32-34).

In the passage above, the way in which the representations of place available in the culture are introduced suggests that they are falsely mythologising, demeaning and inaccurate: 'supposed to be' and 'lie' both indicate that there is a gap between the representation and the perception. It suggests that the position of colonial identity constructed by phase one writing is no longer a position which can function with any relevance to individuals in the society represented in that text. But the passage goes on to indicate that a replacement of those 
constructions of place which are specifically Anglocentric, and therefore of limited relevance, is particularly problematic. The passage draws explicit attention to the conditions and operations of colonialism, in this instance through the reproduction of the cultural mores of the colonising society in the education system. The material offered by the educational establishment is shown as being contradictory, but not being articulated by that institution as contradictory. It is the colonial subject in that education system who has to attempt to reconcile the siting of origins in English culture and English history, the fact that one is told that '[h]istory began slap-bang in England, with the construction of a 'native' identification with the land in the song 'Bird of my native land'. In this song in which the tui is described as a 'beautiful stranger,' 'native' is far more indicative of the desire for a position of autochthonicity than of its fulfilment. The term indicates the attempt to assert a position of autochthonicity by an act of appropriation whereby the signification of 'native' itself is changed. In the context of the song, for colonials to identify themselves as 'natives' is not to imply kinship with the indigenous inhabitants but, in fact, to replace those indigenous inhabitants. In the 'Natives Associations' formed in New Zealand in the late 1880s, the 'natives' were pakeha New Zealand-born New Zealanders, not Maori. The associations were set up to 'foster national self-awareness, 89 and although this might suggest an incipient political nationalism characteristic of Gray's phase two writing, the description of the tui as a 'beautiful stranger' is an exoticising description in the manner characteristic of phase one writing. The contradiction between the

89 Information taken from Patrick Evans, Penguin History of New Zealand Literature (Auckland: Penguin Books, 1990), pp.27-28. 
attempt to identify as autochthonous and the attempt to claim English history as a history of cultural origins, and the problems this contradiction causes for the colonial subject, is shown in the text.

What is also demonstrated by the text is the loss inherent in this appropriation of the 'native'. The replacement of the 'autochthonous native' by the 'colonial native' results in loss. The autochthonous Maori culture is shown as being displaced and then reconstructed as a mimicry of its former self; it is shown as both debased and controlled by the white settler. The native plants which are grown in backyards are mimic figures of the traditional English garden. At the same time, the description of them as being 'cowed and sick' suggests that they are symptomatic of the destroyed bush, of the clearing and burning carried out by the settlers, and of the domination of the usurpatory culture. The simile of 'beasts in a zoo' suggests that the associative categories of 'nature' and 'civilization' are still operating at some level, and that nature is still associated with the 'autochthonous native' culture, whilst civilization is associated with the colonising culture, but the figure also suggests a most uncomfortable conjunction between nature and civilization. Nature is no longer present as a utopian idyll outside the space contained by civilization, as in 'How Pearl Button Was Kidnapped,' but is represented as either being destroyed or tokenised by the colonising culture. The passage suggests that the installation of the colonial presence results in the irretrievable loss of the autochthonous culture, and that this autochthonous culture is 'lost beyond the hills,' and what appears to be its presence, in gardens, in 
school yards, in zoos, is in fact a trace, the token which marks its absence. 90

The other form of loss is the loss of the myth of an autochthonous relation to English culture, which results in the feeling of being cheated out of an inheritance of autochthonicity. The text suggests that there is another problem with literary and visual representations in the colonial culture, not because they are falsely mythologising or exoticising, but because the place of which they give a sense is not the place in which the recipients of those cultural representations live. The English cultural representations described in the text appear to give a guarantee of cultural identity and cultural authenticity, but when that authenticity is recognised as chimerical there is no substitute which is not precisely a substitute, the presence of which is always a reminder of loss. In The Godwits Fly colonial identity is represented as founded on two poles of irrecoverable loss and this loss is explicitly demonstrated to be encoded in the representation of place. Both identification and identity are here shown to be stricken with indeterminacy. Where there are attempts to register the uniqueness of the sense of the new place in Hyde's texts the extremely problematic nature of sense of place is registered; there are always equivocations registered, either explicitly in overt statement, as above, or in textual implication.

90 Frame's Living in the Maniatoto explicitly represents the process of colonisation as producing a loss of autochthonousness, and a subsequent tokenising of the lost objects:

... because if you take part, however remotely, in destruction, you also take pleasure in recreating what you have destroyed, there are many plant nurseries in Kaka Valley where you may buy all the native shrubs and trees as well as the more quickly growing silver dollar gum, and casuarina, and sweet pea, which will screen your house from the neighbours... (p.22). 


\section{The split address: the co-presence of phase two and phase three features.}

Gray suggests that the establishment of phase two writing is enabled by the development of a sense of political nationalism. Hyde's texts are explicitly concerned with the question of national identity and what it means to be colonial. Nor the Years Condemn charts of a growing sense of national identity, and suggests that one period in the history of the nation has finished and another is beginning. The text charts specific political and historical events, for example the death of Massey, and puts them in a context of the development of a nation:

They had carried Massey through packed streets in Wellington, in a glass-walled funeral coach and a coffin draped with the Union Jack and a fine Maori mat. Now they were building for him at Point Halswell, looking down over the Heads where the troopships had steamed out, the expensive marble tomb his plain farmer's heart had never demanded. The country was living well beyond its means, publicly and privately; but not publicly beyond its reasonable possibilities or its looks. There was a sort of virtue in that ... (NYC pp.116-117).

The country is represented as having a sufficient past and a sufficient sense of past to be establishing monuments to it, in short it is represented as having a history of its own. ${ }^{1}$ The passage represents these events as symbolising the passing of an era. In this context, burying the Union Jack and the maori cloak along with Massey also becomes symbolic. The burial of these signs of Empire and autochthon suggests that nationhood can only be constructed out of the demise of Imperial possession and autochthonous culture. The passage

91 This representation stands in contrast to the English history in The Godwits Fly discussed above which illustrates the colonial's separation from the imperial nation. 
charts the founding of a new era on the passing away of the old one; it suggests that it is the development of a nation which is the matter at hand, rather than the progression of a colony.

In the section of Nor the Years Condemn which is explicitly concerned with a significant moment of political nationalism, what is referred to as 'lost beyond the hills' in The Godwits Fly is invoked. In the final chapter called 'That Night', which is set on the night of the 1935 Labour election victory, the suggestion of the beginning of a sense of national identity is related to a song which will come from 'back somewhere in the hills'. One of the main characters Bede Collins thinks,

'We've still got to find our own song. It isn't God Save the King. It isn't the Internationale, it isn't the Marseillaise, it isn't even darling Tipperary. I don't think it's May God defend [sic] New Zealand, though somebody will have to soon. I don't care. It's back somewhere in the hills, waiting; or one of these men has it in his throat' (NYC, p.345).

This passage articulates both the recognition of the inauthenticity of the products of other cultures when used as signifiers of New Zealand national identity, and the need for the representations which register identity to be locally produced if they are to be of any value. Here the desire for some specific and tangible form in which the intrinsic essence' of the new national identity can be realized is clear. But even at the moment of its enunciation the project is problematic. Not only will the intrinsic essence of New Zealand national identity be, in the end, as metaphysical and as much a myth as the colonial or imperial identity which it supercedes, but by entering a competitive relationship with the imperial nation it risks being consigned to provincialism. 
When Bede Collins thinks about a national song which will come from 'back somewhere in the hills,' she articulates a desire for national identity to spring from a close interraction with the land - in other words a desire for autochthonicity. At the same time the particular terms of this articulation are a reminder that one of the problems faced by a colony asserting a new national identity against the original colonising nation is that it is entering into a competitive relationship to the other. As Seamus Deane suggests:

Because they [nationalisms] universalize themselves [as the ideal model to which all others should conform], they regard any insurgency against them as necessarily provincial (Nationalism, p.9).

So again, the whole project of establishing a national identity is fraught with ambivalence. At the very moment of a tentative assertion of an embryonic nationalism, the terms of that assertion, that identity will come from and be of the backblocks, rewrite this nationalism as provincialism.

These texts do not construct of a sense of identity which is coherent; it is one founded on loss, splitting and separation. The type of national identity which is directly articulated in the texts is repeated in the indirect articulations of national identity readable in the nature of particular representations of place. The sense of a split identity is registered in the textual address.

As suggested above, the split in the textual address is located in a different place in Hyde's texts from where it is located in the texts of Mansfield and Lady Barker. I discussed above the way in which a split in colonial identification was located in the addressor in Mansfield's and Barker's texts. I would suggest that the split colonial 
identification is most visible in Hyde's texts in the construction of the addressee.

The texts falter between addressing a New Zealand audience and addressing an English one. The addressee is both 'English and not English'. The identification of the hills as 'New Zealand' hills in the passage from Nor the Years Condemn, which is discussed above as a representative feature of phase two writing, not only signals an identification with the new land rather than the originating culture as suggested there, but also suggests an address to an English audience. The reference to the blue circle of the inevitable New Zealand hills far away' (emphasis added) rather than to a specific range of hills or simply to 'the hills' with an assumption that both reader and author presume that they are in New Zealand suggests the need to display landscape to an outside observer. The explicatory quality in the identification of the hills indicates a northern hemisphere audience, yet the attempt to define a specifically New Zealand sense of place, which is signalled by the tag 'inevitable', implies that the point of view is based firmly in New Zealand and that the New Zealand difference is not seen as exotic (there is nothing exotic about inevitability). At the same time there is not, in this description at least, a sufficient sense of the familiarity of the addressee with the landscape for the registering of sense of place as colourful to be unnecessary, for it to be part of a 'shared, felt milieu, or 'a familiar and meaningful backdrop.'

In Wednesday's Children New Zealand is described as 'a country where everyone intones we are more English than the English' (p.162). Again this representation displays a relationship to English culture but it also simultaneously displays a separate, implicit nationalism. Certainly coloniality is suggested (in Bhabha's terms) by the presence 
of mimicry and the excess or difference that it produces. The society is not English, but the attempt to reproduce itself as the 'same', as English, results not in a sameness but in a difference; it becomes 'more' English in an excess of Englishness which reveals the masquerade. However the phrase also presents a totalizing analysis of New Zealand society which reveals, paradoxically, not the dependent or derivative relationship between the two places which would seem initially to be apparent, but that there exists a sense of a homogeneous New Zealand nation which is analysable. So the split in the sense of identity in Hyde's texts is presented both explicitly in the narrative and implicitly in the nature of the representations of sense of place in that narrative.

As has been discussed above, Hyde's texts register the uniqueness of the new sense of place' and the flamboyant and assertive proclamation of literary rights by the use of the landscape as a 'battlefield on which to claim [a] stake'. The politicisation and growth of literary nationalism which Gray marks out as a prerequisite for the move into the second phase is very evident in Hyde's writings. However, at the same time the set of values which Gray suggests mark out phase three writing are also present in Hyde's texts:

Phase three writers value an autochthonous readership first, for whom the advertisement of colourful landscapes is simply ludicrous. Somehow the familiar is never strange. The sense of place in phase three writing is back where it should be, merely part of a shared, felt milieu, a familiar and meaningful backdrop (Gray, p.9).

The sense of familiarity of place is present in the texts not so much in the description of the New Zealand landscape, both urban and rural, but in the way the other landscapes of other countries are represented as strange and colourful. So in these instances, reading off the nature 
of colonial identity from the representation of place, it would seem that there is a transition in identity from the anxiety to stake a claim in the phase two representations of sense of place to a sense of belonging to the land, which finally appears to achieve the security implicit in Gray's delineation of the phase three sense of place.

In The Godwits Fly, it is Australia that is depicted as exotic and unknown in contrast to the familiarity of New Zealand:

Countries on the map are misleading. True, Australia was coloured plain red, like New Zealand, but it was so large, and the names of such odd products, pearl-shell, molasses, trepang, were printed in little letters round its coast, that somehow you would have expected it to jump out at you like a Jack-in-thebox, saying, 'Here I am, I'm Australia.' Instead, it was plain, indifferent and lonely, with a few startled night-birds flying out of its armpits, and the high gig-wheels turning in deep ruts (Godwits, p.55).

What is made specific in the representation of land in this extract is absence of familiarities based on the common colonial status, and thus the particularity of a New Zealand point of view. Both Australia and New Zealand are part of the British Empire, but rather than any commonality between the two, what is emphasised is the gap between Imperial representations of the land (as the scene of material exploitation, within scopic control) and the experience of land as exceeding those representations.

In contrast, the representations of New Zealand, although they are presented similarly from a child's perspective, suggest a self-referring use of language, and a specifically local context of myth about past and present:92

92 Both of which are, of course, characteristics of Gray's third phase. 
There were red-painted stations, stinking of freezing-works and sheds where tallow is rendered down, and the excursionists sang lustily:

$$
\begin{aligned}
& \text { Kaiwarra, Ngaurangha, Petone, } \\
& \text { Kaiwarra, Ngaurangha, Petone, } \\
& \text { Kaiwarra, Ngaurangha, Petone, } \\
& \text { The next stop is The Hutt.' }
\end{aligned}
$$

The Hutt was a little river, willow leaves and sunlight dropping into it like tarnished coins. In its pools were electric eels, and if you trod on one it would electric-shock you to death. Also, though the wide pale water looked very shallow, its ripple broken by banks of gravel, there were places where the current pulled you under and drowned you. Lots of people had drowned in the Hutt. It was the nearest to real wild that the children ever got (Godwits, p.33).

The song the children sing represents a direct relation to the surroundings, one that encodes them in familiarity. It declares that the land about which it is sung is a land that is known. The myths about the danger of electric eels and the number of people drowned in the Hutt are specifically local and locally produced, implying a settled community which produces them. The figures of exoticism are contained within a structure of what is known and secure, so that for all its putative dangers, the electric eels and undertows of the Hutt are not 'real wild'. In Mansfield's texts 'Ole Underwood' and 'Old Tar' even Wellington and Makara are represented as wild and exotic. There is obviously a marked difference between the representation of wild in and
those texts the representation of wild in Hyde's texts. In The Godwits Fly only make-believe wild is present within the familiar colonial community and 'real wild' is expelled to Australia.

Australia is shrouded in the 'mythological haze' which Gray notes as a characteristic of phase one writing. It is against this exoticism that New Zealand is constructed as 'home'. Australia is the location of 'a 
great lake, with thousands and thousands of black swans. You never see them in such numbers, except in Western Australia' (Godwits, p.19), and hundreds of [horses] - a heaving convulsion of red-skinned, rolling-eyed, autocratic horses' (p.57), and 'a whole hill alive with rabbits, brown-squirming (p.62). The plenitude and vigour of the wildlife is represented as frightening, alien and paradoxically unnatural, as are the larks in 'The Woman at the Store'. Similarly, the children described in Eliza's visit to to Sydney are reminiscent of the deranged child in the Mansfield story:

... another child crawled out from under the table. Its face was very dirty, ... its white legs wobbled. ... to tell its age, from its preternaturally aged face, was impossible. ... [Polly] hit the dirty child .... 'She hit me on my cut,' he shrieked. ... Eliza told Polly the story of the three bears. She was brighteyed, but liked the same thing over and over. "Tell us again, tell us again,' she shrilled. Then suddenly burst into shrieks of laughter, and ran inside the house (Godwits, pp.195-6).

It is not only the children who are represented as unwholesome; the whole family is surrounded with images designed to produce disgust. The same treatment is meted out to Australia and the Australians in this text as is meted out to colonial New Zealand and the colonial New Zealanders in Mansfield's texts. This vitriolic assertion of inter-colonial difference cuts across the class and gender based sympathies exhibited in other parts of Hyde's texts, and it is here that we can trace the disavowal present in Hyde's text. The city of Sydney is represented as threatening, a 'maze of little boxed streets, whose nonentity became sinister when one had passed twenty of the same shape and size,' and the fear which the city represents at points becomes paranoid or hysterical:

Of the men she did not feel at all afraid. The women, sullen at the street corners, were more ominous. As they moved, the 
great full breasts under their sleazy jumpers swung like udders, their sullen faces and feet might tread the world down. But more than that was the voiceless, lightless cry of the streets, and its words were 'I kill' (Godwits, p.200).

The dehumanising effect of the city is contrasted to the New Zealand bluegums, gleaming and steadfast, ... the wavering columns of light in the harbour water' and the smell of gorse in the dark of the New Zealand night. Although the moments cited above where women are seen as ugly and threatening and the working people only worthy of scorn and derision are recuperated by a socialist and feminist analysis, it is specifically in the representation of the Australian city as threatening, murderous and unfamiliar that the socialist and feminist analysis in the text breaks down. What secures New Zealand national identity as whole and coherent is the projection of anxiety about the nature of the colonial onto Australia.

The contrast between Australia as foreign and discomforting and New Zealand as familiar is explicit in the section describing Eliza's return from Sydney:

Over in Sydney, she thought, at this time of year all the gardens would be parched and brown, and I'd be lying with nothing on, probably in a cold bath that would feel hot and sticky, wondering how on earth I'd ever get cool again. Here the Christmas lilies, wet with the rain that fell the day of her coming back, were broad white cups, their gold stamens sticking up, nearly drowned. She thought, 'How thirsty they'd be in Sydney now, how terribly thirsty (Godwits, p.210).

Australia is the land of life-threatening extremes, of drought and of alarming plenitude. (Australia is depicted in Hyde's texts in the same way that New Zealand is depicted in Mulgan's Man Alone.) It is against these extremes that New Zealand as a place is represented as a measure of normality, and it is the metonymic relationship between 
New Zealand and normality which is constructed in the text by the process of disavowal which means that sense of place and sense of identity in Hyde's writing belongs to Gray's third phase just as much as to his second phase. 


\section{CHAPTER FIVE \\ The domesticated angel: \\ Hyde's texts and the problems \\ of essentialism.}

All the mythic versions of women, from the myth of the redeeming purity of the virgin to that of the healing, reconciling mother, are consolatory nonsenses; .. Mother goddesses are just as silly a notion as father gods.... Myth deals in false universals, to dull the pain of particular circumstances (Angela Carter, The Sadeian Voman).

\section{Introduction.}

In the previous section I have discussed the way in which sense of place is represented in Hyde's texts and the formulations of colonial and national identity which those representations of place imply. The previous discussion has not, however, paid specific attention to the way in which gender difference operates in representations of sense of place in Hyde's texts. In this section I will argue that in her texts there are suggestions of different relationships to place for male and for female characters. In Hyde's texts, women are represented as identifying with the natural world whereas men are represented as destroyers of both the natural world and of women. 
From these representations of difference between the sexes it might seem as though Hyde's texts present simply an essentialist analysis of gender relations. I will argue that although Hyde's texts do suggest an essentialist position in their depictions of the relationships of women and of men to the natural environment, the texts also interrogate those essentialist positions which they represent in the following ways. A distinction is made between female and feminine in the representation of the many androgynous young women figures who are described as 'boyish' and who, although female, are represented as rejecting the constriction of the feminine role; Eliza Hannay, for example, claims 'I'm not a woman; not for ordinary purposes' when she wants the freedom to go travelling (Godwits p.162). In The Godwits Fly the relationship between women and nature is also interrogated and the text provides a critique of what the society represented in the text constructs as 'natural' to the female. Similarly Starkie, the central character of Passport to Hell and Nor the Years Condemn finally takes up a gendered position which is different from the position of masculinity normally associated with his biological sex. In these two texts, he is given peace only when he is 'feminised', and although Nor the Years Condemn ends up with a depiction of man, woman and children in what might seem to be a typical nuclear family, within that family unit the power and blood relations are very different from those in a typical nuclear family. Through the representation of female characters with conventionally masculine attributes and the representation of male characters with conventionally feminine attributes Hyde's texts controvert the notion that male and female behaviour is produced by essential sexual characteristics. . 
Some recent feminist critics have fully endorsed the essentialism which seems to be present in Hyde's text Wednesday's Children.93 I suggest that this critical position is problematic both in itself and with respect to Wednesday's Children and Hyde's other prose fiction texts. Firstly, for the reasons outlined above, I would suggest that the representations of men and women in Hyde's texts interrogate the very assumptions on which essentialist feminist criticism is based. The second problem with an essentialist feminist criticism of Hyde's texts is that it simply inverts the binary oppositions within which essentialist 'masculinist' criticism functions. So, for example, it valorises the representation of woman as goddess as a positive image of women and of female power. However, as the epigraph from Angela Carter suggests, the notion of female goddesses is as silly as the notion of male gods, and in fact the valorisation of female goddesses is a utopian fantasy which prevents a more trenchant and rigorous analysis of the social, cultural and political mechanisms by which women are oppressed. In the particular case of Wednesday's Children this type of essentialist feminist analysis fails to pay attention to significant areas of the text and, in doing this, depoliticises the text.

An analysis of the novel which removes the text from its social, cultural and political context, from larger historical and political concerns, is working within the same binary opposition as masculinist essentialist criticism which denominates the realm of subjective

93 In feminist literary theory, essentialism (the belief that attributes are dependent on the intrinsic character or condition of anything and not on extraneous circumstances) is applied specifically to gender difference. An essentialist feminist reading of a tert would take as a given that males and females are essentially different from one another, and that their essential differences are related to their biological difference. 
experience and vision as female and the realm of significant action and event as male. The essentialist feminist readings to which I pay attention in this section take no account of the political and historical specificity of the text but concentrate instead on an ahistorical and universalising consideration of the nature of female experience. To remedy this occlusion I do not advocate an expressive realist reading of the text, but rather one which attempts to investigate with greater contertual specificity the ways in which the representations of gendered subjects function in the text .

The representation of the protagonist of Wednesday's Children as a 'domesticated angel' (WC p.18) seems perilously close to the Victorian representation of woman as 'the angel in the house' 94 which is seen by many feminist critics as part of an oppressive patriarchal politics, and it is also perilously close to the representation of women produced under Italian and German fascism in the nineteen-thirties. After reviewing a feminist analysis of this fascism, I contend that the text locates itself as anti-fascist by the way in which it invokes and presents the Italian invasion of Ethiopia. I conclude that it is this specific political context which makes the text's representation of domestic femininity subversive.

94 The phrase 'the angel in the house' is taken from Coventry Patmore's long sequence of poems of the same name which tells of a courtship and marriage with an excess of religious sentimentality. The title has been taken up by feminist literary critics as a shorthand phrase used to signify one of the stereotypes of the female with which the woman writer must contend. 


\section{Apparent essentialisms in Hyde's terts.}

There is often a difference in Hyde's fiction between the relationship which male characters are shown to have with the natural environment and the relationship which female characters are shown to have with that natural environment. Men are represented as possessors and destroyers, whereas women are represented in relationships with the land which are both reciprocal and annihilatory.

In 'Glory Hole', the first chapter of The Godwits Fly, Bob Malley, an adolescent neighbour of the Hannays', is described as being the 'owner' of the 'Glory Hole' (p.5), a hole which he has tunnelled through the ground from the family wash-house to his mother's bedroom and which he claims contains fairies. Bob Malley's predilection for digging holes in the ground is approved of as a potentially profitable occupation. John Hannay suggests that Bob could become an engineer, and his mother suggests:

A grave-digger would be better. At digging holes in the ground he's the beat of a rabbit, and there's a trade won't go out of fashion' Godwits p.8).

Bob's relationship with the earth is characterised as involving destruction, ownership, financial gain and death. In Nor the Years Condemn, in the description of the relationship between the men building the dam at Arapuni and the landscape those features are repeated. The Waikato river is anthropomorphised and gendered, described as a woman who is violated (p.187), and the action of the male engineers on the female river is described as an 'outrage' (p.188). The whole of chapter X. 'The Song of Arapuni', depicts the relationship between men and the landscape as a gendered relationship and one which involves acts of possession and destruction. 
In a passage from A Home in this World the apparently essentialist connections between the female and the natural world and between the male and death are made even more explicit. The gender-specific images of 'those who feel their sharp new nationalism like a boy just past puberty feeling his manhood' and 'that great army swinging by, hoping to find in death the justification for the fact that it carries maiming and murder, that it has kept the road open through the centuries to the place of skulls' are placed in opposition to an image of the earth which is specifically marked as female:

I say, may the very need of earth, which we have wronged but which we also have loved, and which, therefore, must forgive us (like the woman earth is), strengthen all the homeless on their dark journey tonight (Home p.11).

Male sexual maturity is concatenated with destruction and death and the earth is here identified with the female and the female is specifically constructed along a conventional model as an object of desire and as offering a source of emotional succour. The relationship between female characters and the natural landscape is represented as a reciprocal one in The Godwits Fly:

The bush loves Eliza, wants her.... she thought, 'I'll run away, live with the bush and never be turned out. It wants me, if nobody else does.... It's funny that the natural sounds never wound, never irritate. ... I feel as if they will take me, hide me, cover me up; and I never feel that about people' (Godwits. p.89). 95

95 A similar phrase 'I'll run away and live in the bush,' occurs on p.99. At the outset of the novel Eliza is represented as identifying with the earth to the extent that she feels death would hold no fear if it included being enveloped by nature: 'Lying on her stomach, with the brown, hot earth beating up at her ... Eliza thought she wouldn't mind dying at all' (Godwits p.15). A similar reciprocity is present in Eliza's relationship with the earth on her return from Sydney (quoted above). In Mulgan's text, the male characters are represented as having a combatative relationship with the natural environment, but the female characters are not shown to have a corresponding reciprocity with the natural 
The bush loves Eliza and Eliza loves the bush; the relationship between the two is nurturing, protective and reciprocal. The earth is represented as a fertile. nurturing mother and a place of refuge. It has 'quick soil, ready,' and 'feel[s] all contacts strongly through its veins and marrow' and 'children mov[e] inside its movement' (Godwits. p.108).

From these examples of the figurative language in Hyde's terts, the version of the relationship between women and nature presented there might initially seem very different from that presented in Christina Stead's 1934 story 'The Triskelion'. In that story (which contains several unmotherly mothers) the mother of one of the narrators exclaims:

How I hate those birds. And how I hate this everlasting gush and hiss of the sea, and those swishing trees... I hate nature: it is full of cries and tears like a female madhouse. 96

Although the female speaker in Stead's text declares her hatred for nature rather than her love of the bush, the simile used still constructs an analogy between the natural world and female nature. These connections are reiterated in Hyde's text, particularly those between nature and motherhood. In the section called 'Carly' there is a gruesome description of a woman giving birth: "The woman's knees sprawled out, and Carly focused her face, a blind, tormented face, torn in two every time it quacked (Godwits p.220). This description is

environment. They are represented only in their relationship to male characters, as relative creatures.

\% Christina Stead, 'The Triskelion' in Goodbye to Romance: Stories by New Zealand and Australian Women Writers 1930 - 1988, eds., Elizabeth Webby \& Lydia Wevers (Wellington: Allen \& Unwin, 1989), pp.5-18. 
followed by another passage which specifically links child-bearing to the natural world. The nursing Sister says:

And we don't call in the doctor unless it's absolutely necessary. or give them chloroform too early. It's better to leave it to Nature.

[Carly] got out of the cab a little way from Laloma, and wandered along by the side of the road. Broom-brushes touched her, and she saw how the dark pods, turning brown, were twisted and split to show neat little rows of seeds, ever so pretty. Fly far away....

White woollen babies; some girls had them as early as sizteen. She herself, if Trevor Sinjohn hadn't broken off the understanding, might have had a baby by now. All her girl friends did. She accepted the position mutely; they were right, she was wrong. It was right to be hideously tortured, like that woman on the high flat bed, so that in a little while you can say, 'Oh, isn't he a duck?' (Godwits p.221).

The nursing Sister talks about the childbirth in the context of 'Nature', and this idea and Carly's subsequent musings on babies are connected by a close observation of a piece of the natural world. However, although the passage quoted above implies an affinity between women and the natural world, it also starts to question the specific nature of the relationship between the two. It starts to interrogate the way in which the circumscription of woman's role by biology is construed as right and natural. This interrogation is conducted implicitly as well as explicitly in the text. 


\section{Essentialist notions of gender interrogated in Hyde's texts.}

In this passage, Hyde's 'tessellative' technique works to produce a series of images which evoke a set of associations with ideas in other parts of the text.97 This method of thematic patterning through the repeated association of image and idea allows the text to present detailed analyses of character and society by means which are both indirect and evocative. It is by virtue of this tessellative method that Hyde's text transcends the binary oppositions of realist or impressionistic, social objectivity or introspective subjectivity. None of the individual fragments are proselytising or have a wide scope but taken together they build up a wide ranging and detailed picture of a specific society and a particular analysis of that society. At the same time the inherent indirection of this tessellative narrative technique ensures the avoidance of the linear, univocal, totalizing perspective which characterises Man Alone. For example the image of the woman giving birth cited above is a fragment of description which is simultaneously realistic and impressionistic; 'sprawled' is both descriptive of a physical position and signifies the perception of a loss of physical control and dignity. The next piece of the description is prefaced by the attempt to see objectively, to 'focus' on the object under description, but what is seen, a blind, tormented face, torn in two every time it quacked, is described in terms which cannot be comfortably assigned as either literal or metaphoric, as either objective or as subjective and impressionistic.

97 The metaphor of tessellation seems to me an appropriate one by which to characterise Hyde's writing, as the images are simultaneously discrete and contiguous rather than being placed in a continuous sequence, yet it is their unstated relationship to one another which produces the thematic patterning of the text. 
The text shows up 'Nature' as a euphemism which forecloses on any questioning of the constitution of that 'Nature': the Sister's bland statement that it is best to leave things to 'Nature' is counterpointed by the text's demonstration that leaving women to 'Nature' is a euphemism for leaving them to suffer when there are means available to alleviate that suffering. The definition of nature as 'pretty' is also undercut in the text. The sentence about the broom pods, which starts in omniscient narration but then moves into free indirect thought, echoes the terms used to describe the woman in labour; 'sprawled' and 'torn' become 'twisted' and 'split'. Thus the text implies that the vegetative reproduction which necessitates the dehiscence of the broom pods is no more 'pretty' than the human reproduction which necessitates that the woman is torn in two. Through the narration of Carly's thoughts the passage shows how this image of birth which involves the destruction of the mother is recuperated into a socially acceptable version of birth. The sentence in question shifts from omniscient narration to free indirect thought at precisely the point that its focus shifts from the rupturing involved in the release of new life to a sentimentalised version of that new life. In this way, the sentimentalisation of childbirth is associated with the character of Carly, who throughout the text is shown to abide faithfully by the socially prescribed rules for female behaviour. ${ }^{98}$ Carly 'sees' only the product of the labour, the 'neat little rows', and this in a sentimentalised fashion, as 'pretty'. The 'white woollen babies' (p.217)

98 We are told that she wants to be a nurse because a dying friend describes nurses as 'angels' (Godwits, p.217) and thinks of the nurse in the terms provided by a jingoistic first world war ballad which describes her as a 'rose of No Man's Land' performing a salvatory function with respect to the 'curse' of war (p.219). In the chapter 'In Your Stupidity' we are told 'nobody could say Carly wasn't respectable' (Godwits p.162). 
which she imagines before witnessing the scene in the hospital are reinvoked afterwards (p.221). This image, which again is a socially acceptable and sentimentalised one, swiftly replaces that of the baby delivered in the hospital which 'isn't all right' (Godwits p.221).99

However the narrative is structured so that the disparities between the birth scene and the socially acceptable myths about birth are made apparent. The 'quack[ing]' of the mother being torn apart in childbirth returns in the sentimental reference to a new born baby and undercuts it. It is made clear in the text that the phrase 'Oh, isn't he a duck? (emphasis added) demonstrates a general social attitude rather than recalling a specific incident in Carly's past, and this, in conjunction with the way in which 'duck' recalls the context of 'quacked' (a context graphically associated with 'torment' and 'horror'), provides a biting critique of the disparity between the social construction of labour and its material circumstances. This disparity is further emphasised by the movement from free indirect thought to the employment of irony. 100

In the phrase 'It was right to be hideously tortured, like that woman on the high flat bed', the disjunction between the terms 'hideously

99 The red and white of the Red Cross Nurse (p.219) returns in another form in the 'pattern of scarlet and white' of blood and sheets at the birth of the baby (p.221). Again the tessellative technique emphasises this point about the disparity between what it is socially acceptable to articulate and the material conditions on which an articulation is based.

100 As Michal Peled Ginsburg points out, the difference between free indirect discourse and ironisation is that whereas with free indirect discourse it is impossible to decide that either the narrator or the character is the origin of an utterance, and that the voices exist in a 'structure of undecidability, where one cannot opt for either one or the other as being the "meaning" of the utterance', with irony its very presence 'is a sign of the distinction between' the 'voice of the character and the voice of the narrator which englobes it', and that therefore it is possible to 'distinguish clearly between two voices ... . which constitute the utterance'. Reference, Michal Peled Ginsburg. 'Pseudonym, Epigraphs, and Narrative Voice: Middlemarch and the Problem of Authorship,' English Literary History 47 (1980):p. 550,p. 552. 
tortured' and 'right', where it is a given of twentieth century western culture that torture is an infringement of a basic human right, makes it impossible for the reader to agree with the position articulated in Carly's thoughts. In its use of irony here, Hyde's text moves towards an examination of the construction of the position of woman and provides a critique of the apparent 'naturalness' of this construction in the society which the text represents. Hyde's text starts to move beyond the essentialist view which simply valorises a direct correlation between woman and nature or makes presumptions about the naturalness of woman.

Interrogations of the assumptions about the 'nature' of woman are apparent in other parts of this text as well as in Hyde's other texts. The term 'woman' is thrown into question whenever its limits are transgressed. That Eliza Hannay claims not to be a woman for 'ordinary purposes' raises the question of what the 'ordinary purposes' are and how these 'ordinary purposes' contain and construct the term 'woman'. To Eliza's assertion that she too can go to London. Timothy replies 'You can't, a woman couldn't' (Godwits p.162). Timothy's reply is articulated as a statement of fact, not an opinion, but since throughout the text the godwit plan has been positioned as a part of both Augusta's and Eliza's dream, his assertion of the impossibility of Eliza making the journey on the grounds of her biological sex cannot be taken for the 'fact' which Timothy's articulation suggests. Timothy's denial makes no distinction between what might be socially imposed limits on action and what might be inherent biological limitations and the reader is positioned to reject Timothy's point of view. In this chapter, 'In Your Stupidity', it is made clear it is the force of social convention which produces Timothy's response and which makes no 
distinction between biological constitution and gender roles. The text's moves produce a critique of this obfuscation and the restrictions it produces. Eliza's comment that she is 'not a woman; not for ordinary purposes' suggests that the only way to escape from the constriction of the gender role ascribed to female is to deny her biological sex by 'turnling her] hair up under a cap' and becoming a 'cabin-boy' (p.162). Hyde's text here attempts to challenge the esssentialist notion of a direct correlation between female sex and the prescription of gender roles although it cannot articulate its moves in these terms. What is implied in the text is that being a woman is a position which is constructed rather than one which is connected to biological constitution.

In Hyde's other texts, other female characters are also shown taking up positions not necessarily identical with those presumed to be natural to their biological sex. In Wednesday's Children both Pamela and Attica are described as boyish. Pamela has 'cool schoolboy lips' when she kisses Wednesday (WC, p.100), and the term is repeated later where the kiss again has the same adjective attached to it (p.167). Later on in the text, when Attica's hair is bobbed it is her whole person and not just her hair cut which is described as a 'page-boy' (WC p.194). These terms which apply to the opposite sex are all presented in a contert of approval rather than as pejorative terms, and these characters are ones for whom the possibility of less constricting gender roles are indicated.

Although in Hyde's texts there is not the explicit analysis which argues that gender roles are socially constructed (as there is in a text 
like Virginia Woolf's Orlando for instance 101 ), the radicality of the position with regard to gender identity taken up implicitly by Hyde's texts is illustrated by the difference between the analysis which they present and the analysis present in the literature of the day. For example, Sheila Kaye-Smith's Joanna Godden ostensibly provides a positive portrayal of $L$ independent woman owning and running a farm and even deciding to have a child out of wedlock. ${ }^{102}$ However, the text sanctions her actions, not from a feminist position which envisages a role for woman outside the confines of the nuclear family or outside the contemporary constructions of femininity, but insofar as Joanna Godden's actions uphold the patriarchal beliefs of the Catholic church about womanhood and motherhood.

Hyde's texts do attempt to articulate the distinction between sex and gender whereas in other contemporary texts this distinction is only revealed in the attempt to deny it. Whilst in Hyde's texts assessment and categorisation by biological criteria is often transgressed, in the (supposedly) non-fiction texts of journalism the ways in which the lives of women exceed their biological categorisation is resisted.

The article given in full in figure 5.1 below, entitled 'Being a Girl', appeared in the Farmer's Union Advocate for 29 July 1922 (it was reprinted from the English The Daily Mail). This piece of journalism from the twenties suggests considerable anxiety about gender roles, and in particular the anxiety to fix gender roles, but paradoxically in the passage below, the attempt to fix the term 'girl' (and to deny the

101 Virginia Woolf s Orlando: A Biography was first published in 1928 by The Hogarth Press. Orlando clearly articulates the notion of gender identity as constructed rather than the product of an essential biological determination.

102 Sheila Kaye-Smith, Joanna Godden (London: Virago). 
semantic derogation which characterises it) serves to highlight the distance between biological sex and gender role, to highlight precisely the way in which being a 'girl' or being a boy for that matter is learnt rather than innate behaviour, as well as making it increasingly plain that the term referring to the female is the devalued half of the binary opposition.

Some of the contradictions in the article are suggested in the way in which the term 'girl' collapses on itself in the course of the discussion. The passage simultaneously highlights and denies the semantic derogation of women displayed here. The shift in signification which the writer here wants to indicate is problematic. It is trying to describe a new type of femininity, but still takes part in a semantic derogation of women, where the signifier is simultaneously the label for a female child, the label for particular attributes of which society approves in women 'brave, generous, fair minded' (as opposed to 'gentlemen unafraid'), and the castigatory term for faults associated with the feminine. There is a presupposition of a semantic separation which is not possible, as the progress of the article shows the difficulties of making such a distinction. It reinscribes the old tropes of girlishness as it tries to eradicate them because it implies that the negative connotations of 'girl' are a product of the innate characteristics of certain bad females who bring the rest into disrepute. What the passage does, in fact, is reinforce a particular cultural model of female behaviour, a particular construction of the feminine.

The passage actually contains the assertion that 'girl' (as term of abuse) has nothing to do with girls in modern society (which would imply that the term is the label for a particular social construct, a constellation of qualities unconnected to gender, which are not socially 
(By the Princess Nusrat Ali Mirza, 'Elizabeth Marc')

Various writers of letters to 'The Daily Mail' have complained against the apparently unchivalrous attitude of teachers and guardians who train youth to manhood by the constant exhortation to behave like a man and not like a girl.

But 'behaving like a girl' has today a special significance that has nothing to do with the feminine world in general, but with one kind of female in particular. And she is nearly obsolete - in the younger generation at any rate.

In every girl's school or Guide's camp the reproach 'How like a girl!' is hurled - believe me, it is heard more often among girls than in boys schools.

To be mean, to sneak, to funk, to cry for insufficient cause, to be (pe)tty, to be dishonourable - all of these things in a community of girls earn the instant opprobrium, 'Oh, how like a girl! Just like a girl'

The girl of today, watching her younger brother funk a cricket ball has no more bitter taunt than 'Girlie! girlie!'

The boy, seeing his small sister weep over a dead goldfish, can think of no greater stimulus to philosophy than: 'I say - buck up! You're behaving like a girl!

Ask the schoolboy what his sister is like. And if you have sufficiently earned his confidence he will say: 'Oh, she's a regular sport. Not a bit like a girl.'

And the mother of to-day inculcates self-control, courage, unselfishness, and fair play by the constant reminder, both to Mary and John, that unworthy behaviour 'is just like a girl you know.'

But 'the girl' of the taunt is not the girl of to-day.

She passed away with the dames' schools 'for the daughters of nobility and gentry.' She screamed at a mouse and fainted at the sight of blood. She wrote poetry and kept a confession book; she breathed spite at school just as she whispered scandal when she grew up. She was the girl of the parlour - not the playing fields.

When the boys and girls of to-day are told not to behave like 'a girl' they make no mistake.

'A girl' does not refer to their mother, their sister, or anyone they are likely to love.

'A girl' has nothing to do with the brave spirits who marched with the men in the great war.

On the contrary, it typifies the girl who all women avoid and whom all mothers pray their sons may escape; the mean, 'catty.' jealous woman who snatches unfair advantages and stoops to any meanness to gain her ends.

The teachers and parents who are teaching boys to be 'gentlemen unafraid' and girls to be the brave, generous, fair-minded women of the twentieth century offer no insult to womanhood when they urge young 1922 not to 'behave like a girl.'

That girl is in the lumber-room of the past, with the woollen antimacassars and the wax fruit ${ }^{103}$ 
desirable); however, it then relocates the word as a term whose referent is a particular sector of the female population, and ends with the implication that it is the correct education and exhortation from teachers and parents which can teach girls and boys not to be 'girls'. One is reminded here of Maxine Hong Kingston's comment on the double signification of the ideograph which means (specifically female) 'I' and 'slave': 'There is a Chinese word for the female I - which is "slave". Break women with their own tongues!'104 The term 'girl' in the passage under discussion acts in exactly the same way; for a girl to name herself a girl is take on the label of opprobrium.

So, whilst this piece of journalism actually reveals the separation of sex and gender in that it suggests that 'being a girl' is a position which can be taken up by individuals of either sex, it does it inadvertently. In the passage there is an awareness of a shift in gender roles, that there is a 'modern' girl whose social constitution is somehow different from the social constitution of her predecessor, but the article still insists on inscribing gender difference (in the form of stereotypes) and gender discrimination (in the different values invoked as the aim for the girls and boys as adults) whilst implying that there is sex equality and denying the semantic derogation displayed in the terminology. In Wednesday's Children the description of both Pamela and Attica as 'boyish' presumably invokes for them the approval that neither 'masculine' nor 'girlish' could.

The transgressions of conventional gender demarcations in Hyde's texts which are outlined above do serve to articulate a distinction

104 Maxine Hong Kingston. The Woman Warrior, ( London: Pan Books-Picador, 1981) p.49. 
between sex and gender. However, the clearest demonstrations of a radical split between sex and gender occur not in Wednesday's Children, but in Passport to Hell and Nor the Years Condemn.

Starkie's misfitting is not represented just in terms of racial or class identity. His location in relation to the gendered positions available in the world of the text is in oscillation. An implicit critique of the constriction of rigidly assigned gender roles can be seen in the way that whenever Starkie is seen to relinquish a conventionally masculine gender role, his situation is granted some sense of security and happiness, a momentary sense of 'home', of the resolution of the problems of location and identity that are consistently foregrounded elsewhere in the two texts by Starkie's continual shifts of physical, geographical and domestic location. At the same time, wherever his actions serve to reinforce the conventional male roles and male privilege, the situation or structure in which he carries out these moves is made or becomes intolerable.

In Passport to Hell aboard the Kittawa, Starkie is depicted as happy carrying out the domestic function usually ascribed to the female domain. It is only when he becomes involved in a struggle for mastery with another male that the situation becomes uncongenial (pp.19-22). In Nor the Years Condemn one of the few moments of peace and security which Doug is allowed occurs in chapter XI, 'White Australia,' when he becomes 'house-boy' for four young women in Sydney:

Four girls Starkie met in a wine-shop, Jean, Olive, May and Gertie, took him home to their flat at Barlinghurst and made him their house-boy for the few days he stayed in Sydney.... Starkie did their cooking, lit the chip-heater, tidied up, minded the flat, wearing Olive's apron.... They slept four in the one big bed, with Starkie curled up by the stove in the kitchenette (NYC, p.218). 
The young women give Starkie money for his train fare when he moves on. The conventional gender roles are completely reversed; the women go out to earn money whilst the man stays at home and provides food and domestic comfort. The household is an unorthodox one structured on female communality ('They slept four in the one big bed'), one in which the male presence is marginalised ('with Starkie curled up by the stove in the kitchenette'). In contrast to this, in the same chapter, is Pat and Elsie's household where Starkie also stays briefly. The members of this household are an apparently hen-pecked husband, (though he is the one who holds the ultimate authority), a nagging, racist wife who believes in Christian Science (and takes an instant dislike to Stark), and an adolescent son who has piano lessons and keeps rabbits.

Starkie perceives the child as effeminate, which he sees as a fault, and locates the relationship between the mother and the child as responsible for producing the effeminacy: ' . . . a nice kid, with floppy hair and a crystal set, shouldn't be called Claudie and stick to rabbits after he's fourteen, and be chivvied about his practising ... ( p.212).

Starkie tries to provide a conventionally masculine role model for the young child in that household by telling him stories of the war and buying him a bulldog pup. It is these actions - which reinforce conventional gender stereotypes - which make it impossible for him to stay in that household. Starkie's desire to make Claudie more 'manly' is twofold. He is disturbed by what he registers as the signs of the child's effeminacy - the cognomen, keeping rabbits and taking an interest in music - and by the child's relationship to the mother. As a 
replacement for these signifiers of femininity he gives to the boy a classic signifier of male aggression - a bulldog, which is both a threat to the mother and a liberation to the child. He wishes to intervene in the power relationship between mother and son, wishes to see the son represent himself as an independent male rather than a child under female jurisdiction. In telling Claude war stories he is initiating Claude into the 'fraternity of men' (p.212). As Starkie embarks on this initiation process, Claude's father comments 'Boys will be boys' (p.208), but the text makes it clear that it is social conditioning, not innate propensity, which makes boys into the sort of men whom Starkie recognises as 'manly'. Starkie's success in his endeavour is measured by the degree to which the boy now devalues his mother's nurturing activities: Elsie cooks the boy his favourite meal, but the boy is so taken up with the bulldog that he now takes for granted the care extended towards him.

This incident is shot through with the formations of conflicted subject positions. Elsie is an oppressed female, but she is part of a white majority and reinforces the operations of racism. Starkie is oppressed by racial discrimination but his behaviour in this instance is misogynic and homophobic. The passage delineates the way in which each contributes to the other's oppression and through using a mixture of dialogue, indirect thought and free indirect discourse, the passage creates sympathy for both parties. ${ }^{105}$ In this dynamic Pat, the father, is shown to be the only one who does not suffer from any form of

105 This encounter strongly resembles the Miranda complex which is articulated by Laura Donaldson, in that the two subjects who are the subjects of oppression cannot see each other as such and consequently each collaborates in the other's oppression. Laura E. Donaldson. 'The Miranda Complex: Colonialism and the Question of Feminist Reading.' Diacritics Fall 1988, pp.65-77. 
oppression, and in this way the text shows how the construction of the white, male, heterosexual as normative operates in the production of racial and sexual discrimination.

It is Starkie's active attempt to promote and reinforce male dominance and male heterosexuality which results in it being no longer possible for him to stay in a domestic and geographical location which is otherwise clearly congenial to him: his 'stomach' is 'replete, his body drowsily comfortable, and he like[s] Australia' at this point in the text (NYC, p.207).

Starkie's gender position oscillates in the two texts between an identification with masculine and feminine positions, but where he is ultimately located at home at the end of the second text is in an extremely feminised position. He is the caregiver in an unconventional domestic structure and does not claim any right of possession over the woman and children in that household. Although the household might initially appear to be conventionally composed of man, woman and children, within that family unit, the power and blood relations are very different from those in a typical nuclear family. The mother is not the biological mother of most of the children and neither is Starkie the biological father of most of the children. The two adults are not married and and power relations between the two completely inverted.

When Starkie articulates a stereotypical and negative view of women as either sex objects or 'nagging' shrews it is controverted by Dorrie, the fruit lady. 106 When he tries to kiss her against her will, she

106 In Sargeson's stories. 'The Hole that Jack Dug' for example, this type of stereotypic and negative representation of women is presented uncritically. 
retaliates and he realises that she is 'neither frightened nor enchanted' (NYC p.335). It is Dorrie who reverses the position of dominance and who eventually makes the successful sexual advance towards Starkie, and when Starkie threatens to cut Dorrie's throat she remains completely unintimidated. The text suggests that the violent masculine identity which Starkie demonstrates is a position which is taken up rather than atavistic behaviour. Starkie says ' "The others wasn't like that. I'd got to be the Killer, eh?" ' (p.343). Dorrie dismisses Starkie's naming or identifying himself as the 'Killer' and helps to replace that version of himself and his masculinity with the possibility of a more productive (more núturing) identity. His redeeming feature is seen to be his commitment to giving the children a home and keeping them out of a 'Home'107 (p.339).

It is the financial power of Dorrie and her social standing which enable Starkie to have his home; it is Dorrie on whom he is dependent, and without whose help he cannot manage. Consequently, she has the power to lay down the conditions under which she will help him (which is a direct reversal of the conditions of his earlier marriage to Terry), and when she displays aggression towards him in threatening to cut his throat the purpose of the threat is to ensure the welfare of both Starkie and the children.

In the relationship between Starkie and Dorrie, Starkie moves from reiterating conventional and stereotyped notions of women and similarly stereotyped notions of himself as a man, and from reinforcing conventional assumptions about the power relations and sexual

107 'Home' of course here refers to an orphanage which is the antithesis of any of the positive possibilities for home offered in the text. 
relations between men and women to an acceptance of a subordinate, supervised and conventionally feminine position. In other words, the problems of identity and location are ameliorated for him when he relinquishes the privileges of the male position in the nuclear family and takes up a gendered position which is very different from that usually associated with the male ser. 
The problems with an essentialist feminist critique of Hyde's texts.

It is in making the distinction between sexual identity and gender identity and in envisaging the possibility of differently constructed gender identities that Hyde's texts articulate a position which moves beyond essentialism. Unfortunately, some of the recent feminist criticism which attempts to valorise Hyde's writing does so on the grounds of an essentialism of which I have argued Hyde's texts offer a critique. Both Shelagh Cox and Susan Ash read Hyde's Wednesday's Children as a celebration of a specifically female form of creativity. ${ }^{108}$ Both these critics comment on a passage in the opening chapter of Wednesday's Children. 'Wednesday Enters for the Doubles' and I will discuss their comments and the passage in detail in order to outline some of the ways in which an essentialist feminist reading of this text both overestimates and underestimates the potential radicality of Hyde's text.

In an extended passage at the opening of Wednesday's Children the main protagonist, Wednesday Gilfillan, is presented in a number of guises:

But the drunken man remembered yet more of his youth. With wonderful clearness he saw the great rosy and crystal wings unfold behind her head. He saw the lissom slightness of Wednesday's body, and how it could dance like a mad shepherdess, who is nevertheless at heart so respectable that she might easily induce Pan to wear pants. He saw Wednesday girt about with symbols, corn-sheaves, stout doves and olive branches.

108 Shelagh Cox, 'Creating a Bearable World: Imaginative Transformation of an Alien Society in the Fiction of Robin Hyde \& Angela Carter,' Women's Studies Conference Papers 1982, pp.11-18; Susan Ash, introduction and afterword, Wednesday's Children (Auckland: New Women's Press, 1989), pp.5 - 7, 289 - 95. 
'Scuse me,' he stammered again, weak but defiant, 'I think you're beautiful.' He repeated 'beautiful' several times softly and with awe, like a priest at a ritual ....

'I'm glad you think so,' she said, and went on, feeling the silvery rain slip round her like a garment. She was glad that the drunken man had mentioned she was beautiful, glad that all men whosoever should see and know it. It was true. That she was a vole was also undeniable, but Naples would have been the first to flatten the nose of anyone who suggested that voles are not lovely and pleasant in their aspects, as in their lives and personal habits. Behind her voleishness the other and taller presence shone out. It could carry wheat-sheaves and poppies without looking incongruous. It was a sort of domesticated angel, yet not without a sense of humour. Men found it irresistible. Only temporarily, Wednesday had to admit. She supposed that was because at moments of crisis, such as happen in the best-regulated love affairs, she lost her grip of the wheat-sheaves, and sat huddled up, just a vole (emphasis added, WC p.18, ).

In commenting on this passage, Shelagh Cox identifies the angelic vision as something positive, as a product of a 'power of transformation,' as a productive alteration in the way of seeing. She states, 'The world to be seen is unaltered: it is the way of seeing that varies.... Wednesday's own method is exemplified by a contrast that takes place at the beginning of the novel. Two people see her in Auckland. One is a drunk who has the power of transformation .... A clerk in a newspaper office is not lucky enough to possess this power. Cox continues to valorise this transformed vision as an escape from what the 'code of respectability permits one to see,' (Cox, p.12). What she glosses over in her syntaz is the distinction between seen and seer, object and subject, transformer and transformed. In an attempt to celebrate female creative and visionary capability, she makes an implicit and mistaken correlation between the female protagonist's transforming power and the angelic vision. Because the feminist politics of her analysis are grounded in essentialist assumptions, Cox's 
critical position demands that the transforming power is attributed to females rather than males: this results in the attribution, in her article, of the transforming power to Hyde the author and to various female characters, and a subsequent lack of attention to the fact that it is a male character who initially possesses the 'power of transformation:

However, it seems to me that the distinction referred to above (between seen and seer, object and subject, transformer and transformed) is crucial in an analysis of the sexual politics of the text. It is in the sight and consciousness of a drunken male bystander that the transformation takes place, and this in no way under the control or will of the protagonist. It is his definition of beauty to which Wednesday is subject. Cox's commitment to celebrating female powers of transmogrification means that following on from her misattribution she is unable to produce a critique of dynamics within the passage. The whole opening chapter, it is true, continually emphasizes the functions of the imaginative process and of perceptual difference in the construction of reality. These functions, it is implied, allow individuals to construct possibilities beyond the restrictions normally imposed by the cultural hegemony.

However, what the drunken man recollects is his own youth, by using his imagination, his 'power of transformation' to regain for himself the lost sexual potency of his youth; the image he projects is that which is concomitant with the object of his youthful desire. Cox wants to read the text as prescriptive, because she wants to see Wednesday as the active subject of her own mythologies and in control of an exclusively female creative power, but here Wednesday is the passive object of a male gaze and the terms in which the object is thus 
viewed within the text are male authored, male engendered and therefore more constraining than Cox's analysis might suggest.

Susan Ash in a 'Critical Afterword' to the republished text of Wednesday's Children identifies the fact that the transformation takes place in the consciousness of the Auckland drunk, whom she terms an 'ideal seer' (WC p.289), yet rather than questioning the nature of the vision, she too celebrates the 'female imaginative realm' (WC, p.294). She claims that Hyde uses 'mythological allusions to move beyond an affinity with the natural world, to ally Wednesday with the primitive goddesses and to endow her with inherent magical power' (WC p.289). Both Ash and Cox see the angel and goddess image into which the character is transformed as being positive and both designate the realm of the imagination as specifically female.

The analyses which Cox and Ash offer are based in the AngloAmerican school of feminist criticism. ${ }^{109}$ In both accounts there is an attempt to redress the critical neglect or dismissal of Hyde's work and the way in which it represents female experience by paying attention to the images of women in the text. The criticism offered by both Cor and Ash is valuable in that it does take the novel seriously, whereas

109 The terms 'Anglo- American' and 'French' when used to describe feminist criticism refer not to the nationality of the critic but to the broad theoretical position within which the critic is working. Anglo-American feminist criticism works within humanist and essentialist presumptions. 'Gynocriticism' is a term which was introduced by Elaine Showalter in the essay 'Feminist Criticism in the Wilderness' published in 1981 in Critical Inquiry 8.1. pp.179-205. It is republished in Writing and Sexual Difference ed. Elizabeth Abel (Chicago: University of Chicago Press, 1982). pp.9-35. In that article she make a distinction between two types of feminist criticism, 'feminist critique' which re-reads male texts and offers a feminist critique of the images of women presented in them and 'gynocriticism' which deals specifically with writing by women, and analyses the way in which it differs from men's writing. 
earlier masculinist criticism had been negative or dismissive. ${ }^{110}$ For example Frank Birbalsingh finds no problem in articulating his own inability to read the text as a fault of Hyde's writing:

'Although some episodes are clearly drawn, it is difficult to tell which episodes are actual and which are imagined by the heroine.... And since we either cannot believe or understand them, we are inevitably puzzled and left with a general impression of uncertainty (Birbalsingh, p.364).

Although Birbalsingh claims to be commenting on the London 1937 edition of Wednesday's Children in his footnotes, his brief summary of the plot of Wednesday's Children bears very little relation to what appears in that (or any) edition of the text:

These fantasies principally concern Wednesday herself, her miscellaneous lovers, her children and relatives. In one fantastic adventure she gets into bed with her dog; in another she tries to earn money as a sorceress and is convicted for it; in a third, her daughter Attica kidnaps a child; and in a fourth, her son Dorset visits the Holy Land. Even if some of these adventures can be understood individually, they cannot be said to join together into a plot that conveys clear meaning (p.364).

Only one of the adventures which he relates is accurately represented in his summary. Wednesday finds her son's dog keeping warm in her bed when she retires for the night; she does not act as Madame Mystera for financial gain but for the general well being of the individuals and the community of the Auckland slums; and Dorset

110 A Feminist Dictionary (London: Pandora Press-Routledge, 1985) p.258, credits Rebecca West with the first written use of this term. It gives a quotation from a piece by West in the Manchester Daily Dispatch, November 26 1912: 'Mr Edgar takes the usual masculinist standpoint of regarding women as incompetent weaklings except for their maternal functions.' The dictionary further defines the term as 'male supremacist' and adds a parenthetical comment that the term is 'not a symmetrical concept' with 'feminist'. In the context in which I use it, 'masculinist' is intended to indicate a standpoint which claims to be neutral but has an inherent gender bias, and takes the male as normative. 
is hi-jacked by an inmate of a lunatic asylum and doesn't go anywhere near the Holy Land. Cox and Ash providing an essentialist feminist analysis of the text have no problem in deriving a 'clear meaning' from the plot. They draw attention to the way in which Wednesday's Children delineates women's oppression and offers a critique of the relations between men and women; Ash usefully suggests that the text provides a critique of 'a society which marginalizes and trivializes female experience' (WC, p.295).

Although James Bertram does not suffer from the comprehension problems under which Mr Birbalsingh labours, in his commentary on Wednesday's Children he is content to repeat E. H. McCormick's dismissive comment that the text is "fantasy without ballast and a distaster" ' and to add a few more of his of own:

Certainly it is an unsatisfactory book, this fairy-tale of a woman who defies her family and the conventions, and lives on an island in Auckland harbour with (as she claims) a startling brood of children by a series of exotic lovers - until finally a real suitor arrives to shatter her dream-life and her illegitimate dream-children. ${ }^{111}$

From the phrasing of his sentence and his lack of specificity it would appear that, in Bertram's view, what makes the text unsatisfactory is its subject matter. The only value which Bertram ascribes to the text is that it is 'true to the writer's own inner experience' (Bertram, p.183). The commentary which Cox and Ash provide is within a framework which asserts the validity of domestic 
and emotional life and female experience as appropriate subject matter for a serious novel. 112

However because of their anxiety to counter the explicit and institutional discrimination meted out to Wednesday's Children by masculinist critics with feminist accounts of the text, it seems to me that by working within an Anglo-American gynocritical framework, both Cox and Ash repeat some of the limiting critical practices of their masculinist colleagues. They simply reverse the masculinist assumptions that male action and event are the appropriate and central concern of literature to replace it by an assumption that female imagination and creativity should be the central concern of literature: they do not question the assumption that experience can be divided up into male experience and female experience. Like Bertram, the two feminist critics value the text for its autobiographical content: $\cos$ continually blurs the distinction between author and protagonist and Ash draws parallels between the life of the author and the path of the protagonist. All these critics share the implicit assumption that there is essential female identity and essential male identity and that the two are binarily opposed: they simply value the terms of the binary opposition differently 113. All these critics share the assumptions that the female is 'of her nature' connected to the realm of the irrational, the imaginative and the insane rather than the rational, the logical and

112 It is a contention of many feminist critics that men's actions and concerns have been deemed the only appropriate subjects for valuable literature by male writers and male critics. Elaine Showalter's A Literature of Their Own (London: Virago, 1978) is one of the most well known critiques of this kind.

113 Ash in particular talks of Wednesday 'creating female stories and shaping female experience'( p.292), of her '"authentic" ... essential existence'(p.293). 
the sane, but $\operatorname{Cox}$ and Ash value rather than disparage the female half of the binary opposition. Ash claims that

fantasy (like madness) is a valid, powerful means for creating alternatives to unacceptable possibilities in women's lives. . Wednesday's suicide is not a failure to live in the 'real' world, but rather a disavowal of a society which marginalizes and trivializes female experience (p.295).

A reading which celebrates the alignment of the female with the insane runs the risk of reproducing the mechanisms by which the oppression of women has operated. Elaine Showalter's warning about the dangers of reading madness as a form of protest or resistance is very pertinent to Ash's argument which 'comes dangerously close to romanticising and endorsing madness as a desirable form of rebellion rather than seeing it as the desperate communication of the powerless.'114

Rather than endorsing madness as 'valid and powerful' and cheering suicide as a productively rebellious act (both of which seem highly dubious claims), a more profitable avenue for the feminist critic might be to follow the lead suggested by Carter in The Sadeian Woman and start with the presumption that all the mythic versions of women, from the myth of the redeeming purity of the virgin to that of the healing, reconciling mother, are consolatory nonsenses' and to explore the way in which the mythic representations in the text function and examine how they deal in 'false universals' which 'dull the pain of particular circumstances. 115

114 Elaine Showalter, The Female Malady: Tomen. Madness and English Culture 1830-1980 (London: Virago, 1987), p.5.

115 Angela Carter, The Sadeian Woman: An Exercise in Cultural History (London: Virago, 1979), p.5. 


\section{Interrogating the domesticated angel.}

Both Cox and Ash celebrate the representation of Wednesday as a 'domesticated angel,' but neither of them connect this figure with the Victorian 'angel in the house.' Yet there are striking similarities between some aspects of the representation of Wednesday Gilfillan and that of the paradigm of angelic domesticity, Honor, the poet's wife in Patmore's The Angel in the House. ${ }^{116}$

The opening and closing sections of The Angel in the House contain depictions of Honor as the loving mother of many children and in Wednesday's Children the importance which Wednesday places on mothering is reiterated throughout the tert. In 'The Rose of the World', the first prelude to Canto IV. Honor is described as possessing a 'countenance angelical' on which the 'best things that the best believe I... are kindly writ' and where the 'faithless, seeing her, conceive/ Not only heaven but the hope of it; ( $p .23)$. The text suggests that she inspires people to see beyond this life to something else when they look at her. Wednesday similarly inspires a vision of 'great rosy and crystal wings unfoldling] behind her head' which indicate an 'other and taller presence' (WC p.18). Elsewhere, Honor is simultaneously likened to an animal and an angel:

... like a bird/

Sole warbling in a windy wood;

And when we knelt, she seem'd to be

An angel teaching me to pray; (Angel, p64).

116 Coventry Patmore, The Angel in the House (London: George Bell \& Son, 1905 ). Further references to Angel in the text. 
Ash specifically celebrates these qualities in Hyde's protagonist. She cites with approval Wednesday's ability to 'nurture her family; her resemblance to a vole, a seal and a fawn, and her role as a visionary as well as her kind alleviation of others' pain and her desire for the perfect child (WC, pp.289-90). It is in this correspondence between the paradigm of Victorian femininity and the 'female hero' of a feminist analysis that the problems of essentialism are made explicit, for it is precisely this 'angel in the house' that a whole series of feminist thinkers have been trying to remove.

Virginia Woolf gives her now famous account of the encounter with the Patmoresque spectre:

The shadow of her wings fell onto my page; I heard the rustling of her skirts in the room. Directly, that is to say, I took up my pen in my hand to review that novel by that famous man, she slipped behind me and whispered: ' my dear, you are a young woman. You are writing about a book that has been written by a man. Be sympathetic; be tender; flatter; deceive; use all the arts and wiles of our sex. Never let anyone guess that you have a mind of your own. Above all, be pure... I turned upon her and caught her by the throat... Killing the Angel in the House was part of the occupation of the woman writer. ${ }^{116 a}$

Not only is the domesticated angel a figure which is abhorred by one of the most prominent voices in twentieth-century feminist letters, but it is a figure which reproduces a particularly reactionary construction of femininity, and one moreover which is identical to the ideal version of woman promoted under German and Italian fascism in the 1930s. If killing the angel in the house is one of the main tasks of the woman writer (or rather the feminist and non-reactionary woman writer), and Hyde's text seems to reproduce rather than dispense with the figure, how can Hyde's text be read in a way that does not consign the text to

116 a Virginia Woolf. 'Professions for Women' in The Death of 
a complicity with conservative (or even fascist) politics? The answer to this question cannot be found in a recourse to essentialist feminist accounts, not only because they value the same qualities that are valued by a reactionary politics but also because the essentialist feminist accounts implicitly denominate the realm of subjective experience and vision as female and the world of action and event as male, which leaves them unable to take in to account the larger historical and political concerns signalled in the text.

I argue that it is precisely the positions taken up in relation to the political concerns in the text which allow a more productive analysis of the female protagonist of Wednesday's Children. 


\section{The role of women in fascist ideology.}

In the discussion that follows I will briefly outline the construction of femininity produced from within the German and Italian fascist movements. (As suggested above, this version of female identity is very similar to that valorised by the essentialist feminist accounts.) I will then go on to suggest that the explicit engagement of the text with a world politics of fascism and imperialism has a direct bearing on the way in which the figure of Wednesday Gilfillan can be read in the text. The radical nature of the domestic relationships in the text becomes more explicit when read in conjunction with the text's interrogation of imperialist and fascist politics.

Fascist ideology effected a reappraisal of the role of women.117 According to Maria-Antonietta Macciocchi they were forced out of the workplace, back into the home and back into the stereotyped roles constucted for them in the nineteenth century. In Mein Kampf Hitler placed women's reproductive function as the highest service they could offer to the state:

Even more imperative than the shared work is the duty of men and women to perpetuate the human species. It is the nobility of this mission of the sexes which is the origin of the natural and specific gifts of providence. Our task is higher...the final goal of genuinely organic and logical evolution is the foundation of the family. It is the smallest unity, but also the most important structure of the state (Macciocchi, p.73)

117 The following account is drawn from several sources, mainly from MariaAntonietta Macciocchi, 'Female Sexuality in Fascist Ideology' in Feminist Review 1 (1979), pp.67-82, but also from Claudia Koonz, Mothers in the Fatherland (London: Methuen, 1988). Both Macciocchi and Koonz make explicit reference to the Woolf passage quoted above in their elaboration of the relationship between femininity and fascism. 
Women's function within the state, that of motherhood, of giving birth to the nation, prioritized above all else, is arrived at through the family and vice versa. The family is placed in microcosmic relation to the state so women's relations to the one are always contingent upon the other. In Mussolini's Italy, on 18th December 1935, one month after the sanctions imposed by the League of Nations following Italy's aggression against Ethiopia, Mussolini declared The Day of Wedding Rings and asked women to give their gold wedding rings to the state. 118 In return Mussolini gave each woman an iron ring, in effect marrying her to himself and the economic and military endeavour of the state. Macciocchi further anaylses the conflation of women's public and private function within the state.

In marriages celebrated under Fascism, the bridal couple would receive not only a prize of five thousand lire (a paternal dowry from the Duce), but also a copy of the encyclical 'Chaste marriages' .... This encyclical imposed on the woman a single vocation, that of serving her husband after the ceremony; on the couple it imposed a very pure marriage with the sole aim of procreation. The woman was cheated even in 'her propriety' of her sons who, by virtue of the law and in all the Catholic practice and theory, were to all intents the husband's absolute property once again. But of which Husband ? (Macciocchi, p.76).

She goes on to explain how Mussolini throughout his speeches speaks of 'sons of Rome' and 'sons of Mussolini's Italy', which conflates the ideologies of patriarchy and fascism, and constructs women as devoid of sexual desire, devoid of autonomy, but continually sexually available for their procreative function within a legitimate marriage. One can see here, in an extreme form, the version of female identity

118 The significance of the Italian invasion of Ethiopia will be discussed below. 
that is contained in the vision of the Auckland drunk when he looks at Wednesday Gilfillan. It is a vision of the conflation of sexual availability, domesticity and chastity.

Chastity was an important element in the policies on race produced by both Italy and Germany. Both fascist states manifested considerable anxiety about the legitimisation of patrilineality where the purity of the nation was at stake. Hitler's theories on the 'master race' are well known and Mussolini felt compelled to assert his own version of 'racial purity' in his Manifesto on Race after the grounds of racial inferiority had been used to condone aggression againt Ethiopia. 


\section{Abyșinian Campaigning.}

In this section I will briefly examine the context of international politics which Wednesday's Children sets up and I will discuss the ways in which this context allows a reappraisal of the 'domesticated angel.'119 It has gone completely without comment that Wednesday's Children is set with great historical specificity against a background of world politics in 1935, and in particular against the Italian invasion of Ethiopia under Mussolini's fascist dictatorship. References to the sphere of international politics is contained in the opening of the first chapter. We are told that there are

.. still some Flat-Worldians, or as Swift called them, BigEndians, who have not yet been trained by crossword puzzles, the increasing strangeness of politics, or the mystery of the League of Nations (which is so rapidly replacing that of the Holy Trinity in modern life) to use their imagination. (emphasis added, WC p.13).

What may seem initially to be an eclectic and almost quirky collection of ideas contains a reference to a context that will be reinvoked throughout the rest of the text. Thus the 'increasing strangeness of politics, or the mystery of the League of Nations,' are not whimsical irrelevances. They serve to construct in this text a background of world politics in relation to which the domestic events of the narrative must be understood. 120 .

119 It is interesting that Susan Ash complains of the way in which female writers (in this case Mansfield) are depoliticised 'by denying that specifically female experience has a politcal dimension. For Sargeson, Fairburn and likeminded critics, events and details common to female experience and the "larger social context" are mutually exclusive' (diss., U of Otago, p.11). However she herself is silent on the explicit political context of Wednesday's Children.

120 My account is drawn from those of Keith Sinclair in A History of New Zealand (London: Allen Lane-Penguin, 1980), p.276-79, W. H. Oliver in The Story of New Zealand (Wellington: Oxford UP, 1981), pp.228-243 and F. L. W. Wood in New 
The League of Nations was founded after the 1914-18 war with the aim of preventing further armed conflict and ensuring peace and freedom. As a signatory to the Treaty of Versailles, New Zealand was one of the founding members of the League of Nations. This act can be seen as radical in two ways. Firstly, the institution was associated with progressive political positions because of its founding premises of collective and international operation. The notions of 'benevolent internationalism' and collective action were strongly associated with the international socialist movement (Oliver, p.238). Secondly both the organisation itself and New Zealand's membership of it can be seen as a radical challenge or 'threat to the integrity of Empire' (Oliver, p.236). New Zealand's membership of the League of Nations gave it a forum for an independent voice in an international context. The British response to New Zealand's tenure of a seat on the League of Nations Council was a vehement assertion that public debate at Geneva between Britain and New Zealand would be an 'undesirable spectacle,' and that the only voice to which New Zealand was entitled was as a 'very, very small fraction of that great Empire' (Wood, p.116). Britain suggested instead that the Dominion should refrain from exercising its right to act independently within the League and should instead 'transmit representations through Britain after consultation' (Wood, p.116). Britain's reaction provides a very clear example ${ }_{L}$ the imperial nation countering insurgency against it by insisting on New Zealand's provincialism (cf. Deane, p.9).

Within New Zealand, one's attitude to the League became a measure of one's conservatism or radicalism. Keith Sinclair comments that at

Zealand in the World (Wellington: Department of Internal Affairs, 1940), pp.114117. Further references in the text. 
that moment in New Zealand history 'often in the speeches of Labour politicians, "the League of Nations" seemed like a new mystic phrase, with no obvious objective correlative, like "Empire" on the lips of the reform ministers' (Sinclair, p.277). The tone of the reference to the League of Nations in Hyde's text seems less idiosyncratic in this context.

The League of Nations was synonymous, then, with New Zealand's assertion of an independent identity from that of imperial Britain, and it was over the Italian invasion of Abyssinia that New Zealand first publicly expressed a separate view from that of Britain.

New Zealand persistently favoured the enforcement of the 'sanctions' against aggressors provided for in the League Covenant, a policy which necessarily involved frequent open disagreements with Great Britain (Sinclair, p.277).

Mussolini's invasion of ${ }_{L}$ wassinia was an act of fascist, imperialist expansion which was deplored by all nations in the League, but in the end nothing concrete was done to help the Abyssinian people, or to force the Italian forces to withdraw. Of all the nations in the League, New Zealand was the only one which refused to recognise the Italian conquest of Abyssinia and continued to call for the protection of the Abyssinian people. The indecision from other countries about the most suitable course of action was produced by an anxiety about the security of their own empires. Their desires to retain their colonies and the dangers of making potential enemies led to policies of appeasement rather than of retribution.

To the first readers of Wednesday's Children in 1937, these political events would have been common knowledge, and support for the League and for the Abyssinian cause would have indicated a specific 
and radical political position. Continual references to the Italian invasion of Abyssinia in the text never allow the larger context of fascism and imperialism to be wholly diverted from the reader's attention. In addition the relationship between international politics and personal politics is constantly suggested.

Dorset, Wednesday's oldest child, cares 'about relationships, personal and international. ... He was terribly concerned over the League of Nations, and the only one who, after the first fine careless rapture of damning the Italians for the bombing of Adowa, really gave a bootlace for Abyssinia' (WC 141). The opinion offered by Ronald, Wednesday's half brother, that Mussolini's actions in Abyssinia make you 'cringe to feel that you're white,' specifically links the international with the personal and makes explicit the racist nature of the fascist occupation of the African country (WC, p.237).

The racism and violence of the Italian operations is again made explicit and deplored in the discussion on Wednesday's island where the 'nigger-killing business,' the League of Nations, and the proposed American peace plan are the subject of conversation (WC, p.257). And when Attica, Wednesday's elder daughter reads about and discusses the Italo-Abyssinian campaign, contempt is expressed for the fascist forces and the failure to stop the racist and imperialist oppression:

Attica who had been reading a newspaper, said passionately: 'I would like to fight, but not like that.' She made a gesture repudiating the Italo-Abyssinian campaign. 'I would land on the East Coast of Africa,' she said, resting her chin on her long hands and glooming at her mother, 'somewhere about Benin. I would ask the British consul to aid me, but he would not' (WC p.63). 
Most significantly, Beppo Luigi, Wednesday's ex-lover, comes back to the island because he is an Italian and about to be drafted by Mussolini's regime to fight in the Abyssinian war. The text specifically links the desire to be on Wednesday's island with the anti-fascist, antiracist and anti-imperialist impetus behind the League of Nations. When Beppo's brother asks ' "What makes me come to this funny little island? What makes me stick here?" ' the answer from Wednesday is ' "What made America have a shot at a Peace Plan, and a League of Nations, however much it went wrong and we all let ourselves down? ... It hasn't got a country. So in the meantime, it becomes naturalised on my island." ' (WC pp257-58). The text declares that the radical political imperatives of the world find refuge in New Zealand, and specifically in the domestic structure of Wednesday's island.

In this specific political context which the novel sets up, Wednesday's prolific mothering can be seen as something different from the 'one big happy family' or the 'breeding programmes' of expansionist fascist states (Koonz, p.xxiii, p.xxxiii). I outlined above the gender politics of fascism which feminist historians have identified, that is fascism's articulation of a woman's role as a wife who is the property of her husband and as a mother who produces legitmate and racially pure children who are the property of the state so the state can continue its imperialist expansion.

It is quite obvious that the dynamics of Wednesday's mothering run counter to those of fascist ideology. There is no husband in this text to bestow the patronym, the sign of legitimacy, on Wednesday's children.

There was no Mr. Gilfillan. There had never been any Mr.

Gilfillan. Gilfillan was, and remained, Wednesday's own 
maiden name. In place of $\mathrm{Mr}$ Gilfillan . . there stood only

Constantine, Edward, Beppo, and finally Michael (WC p.23).

Instead of the patronym which produces the guarantee of patrilineality, the fathers themselves have no patronyms. In this domestic structure, notonly is there no marriage contract and no guarantee of paternity and ownership, but the notion of racial purity is dramatically countered. Wednesday has had children by four different fathers of four different nationalities, Greek, English, Italian and Irish, and through this procreation outside the bounds of patriarchal state and patrilineal family, national difference is reabsorbed into specifically familial value. Wednesday's motherhood can thus be seen not as an adjunct to the fascist enterprise to produce a uniracial empire, but precisely as a subversion of the fascist notion of motherhood. It constructs a family where all races become not just metaphorically, but literally, brothers and sisters. It is through a restucturing of motherhood, rather than a re-evaluation of it, that Wednesday's Children offers an alternative model to the domestic and international politics of fascism. It is, of course, significant that this domestic model is presented in a house called 'L'Entente Cordiale' (WC p.75). 


\section{CHAPTER 6 \\ Epilogue II: L'Entente Cordiale? \\ Traces of Racism}

\section{Introduction.}

This section provides a brief doubling back over some of the material surveyed in the previous section. In the previous chapter I argued that the text establishes a politically radical position which is critical of fascism, racism and imperialism. Wednesday's island is produced as the locus for the antithesis of right-wing values. In this section I argue that the text effects a disavowal of the racist dynamics inherent in the New Zealand Dominion itself. By repudiating racist imperialism located in the northern hemisphere, and relocating the libertarian ethos in an imaginary Auckland islet, the text constitutes the New Zealand location as free from racism and imperialism. The text takes a libertarian stance towards the black Abyssinians, whilst distancing them as the 'other,' but at the same time, it reproduces New Zealand's colonised subject in the form of a racial stereotype. I suggest that a feminist reading which concentrates only on the representation of women's autonomy in the text forecloses on an examination of the representation of the colonised in the text. In particular it fails to pay attention to the representation of the colonial woman. 
Rather than representing any entente cordiale any friendly understanding between nations or within nations, the text betrays the discriminations by which national identity is produced. 


\section{My Blacks.}

Attica's story of what she would do in Abyssinia seems to invite a

feminist reading:

Attica flung back her head, stretched out her white, ungracious arms and legs. She was tall, with a pointed face. 'It's funny she should be such a white child when Tino was almost canary,' thought Wednesday. Attica who had been reading a newspaper, said passionately: 'I would like to fight, but not like that.' She made a gesture repudiating the Italo-Abyssinian campaign. 'I would land on the East Coast of Africa,' she said, resting her chin on her long hands and glooming at her mother, 'somewhere about Benin. I would ask the British consul to aid me, but he would not. Then I would go out myself on safari, under cover of night, and the British consul would send a young officer after me to bring me back. I would say to him: "If you interfere with my blacks, I'll shoot you like a dog," and he would say: "Put down that gun, I'm coming too." When we got to the native kraals we'd be taken before the chief, and I'd point to the north and say: "Follow, the time has come. Will you let the white man stamp you into the earth? I am sent, I am sent." Then I would walk up and down the ranks of warriors, reciting poetry. They would think I was ju-ju, and $g 0 \mathrm{mad}$ and follow me. We would strike down from the north and the east, the people of all the black villages. The Englishman would want to marry me, but he would be caught in the last river by a crocodile. We would go on singing. When we came to Addis Ababa, we would march into the great hall, and I would say: "Have I done well Haile Selassie? Then give me a place in the forefront of the battle." " She clenched her teeth, seeing black men with ostrich feathers in their hair leaping up and down as though scalded, an enormous excitable sea. 'It would be alright while you were marching, darling,' said Wednesday, but the blacks would spear you in your sleep. It's the natural instinct with anything strange of which one is not quite sure' (WC p.63-64).

It is easy to see that Attica represents the New Woman, the type that is described in the Farmer's Union Advocate: a 'brave spirit' who is 
characterised by 'self-control, courage, unselfishness, and fair play' (cited above). In this daydream, the Boy's Own adventure is commandeered to make it very clearly a girl's own adventure. The girl replaces the incompetence of the male British consul with her decisive action and 'spirit.' She is pictured as brave, courageous and independent in her night safari. She is captivating, yet not subjugated by romance, as her potential suitor becomes enlisted in her rebel ranks and then is dispatched into the jaws of the crocodile before he can become the husband. The white woman and the black warrior are aligned with the forces of liberation when the oppressor is located specifically as the 'white man.'

However this reading of the narrative as a subversion of the male adventure tale and the oppressive format of romance by the dream of the autonomous woman fails to pay full attention to the imperial dynamics of racial difference which is also present in the narrative. Rather than a girl's own adventure, the narrative can be seen as a 'romance of Empire.'121 The Abyssinian daydream is informed by a libertarian impulse. It is about dispensing with the ineffectual bureaucracy (of the British and of the League of Nations) and replacing it by revolutionary action in order to end the fascist oppression of the Abyssinian people. But the Abyssinian people are at the same time located as 'other' in this narrative. They are represented as 'my blacks' which not only implicitly construes them as owned by the white girl,

$121 \mathrm{cf}$. 'The making of the British Empire has been a great adventure of which we may all be proud ... an adventure in which men have spilt their blood freely, with a genial courage, with a ready rollicking spirit of gallantry, and with a fine carelessness of danger and death. ... The story of the Empire is a series of heroic biographies, and the most peace-loving idealist of to-day need not be ashamed of the thrill that moves him when he reads of men who fought hard, and dared many dangers, and suffered every kind of hardship, with such admirable disdain of ease' Philip Gibbs (The Romance of Empire (London: Hutchinson, n.d.), p.5. 
but renders them devoid of subjectivity; they are registered indiscriminately, only by their colour and their mass, 'an enormous excitable sea' of 'black men with ostrich feathers in their hair leaping up and down as though scalded,' and it is precisely this vision of the 'other,' simultaneously exotic and possessed, which produces bodily excitement ('she clenched her teeth') for the female 'white child.' This representation of the Abyssinians as exotic 'other' is compounded by the suggestion that they are both atavistic and hostile to the white subject. In this narrative, the autonomy of the white female subject is produced at the expense of the subjectivity, identity and desire of the colonised people.

Yet at the same time it is the 'white man, the Italian imperialist fascist who is explicitly located as the perpetrator of the racist oppression in the narrative. What can be seen here, again, is the mechanism of disavowal. The racism in the account, and the oppression involved in colonisation is located in the operations of the northern bemisphere nations. This disavowal is productive for the New Zealand colonising subject in two ways. Firstly it absolves them from guilt or complicity in racial discrimination and the colonial expropriation of land by pointing the finger elsewhere. It locates 'colonisation' outside its boundaries. Secondly, and by virtue of this first move, it implicitly constitutes New Zealand as a discrete national identity rather than a product of northern hemisphere colonisation. ${ }^{122}$

122 A similar process can be seen in the representation of Australia in Nor the Years Condemn. Racist Australia constitutes New Zealand as non-racist. In the section 'White Australia.' Australia is constructed as racist, and in the following section 'The Water Hole,' as a colonising nation which has dispossessed its autochthonous people. This displaces the operations of colonisation to a location outside New Zealand. 
Within this mechanism of disavowal, the New Zealand colonised subject becomes represented as a hybrid or mimic figure. In the section below I will argue that in Wednesday's Children, the Maori are produced as discriminated subjects. Whereas in the Mansfield texts which were examined it was the colonising subject who was produced as a stereotyped and discriminated subject whilst the autochthonous figures were presented as 'other,' in Hyde's text, it is the colonised subject who is produced as a stereotyped figure whilst the colonised peoples of other empires are produced as 'others.' In both cases this process works towards establishing the autochthonicity of the narrative voice. In Mansfield's text this is a European autochthonicity, in Hyde's text it is a New Zealand autochthonicity.

In Wednesday's Children. Maritana, the 'nurse' who in fact is a general servant, is given an orthographically reductive direct speech and a non-pakeha vocabulary. It is as heavily marked as the speech of the colonising characters in the early Mansfield stories. In the typescript version the presence of terms derived from American stereotypes of black West Indian culture reveals the representation of Maritana (and of Joe) not as autonomous individual subjects, but as stereotypical part-presences, encoding an otherness which is fixed as generally not-white, rather than specifically Maori.

Maritana calls the children 'picanniny [sic],' tells Dorset, 'Hey, boy, wash out them nappies,' addresses Wednesday as 'Mitti Wednesday, and 'honey.' ${ }^{123}$ Even though the term picanniny is expunged and replaced by 'children' in the printed version of the text, 'honey'

123 Robin Hyde, Tednesday's Children B-15, ts., Manuscripts Collection, U of Auckland, 'picanniny,' 1.56, 1.72, 'Hey, boy ...' 1.13. 'Mitti,' 1.72, 'honey,' 1.81. 
disappears, 'Mitti Wednesday,' becomes 'Wendi' and Dorset is told, 'Doretti, you wash up t'ose nappie, hey?'(p.22) the representation of Maori speech is still highly stereotyped and the orthography represents cultural difference, not cultural specificity. The narrative of Maritana's frock consolidates the stereotypical representation of Maori.

Joe had been commissioned to buy her new clothes, new dress, crimson or magenta in colour, new hat with feather, allasame White Queen Woman. 'T'e noo dress, t'e noo potoe, wit' t'e feat'er. I t'ink you get t'e plenty for four poun'-ten. You go t'e pub after, buy t'e wai piro for t'e ten shilling (WC p.124).

Joe buys a dress but no hat and spends most of the money in the pub and then lies to Maritana about the price. When asked to chop wood, he says 'Taihoa,' and disappears. At church next week, the parson says to Maritana ' "My korry, Maritana, ... why you buy t'e frock we see you coming harf-a-mile, allasame like t'e big red motabus?" "T'e plenty good frock," Maritana retort[s] coldly, "allasame like t'e pakeha Queen" ' (WC p.124). In the meantime Joe is in the pub again claiming to have an important government job and likely to be made an M. P. This inset narrative, which is supposed to be comic, reiterates a stereotypic view of the Maori as either feckless and alcoholic, or mimicking pakeha culture. Joe is represented as lazy, dishonest, cunning, boastful and drunk. Maritana's desire to look like a white woman is ridiculed. The difference between the original and the mimicry of the colonised subject is displayed as the (supposedly comic) discrepancy between the head of state and a London bus. The possibility of the Maori becoming a member of parliament is similarly held up to ridicule. 
This representation of Maori people in Hyde's text stands in contrast to some other contemporary representations which are much less stereotypically confined. The cartoon in figure 6.1 depicts a Pakeha deck hand addressing a Maori couple in an orthography which is an imitation of Maori speech. ${ }^{124}$ The Maori reply, in standard orthography representing standard English, interrupts the belittling assumptions of the Maori's venality and separation from the pakeha world, as it informs the deck-hand that the gentleman is about to take up his seat as an M. P. In the cartoon the Maori figures as a representative subject rather than a being represented by a stereotype. In this cartoon, it is precisely the textual means by which the colonised are produced as mimic presences which are called into question.

Similarly in E. M. Smith's 1939 survey of New Zealand fiction, the problem of representing Maori speech is explicitly addressed. The type of representation which is noted as unsatisfactory and condescending is exactly that which is present in Wednesday's Children.

... the greatest difficulty is that of making the Maori use of English a natural expression of his personality and not just a succession of half-stupid, half-shrewd observations peppered with "pai korry" and "plurry" in the best style of the funny story. 125

124 Smart, 'The Retort Courteous,' cartoon, New Zealand Artists' Annual, 2.2 (1931): p.18.

125 E. M. Smith, A History of New Zealand Fiction (Dunedin: Reed, 1939), p.42. 
Fig. 6.1

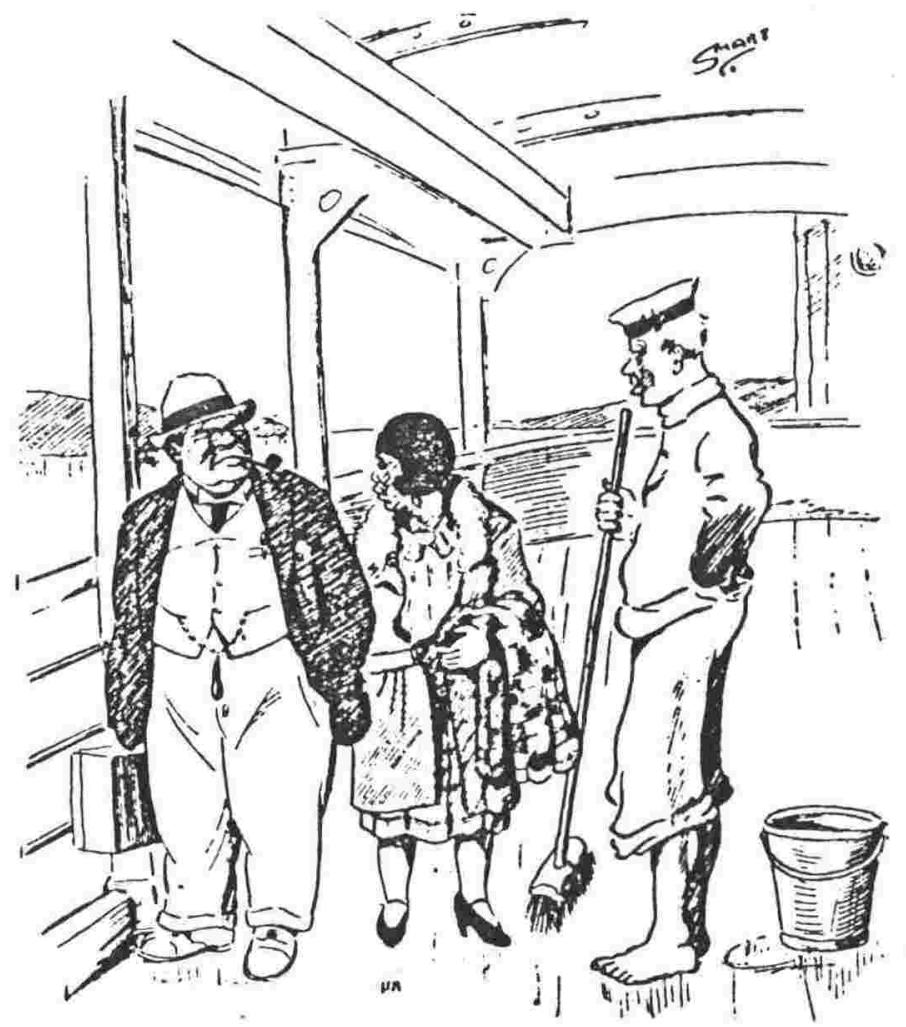

The Retort Courteous.

Deck-hand: "Hullo, off on te honeymoon?"

Maori: "My dear sir, by no means. I am proceeding to Wellington to represent my constituency at the forthcoming Parliamentary session."

Smart, 'The Retort Courteous,' cartoon, New Zealand Artists' Annual, 2.2 (1931): p.18. 
As Smith goes on to point out (pp.43-4), Hyde is one of the most acute analysts and trenchant critics of pakeha dealings with and representation of Maori, which makes the recurrence of racial stereotypes in her fiction all the more telling in its revelation of the insecure subject positions of colonial identity.

The stereotypical representations in Hyde's text cannot then simply be taken as a part of the Zeitgeist, because that text attempts to interrogate the dominant ideology in other places. The particular ideological forces which result in the production of stereotypes are shown to be capable of being undermined elsewhere in the text. What is most striking is the complexity of the conflicting construction of location and identity when class and gender determinants intersect with those of colonial identity. I will try to trace some of these intersections below.

Wednesday's freedom comes from the sudden acquisition of capital which allows her to be liberated from the domestic role usually ascribed to women. But liberation from the domestic role is only achieved by the consolidation of another racially discriminated and lower class woman in that position of (albeit paid) domestic servitude. Before her financial independence, Wednesday is represented not as a person but as 'a brown pot lj]ust there to contain things,' but after her financial independence, which according to the narrative also gives her autonomous selfhood, she acquires a domestic servant whose chief features are her brownness, her aptitude for domestic work, her subservience and her lack of autonomy (p.113).

Maritana wasn't a nurse, she was the nurse, the sort who inhabits palaces or cottages in fairy tales. Her fat bronze face shone like a dumpling, and her eyes were like 
black-currants. Ten years ... She had been everything but wet nurse to the children. First Attica, then, at three-yearly intervals, Naples and Dorset, and now the twins. Wednesday didn't think Maritana could have been restrained from achieving the condition necessary for wetnursing the children, either, but for the fact that she didn't want coloured babies of her own, and hadn't any use for mixed marriages

'But a kitchenful of brownies would have been rather jolly,' thought Wednesday. 'I wonder if it's too late? I must put it up to Maritana' (WC. B-15, ts, 1.10).

The references to 'palaces or cottages in fairy tales' at the beginning of this passage is a reminder that what is being described is a utopian fantasy which posits an alternative to the structures which produce oppression. But this whole utopia turns on the presence of a racially discriminated, lower class, female servant. The class distinction is invoked here not just in the suggestion that Maritana's children would be kept in the kitchen, but in the presumption that Wednesday has prerogative over both the productive and the reproductive capacities of her domestic servant. Here there is the trace of the fascist version of motherhood discussed earlier. This class division between the two female characters (which is not criticised or ironised in the narrative) where Maritana is represented as 'the' stereotypically perfect servant, is complemented by a racial division.

Maritana is rendered in a debasing colonial stereotype as material for consumption, 'dumplings' and 'currants,' as sexually wanton in that had Maritana's inclination been to procreate she would have had to be 'restrained' (presumably by authority and power vested in Wednesday by virtue of her class and racial status), and as trivialisingly, picturesquely exotic, in that a kitchenful of 'brownies' would be 'quite nice,' as interior decor. She is also registered by Wednesday as the site of colonial alienation in that it is claimed that she does not want brown 
babies, or mixed marriages. The desire to be white, or to reproduce white babies further suggests an interpellation [sic] into the position of a mimic woman.

The alterations to this passage in the printed version do little to alter the problematic politics. The 'dumpling' becomes a 'Christmas pudding' and though the passage which suggests anxiety about miscegenation is omitted, it is replaced by a phrase which further emphasises class inequalities without critiquing them, 'but for the fact that babies of her [Maritana's] own would have taken up her time' (WC p.19). Here motherhood is privileged and reserved for the while middle class woman, at the expense of the Maori servant's pleasure.

The rejection of miscegenation on Maritana's behalf sits very strangely with the racial and cultural mix of Wednesday's children. It suggests that racial difference of the intra-European liaisons can be contained by an entente cordiale but that there is still a very important border of racial difference to be policed and kept under surveillance in the interaction of European and Maori. This framework puts a very different perspective on Wednesday's musings: '[s]he could see the enormous kitchen of her house, L'Entente Cordiale .... Whitewash domesticated the big cavern which was the family's favourite room' (WC p.20). The racism which Wednesday's Children both disavows and critiques comes back on the white 'home' front with a vengance. The home in this world of Wednesday's Children is one in which the problems of location and identity are perhaps most fraught when they seem most resolved. 


\section{CHAPTER 7 \\ Rethinking the Blue Fury}

\section{Introduction.}

In this chapter I argue that Living in the Maniototo interrogates the assumptions which support Stephen Gray's analysis of colonial literature. The difference between the textual dynamics of the two texts reveals Gray's analysis as a project of assimilation masquerading as an advocacy of pluralism. I suggest that recent discussions of postmodernism provide a more profitable approach to this text and trace the way in which the presence of the postmodern subject is represented by metaphors of surface and boundary rather than metaphors of depth and presence. I conclude by suggesting that coloniality in Living in the Maniototo can be read, not in a claim to a specific postcolonial identity, but as a violent interruption to the pattern of the postmodern world.

The problems of assigning Frame's texts to Gray's third phase.

In my introduction I suggested that Frame's texts were more difficult to position in relation to Gray's schema than the texts of Mansfield and Hyde, and that this was in part due to the time span of four decades over which Frame's texts have been produced and published. Between the first publication of The Lagoon: Stories in 1951 
and the publication of The Carpathians in 1988 the cultural and social conditions in which fiction has been produced by New Zealand writers have altered drastically. There seems to be a consensus amongst recent critical commentators that these social and cultural changes have altered both the form and the subject matter of novels being produced in New Zealand. In mapping out the recent history of the New Zealand novel, Lawrence Jones suggests a division between a 'provincial period' (1935-1964) and a 'post-provincial period' (from 1965 onwards) and itemises some of the characteristics of change between these two periods he identifies:

Increasing affluence, (and latterly the threats to it), the move to a consumer society, increasing urbanization and suburbanization, the sexual revolution, the feminist revolution, the growth of racial and cultural consciousness, the emergence of a more distinctive youth subculture, and changes in family patterns - these and related phenomena have given the novelists material very different from the more narrow, monocultural society of the previous period. Such change has also presented them with problems, for the conventions and explanatory patterns developed by the previous generations of novelists would not necessarily work for these new materials. ${ }^{125}$

Jones's commentary, whilst not advocating that we see the difference between his provincial period and his post-provincial period as a complete break, does take pains to emphasise the shifts in social organisation, national self-definition and literary models between the two periods. Although Mark Williams stresses the notion of transformation rather than rupture in his commentaries on the last two decades in New Zealand fiction, he also indicates his sense of radical

125 Lawrence Jones, 'The Novel' in The Oxford History of New Zealand Literature ed. Terry Sturm (Auckland: Oxford University Press, 1991), p.170. 
social change in the New Zealand society from which this fiction is produced. He talks of the steady decline of the old liberal consensus with the rise of fierce ideologies on the left (feminism and Maori nationalism) and the extension of a hedonist consumer society into traditionally puritan suburbia.' 126

Williams's comments suggest that 'the air of [cultural] homogeneity' which would have been the milieu in which Frame's earliest texts were produced was no longer present by the time of the production of the latest ones, and Jones's schema effectively bisects the group of Frame's

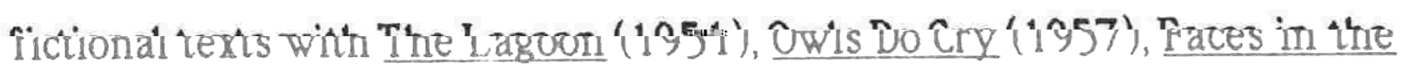
Water (1961), The Edge of the Alphabet (1962) and The Reservoir (1963), falling into his provincial category and A State of Siege (1966), The Raimbirds (1968). Intensive Care (1970), Daughter Buffalo (1972). Living in the Maniototo (1979), You Are Now Entering The Human Heart (1983) and The Carpathians (1988), falling into his postprovincial category. Given the spread of Frame's texts over four decades, decades which have been involved, among the other shifts mentioned above, with the process of cultural decolonisation and the advent of a much disputed postmodernism, it is not surprising that it seems difficult to fit these texts unproblematically into Gray's schema. ${ }^{127}$

126 Mark $\$$ illiams, introduction to 'New Zealand (with the South Pacific Islands)' bibliographical entry in the Journal of Commonwealth Literature 16.2 (1991) p.113. A similar notion of recent changes in New Zealand literature and society is expressed by him in 'The Cultural Context' in Leaving The Highway (Auckland Auckland University Press, 1990), pp.11-29

127 While critics want to identify clearly demarcated categories in Mansfield's work, there is almost the opposite tendency in the criticism of Frame's texts Given the span of almost four decades between the publication of The Lagoon and that of The Carpathians the number of critics who insist on reading across these texts for the presence of the author's unique vision (and its teleology) is 
Gray's third phase is characterised as arising when a culture has 'its mutual understanding of a set of infolded norms and values, its own context of myth about past and present' and values 'an autochthonous readership first, for whom the advertisement of colourful landscapes is simply ludicrous'; in the literature of the third phase 'somehow the familiar is never strange' and the sense of place 'is back where it should be, merely part of a shared, felt milieu, a familiar and meaningful backdrop' (Gray, p.9).

It could be argued that sense of place in Owls Do Cry conforms to these criteria and that because of this it can be identified as a phase three text, but even in this text and more obviously in A State of Siege the notion of a shared, felt milieu, a familiar and meaningful backdrop, is ironised and put under question. In A State of Siege the landscape of the far north is represented as strange and hostile and made to function as a correlative for the disturbed psychological state of its protagonist, Malfred Signal. In the context of the novel, the landscape of the south only seems part of a shared familiarity by means of this

surprising. One of the problems in the criticism on Frame's texts is created by a slavish obeisance to this notion of the unity and coherence of the author. Patrick Evans's copious body of critical work on Frame and her texts is perhaps the most obvious example of the tendency. Evans's critical work on Frame is governed by his conviction that all Frame's fictions are based on an obsession with self. In "Farthest from the heart": the autobiographical parables of Janet Frame', Evans claims that 'anyone familiar with the details of [Janet Frame's] life will know [ ] she constantly places herself at the centre of her own writing. . . Frame is an extraordinarily egocentric writer who finds herself in everything . . $\therefore$ Modern Fiction Studies 27 (1981): p.31. This self obsession leads, he claims, to a body of fiction which is limited because it simply repeats, in coded form, the autobiographical experience of the author. It is however Evans's own obsession with biographical readings which leads him repeatedly to 'decode' the fiction to find that its overriding concern is autobiography (p.39). Critics who insist on regarding the body of texts as a continuum united by the unique vision of the author tend to focus on thematic unities. This has the effect of eliding differences between the texts and foreclosing on the possibility of reading different formulations of colonial and postcolonial identity in different texts. 
defamiliarization of the landscape of the far north. Through the discussion of Malfred's painting, A State of Siege takes issue with the whole notion of the validity of a contemporary, unarticulated, shared, communal way of regarding location or identity.

This process of mocking the mythology of a coherent and secure national identity through its representations of place is intensified in Living in the Maniototo and The Carpathians and because of this it is even harder to assign them to Gray's third phase. In The Carpathians. the parodic description of the institutionalisation of the legend of the Memory Flower by the Tourist Centre mocks the whole notion of a society with its own context of myth about past and present.

In Puamahara the legend of the Memory Flower, rediscovered and reinforced by the Tourist Centre, became the town's treasure. Cities, many knew, have thrived more on their legends than on their gold, oil, gemstones. At the entrance to a city's harbour, a statue depicting a loved story will entice more tourists than a street of wealthy merchants. The legend of Puamahara and Maharawhenua was seized, retold, enhanced, illustrated. A plaster sculpture of a tree with one large blossom suspended from the topmost branch was hastily erected at the entrance to the orchards on the edge of town (Carpathians p.12).

In this passage where local legend is seen not as part of the cultural background, but as cultural property only in the sense that it has a cash market value, there is an explicit mockery of the ideas of 'selfreferring norms and values' and a specifically local 'context of myth about past and present'. The shared communal values are actually those of international late capitalism. The verbs 'retold, enhanced, illustrated' on their own would perhaps represent a natural interaction between community and location, but placing 'seized' before them serves to ironise the idea of a community so grown into its 
environment that sense of place is where 'it should be ... a familiar and meaningful backdrop' and instead portrays a community filled with a sense of desperation about cultural identity and fiercely engaged in the exploitation of cultural resources in an international market.

Similarly in Living in the Maniototo place is not simply represented as a shared and familiar environment, knowledge of which can be taken for granted. Although there is an attention to concrete detail in this text, which produces a sense of familiar place being known and recognised, this concrete detail is heavily interspersed with cultural cliches which are ironised so they work against simple mimetic recognition and make it impossible for place simply to be registered as neutral 'background'; rather than the familiar never being strange, the familiar in this text is explicitly defamiliarised. What is opened up to scrutiny by this defamiliarization is the way in which representations of place are constructed.

To the innocent observer the very title Living in the Maniototo might suggest an unproblematic account of lived experience in a specific (and known) geographical location. The difference between the expectations aroused by what the title signals and the actual content of the text acts as a first step in the defamiliarizations which the text forces upon the reader. The Maniototo figures literally in the text only as the 'home' of the fictional writer Peter Wallstead (pp.55-57), and in the Hungarian Zita's narrative as the place where immigrant families have imposed on them an ersatz cultural identity which is a combination of British nationalism, Maori literature in translation and Celtic Heimweh. 
... they'd [the immigrant families] gone to a camp in Otago on a plain called Maniototo where they were 'processed' and taught to sing ' $O$ Danny Boy the pipes, the pipes are calling; From glen to glen ....' 'God Save the Queen' and 'Come 0 Maidens Welcome Here' (p.151).

Judith Dell Panny notes the correspondences between the fictional writer Peter Wallstead and Ronald Hugh Morrieson, both teachers in rural communities, uncelebrated whilst alive but posthumously acclaimed. ${ }^{128}$ However Peter Wallstead is not actually Morrieson (just as the fictional Margaret Rose Hurndell is not actually Kathleen Mansfield Beauchamp), so the only dwellers in the Maniototo in Living in the Maniototo are fictional and displaced persons. Given the absence of any other character in the text who literally lives in the Maniototo, this textual arrangement clearly opens up the interpretation of the title to a range of metaphorical possibilities, and whilst I disagree with interpretations which elide the differences between 'manifold' and 'Maniototo', 129 the difference between the title and the content of the text certainly serves to wrest the reader away from a simply mimetic and expressive reading of the text where sense of place can function as a shorthand to a known and shared environment.

Place is an issue which is foregrounded in Living in the Maniototo. The text deals with Blenheim, Baltimore and Berkeley, tangentially with Stratford and of course with the Maniototo. In Part One, section

128 Judith Dell Panny, I have what I gave: The Fiction of Janet Frame (Wellington: Daphne Brasell Associates, 1992), p.156.

129 Peter Wallstead is a writer, one who 'never wantls] to leave the Maniototo,'(p.55) but in this passage (pp.55-57), the whole notion of 'the Maniototo', as a metaphor for the special creative province of the artist is highly ironised, as is Peter Wallstead later: Mavis links him with the despised writing teacher. Howard Conway (p.119), who in turn is lexically linked with the conman, Yorkie Wynyard. 
four, the problem of talking about place is explicitly addressed where the narrator attempts to answer the question 'What is Blenheim ?' (p.23). What becomes more and more apparent as the passage progresses is the difficulty of providing any satisfactory answer to the question.

In Hyde's Wednesday's Children by comparison, the process of describing place is relatively unproblematic. The only problem outlined in the description of Auckland (pp.13-16) is that of inducing the unimaginative reader to imagine the 'whiff of a salt sea' which lies 'flat, black and restive at the base of Queen Street' (p.15). The process of representation by which the description is produced is never put into question and the ideal reader is not the stranger who is ignorant of New Zealand's location but, (it is implied), one who can combine a certain degree of local knowledge with their imagination. What the description here aims at is the process of a familiarisation with what is already partly known.

In contrast with the passage from the Hyde text, both place and its representation are problematised in the passage from Living in the Maniototo. What the section opens with is ostensibly a description of Blenheim. The narrator relates particular aspects and details of Blenheim, including geographical location, demographic information, architectural and economic information, street names and local history. So, in a conventional sense one can read this as the reader being presented with a sense of place, a collection of particulars which evoke a specific location for the reader. But the textual strategies suggest that the representation of place in a literary text is in fact more complex than this. The notion of readership is complicated as the assumed audience is marked out as including both the autochthonous 
and the non-autochthonous, 'If you, a stranger, stay in Blenheim .... If you live there... ' (p.21).

What is being foregrounded is the implication that 'place' is the product of a process of signification. Throughout the description of Blenheim the style, tone and narratorial presence all shift continually. The passage contains fleeting imitations of guide book narrative style, the style of social reports, and of advertising material. What becomes clear is that the answer to the question 'What is Blenheim ?' is multiple, unstable and dependent on the the type of discourse in which the answer is framed. In this way all the markers of identity for both the place, Blenheim, and its inhabitants are placed in conjunctions which, instead of intensifying a sense of their concreteness and familiarity, work to problematise the whole notion of the security of identity. The fictional suburb of Auckland is made no more familiar than those of Baltimore and Berkeley, and they with their myths of dead poets are made no more strange than Blenheim 'full of "shocking sights" where the flower gardens hide the human skulls'(p.23).130

130 This phrase clearly has a bearing on the colonial history of New Zealand, but it is also an allusion to Robert Southey's poem, 'The Battle of Blenheim' (Joan of Arc: Ballads, Lyrics, and Minor Poems (London: Routledge, 1894) pp.327-29.:

It was a summer evening.

Old Kaspar's work was done:

And he before his cottage door

Was sitting in the sun,

And by him sported on the green

His little grandchild Wilhelmine.

She saw her brother Peterkin

Roll something large and round,

That he beside the rivulet,

In playing there had found,

That was so large, and smooth and round.

0ld Kaspar took it from the boy.

Who stood expectant by: 
Because notions of cultural identity are scrutinised throughout Living in the Maniototo by the way in which cultural constructions of sense of place are defamiliarised, the text cannot comfortably be assigned to Gray's phase three. Lawrence Jones's observation that change has presented New Zealand novelists with problems because the 'explanatory patterns developed by the previous generations ... would not necessarily work for these new materials' can be equally well applied to the relationship between Living in the Maniototo and Gray's critical taxonomy.

And then the old man shook his head,

And with a natural sigh,

'Tis some poor fellow's skull, said he,

Who fell in the great victory.

I find them in the garden, for

There's many here about,

And often when I go to plough.

The ploughshare turns them out:

Later in the poem we are told of the 'shocking sight' of the 'many thousand bodies' which 'Il]ay rotting in the sun'. Old Kaspar and the dead bodies are refered to on p. 53 of Living in the Maniototo. 


\section{Pluralism, synthesis and autochthonicity: the problems with}

\section{Gray's fourth phase.}

In my introduction I suggested that the fourth phase which Gray marks out in his schema is problematic for several reasons. It has internal inconsistencies which betray the implicitly assimilationist and essentialist politics of his whole argument. Because of these inherent values, the space he marks out as a fourth phase is one into which a text like Living in the Maniototo will not fit, as it subscribes to a completely different implicit agenda.

Gray's description of his fourth phase is much vaguer in terms of textual specifics than his descriptions of the first three phases.

Our view of place, then - to conclude - should become three dimensional, in terms not of the way our world has been, but in terms of the place it is likely to become. A sense of place in that fourth phase is, accordingly, going to have another special meaning of its own. in that new configuration, when we have at last made it our own. (emphasis added, Gray, p.12).

The lack of specific detail is to some extent understandable because with his demarcation and description of phases one to three Gray has the advantage of distance, retrospection and hindsight, whereas in marking out his fourth phase he is attempting to categorise both what is immediately contemporary to his community and what has not yet been written. However this lack of specificity combined with his use of a metaphoric vehicle for which no tenor is deducible ('Our view of place, then ... should become three dimensional, in terms of the place it [our world] is likely to become'), is almost cryptic and serves to make the overriding feature in the description of the fourth phase the reiteration of possession. 
As I outlined earlier, what is most at stake in Gray's account is the importance of being autochthonous, that is having incontestable rights to the possession of the land and the culture. Gray's schema maps out the progression of the colonial subject from being a European coloniser for whom place is foreign to being a colonial identifying with the local habitat, and from there to being a participant in a new nationalism and finally to a nebulous stage of which uncontestable cultural possession is the most prominent feature. The inalienable cultural possession of the colonised land in this fourth phase is achieved by various moves. As discussed in the introduction, what is implicit in Gray's schema is a particular relationship between cultural autochthonicity and the transparency of language: the function of language is not brought into question in any way where there is a legitimate claim to both the land and the language. In situations of cultural autochthonicity, rather than being seen to be influential in image making, language is regarded as a neutral medium for the recording of experience, so what can be deduced from this is that the apparent transparency of language functions as a signifier of legitimate ownership.

Although Gray suggests that the 'tatty and unrealistic concept of nationalism in literature ... can now please crumble and disappear into history', this is not because he perceives nationalism as metaphysical but merely as outmoded: in the transition between phase three and phase four he suggests that the correct area of investigation is 'regional studies ... about the dense and unique specifics of one place,' so critics can 'feel [place']s own meaningfulness'(Gray, p.11). Here regionalism is merely quantitatively different from nationalism rather than qualitatively so. According to his analysis, felt experience of a particular location can be unproblematically expressed in the language 
of that place, and the only difference between this situation and the relationship between national place and national literature is one of scale. Finally again, he assumes that local language can simply and accurately portray local place as it could in that state of autochthonousness before the process of colonising started. The more radical possibility of recognising that regionalism can allow for a greater range of discursive constructions than a totalising nationalism is able to does not enter into Gray's analysis. What is revealed by his underlying assumption of a reality which can be presented unproblematically through a language whose mediating effects are unacknowledged is his appropriation of the status of autochthonousness.

The only features of contemporary writing Gray singles out as being characteristic of fourth phase writing are the 'pluralism of the influences' upon 'bastardized writers like Fugard and Sepamla' and their 'metaphysical ability to synthesize' (Gray, p.12). There is a dimension of sexual and textual politics in Gray's figurative language which has a bearing on the colonial and textual politics being discussed here. In discussing Sipho Sepamla and Athol Fugard's assessment of their literary forefathers and in his suggestion that 'we have new mothers,' Gray warns against substituting new empiricisms for old formulations (p.10), but in his adoption of the term 'bastardized' to describe Sepamla and Fugard's usage of English and the non-English material they incorporate into their semantic frameworks, he maintains the metaphor of linguistic and literary paternity and does not address the implications which stem from that metaphor in terms of gender politics. In the extracts given in Gray's text all the writers cited as having had influence are male. Fugard cites Faulkner and 
Sepamla cites the differing influences of two groups of writers, Shakespeare, Dickens, Lawrence and Keats and Richard Wright, James Baldwin and LeRoi Jones. Of the latter group Gray quotes Sepamla saying ' $[t$ ]hese men I would have liked tenfold because they have all sucked from the tits of my mother' (Gray, p.10). Although Gray goes on to mention sexism very briefly in conjunction with oppression, the reproduction here of the oppressive concatenations of the binary oppositions culture/nature, mind/body, male/ female in the form of the opposition of literary paternity and paternal authority to the land as a physical nurturing female body is passed over without comment or question.

The unstated implications of the metaphors of literary paternity and bastardization seem to me to be as follows: firstly, that there are pure linguistic and literary forms which can be unproblematically recognised, secondly that only pure linguistic and literary forms are legitimate, and thirdly, that certainty of patrilineality is the legitimising factor, an assumption which thereby re-inscribes the law of the father: it is only the literary forefather who is in doubt, not the nurturing ground of the (native) mother, but that certainty does not provide any legitimacy. Having attached the stigma of bastardization to writers like Sepamla and Fugard, Gray locates their only possible return to critical respectability in their metaphysical ability to synthesize,' (Gray p.12); in other words what Gray concludes by revalorising, even though he appears to deny it as a sine qua non earlier, is a literature of seamless unity and coherence. What is advocated is the subsumption of a literature of plurality and difference by a literature of synthesis, of coherence and univocality, as it is this, he intimates, which will makes place 'our own'. 
Plurality and synthesis are, however, completely opposed modes. Gray's scenario combines the two with a sleight of hand in its implicitly assimilationist political agenda: this point in his analysis is the first time where colonised writers are included in his overview but the significance of their previous exclusion and present inclusion goes unremarked. (It is telling that Gray talks of 'multiculturalism'(p.12) rather that post-colonialism, thus effacing a particular area of political discussion from his analysis.) Through the call for regional pluralism and the praise of pluralism in contemporary writers, there is the implication that hierarchical and hegemonic structures of European colonialism have been neutralised and that the distinction between colonisers and the colonised and their hierarchically structured relations has completely disappeared. However the invocation of the metaphysical ability to synthesise re-installs the notions of coherence and unity, univocality and authority. Combining pluralism and synthesis is a strategy in constructing a position of colonial autochthonicity and through this banishing the ambivalences inherent in the position of colonial and thereby guaranteeing the position of colonial with a salvific unity and coherence. 


\section{Living in the Maniototo and the need for a different}

taxonomical space.

I suggested earlier that Living in the Maniototo calls into question the grounds of the assumptions which are present in Gray's schema and this places it somewhere different from the position which he identifies for his fourth phase. Gray's schema envisages plurality in a series of essential regional identities, and finally advocates their subsumption in a textual synthesis. Living in the Maniototo is a text which is perhaps the diametric opposite of synthetic and which presents a version of plurality which is not dependent on essential identity. Gray's analysis presumes a return to an easy, unconscious mimeticism in the fourth phase, but the position which Living in the Maniototo takes up is antithetical to this. It is a self-consciously antimimetic text which contests essentialisms and the mimetic view of representation which shore up these essentialisms. Below I will discuss in detail the specific ways in which Living in the Maniototo exceeds and interrogates the constituent conditions of Gray's fourth phase and in the following section I will discuss what sort of taxonomic space would accommodate this text less problematically.

\section{i) the plurality of influence}

Clearly, a plurality of influences feeds into Living in the Maniototo, yet there is no attempt to synthesise them, and Frame's text puts into question the notion of plurality which Gray's schema advocates.

The late twentieth century 'rich material culturels]' (p.58) of New Zealand, Europe and America all play a part in the production of the text as do their histories and their treatment of their histories. 
However Living in the Maniototo does not attempt an assimilationist synthesis of Maori cultural material nor does it try to claim New Zealand as its 'own' cultural property in the spirit of Gray's rousing finale. The text measures a difference between the Pakeha and the Maori cultures -

$\therefore$ names with which Palmerston North, Marton, Foxton, couldn't hope to compete unless a spark of imagination ... set the place alight like a bushfire. The Maori names Wanganui, Waikato, Tuatapere, Taranaki - were more powerful because they were welded to the place by the first unifying act of poetry and not stuck on like a grocery label; nevertheless, the real triumph would be to set the spark raging in the mundane places' (Maniototo pp.96-97) -

and credits precolonial Maori culture with having an autochthonous relation to the place which the the Pakeha culture does not possess. What is registered in the last clause is not the desire to assimilate the autochthonous Maori culture into the Pakeha culture but the unfulfilled desire for the Pakeha to possess a similarly incontestable cultural relationship to place.131 In the discussion of the representation of place in Hyde's texts I applied Seamus Deane's analysis of the political significance of the act of naming. Deane's suggestion that the naming or renaming of a place, the naming or renaming of a race, a region, a person, is like all acts of primordial nomination, an act of possession' (Deane, p.19) applied here would show that the failure to name or rename suecessfully symptomises the perpetuated failure of the

131 Simon During in 'Postmodernism or Postcolonialism?' (Landfall 155 (1985): p.373) suggests that 'the text shows itself nostalgic for [the Maori language]' but what the text actually shows itself longing for is the autochthonous relationship which the Maori place names signify. It is interesting to note, however, the literal meaning of nostalgia:'homesickness as a disease' from the Greek 'nostos ', meaning to return home, and 'algos', pain. The desire for the resolution of the problems of location and identity can certainly be seen as a disease which permeates the literature examined here. I will discuss this further in the conclusion. 
colonising forces to successfully possess any form of cultural autochthonicity. Living in the Maniototo is able to acknowledge this failure because it does not attempt a cultural synthesis. Gray's analysis covers over or denies this failure by its assimilationist desire for synthesis mentioned above.

In other areas of Living in the Maniototo both the notion and the dynamics of plurality are conceived of differently from the way in which they are conceived of in Gray's analysis. A plurality of literary influences permeate the text from a range of historical and cultural sources: the biblical story of Lot's wife is retold in section two of the 'Prologue'(pp.13-14); as mentioned above, Robert Southey's poem "The Battle of Blenheim' recurs throughout the text in quotation and allusion; the first section of 'Part Three: Attending and Avoiding in the Maniototo' contains a list of texts, supposedly present on the Garretts' bookshelves, ranging from cookbooks and natural history volumes through The Compleat Angler to the works of Rabelais, Chaucer and other texts of Western high culture (p.113). The one text which is missing is the one which continually returns, sometimes overtly, sometimes inferentially throughout the text. Yeats's lines and phrases in the original or in imitation form are inserted into congruous and incongruous locations in the text: in one of the verses from the manifold spoken by 'hypotenuse' there are obvious correspondences to Yeats's poems 'Byzantium' and 'Sailing to Byzantium'; the speaker of the manifold poem becomes a bird who tells us he flew to the highest / bough and I sang / in detail, without violence, a civilized version of my story' (p.69). This poem's consideration of the relationship between art, the artist and the vicissitudes of the material world is fairly consonant with the context of the Yeats poems, but the image of 
a golden bird on a golden bough returns in incongruous places and in dislocated versions; there are 'golden birds brazenly singing' 'in the artificial light' but no boughs for them to sit on in Heavenfield Mall, while in Brian Wilford's house there is a gold wire tree but no bird on it and in Brian's wintery garden there is a dead looking twig, forsythia, which contains its 'yellow memory' but gives no sign of doing so (p.65\&47, p.29). The Old English poem 'The Battle of Maldon' is invoked or quoted several times; it is the name of a square in Blenheim (p.23), and is quoted as an ultimately useless source of comfort when confronted with Tommy, the impoverished artist in Baltimore (pp.3738). Theo is parodied in Keatsian terms as being 'like the "stout Balboa (or Cortez)" on a hilltop "wildly surmising" and planning possession' (p.164). One of the novels which Mavis writes has a title taken from a Dylan Thomas poem "The force that through the green fuse drives the flower'. Roger's sojourn in the desert is couched in Eliotesque terms. There are resonances from Plato and correspondences to Dante. The cultural instrument Landfall even gets a mention (p.221).

Because of the way in which the text incorporates this material, one set of values is not necessarily privileged over another. It is impossible to gauge definitively from the text whether the 'Waste Land' images with which Roger is surrounded parody the Eliot text or the suffering character, or in fact are functioning allusively without any parodic function at all. There is a similar ambiguity with the contrast between 'pale flakes with fingering stealth' and 'decramastic tiles' which might initially be taken to assert the cultural superiority of the 'poetic'. What the text actually does with its attendance on the words of the manufacturing culture is to transform them. Other references are not heavily signposted. The phrase 'glittering eyed' is 
dropped into a description without any indication that it is adapted from Coleridge's 'The Rime of the Ancient Mariner', and in this way the text becomes permeated with words from other texts (p.34). Yet here there is no synthesis of plurality. The intertextual references are not melded into a textual uniformity and the text itself progresses by false starts and inconclusions and with a marked absence of teleological narrative structure to shape the text into a coherent whole.

The text insists on its own intertextuality in its infusion with the words of other texts and discourses, but the relationship between Living in the Maniototo and the other texts which run through it is ambiguous. The ambiguity lies in the realm of ascribing value, and it is this ambiguity about the light in which quoted or reframed texts are to be seen which means that Living in the Maniototo is engaging in pastiche. Frederic Jameson suggests that pastiche

is, like parody, the imitation of a peculiar or unique style ... but it is a neutral practice of such mimicry, without parody's ulterior motive, without the satirical impulse,... without that still latent feeling that there exists something normal compared to which what is being imitated is rather comic. Pastiche is blank parody. ${ }^{132}$

In this way, the apparent plurality of Living in the Maniototo is something very different from the plurality which Gray advocates. The replicated or mimicked texts put into question the notions of identity and origin because the replication proliferates not discrete individual identities (regional identities in Gray's terms) but 'stylistic diversity

132 Frederic Jameson, 'Postmodernism and Consumer Society,' in Postmodernism and Its Discontents (London: Verso-New Left Books, 1989), p.16. Further references in the text to Jameson, 'Postmodernism.' The discussion of the postmodernity of Living in the Maniototo is developed further later in this chapter. 
and heterogeneity' without any means of anchoring it to the reassuring notion of individual identity. The pastiche of the text puts the notion of identity into question in another way too. It poses the problem for the reader: if one person speaks another person's words, to whom do those words belong and how can they be understood? The plurality of the narrator emphasises this problem further. The identity of the narrator is multiple; she is variously Mavis Furness, Mavis Barwell, Mavis Halleton, the penultimate Mavis, Alice Thumb and Violet Pansy Proudlock; she ventriloquises Roger, Doris, Theo and Zita, and her narrative is infiltrated by verses which she presents from the manifold - one of which is narrated by a geometrical shape - and the narrating personae are liable to change during any section of narration without warning. The plurality and resultant instability of the narrator's identity serves to displace the concept of identity as coherent, individual and essential. Because the identity of the originator of the narrative is constantly unstable, the meaning of what has been said also becomes unstable. The way in which the text poses these questions about identity, origin and meaning (by a proliferation of pluralisms and a refusal to synthesise or to assign value) undermines one of the most problematic assumptions in Gray's analysis, the assumption of the transparency of language.

\section{ii) Anti-mimeticism; defamiliarising the language.}

It is a commonplace of literary criticism on Janet Frame's texts that they are concerned with the power of language to enrich or deceive, and commentators have emphasised the importance of language as a major theme in Living in the Maniototo. Certainly the narrator 
articulates the view that language is all we have for the delicacy and truth of telling, that words are the sole heroes and heroines of fiction'(p.92). But the text also pays attention to language in another way; it continually works against any simply mimetic reading, it interrupts the presumption that language is a transparent medium through which we can see to the world of reference. In this way it reveals the participation of language in the production of identities and boundaries.

There are various strategies in the text which force the reader to look at rather than through its language. Perhaps the most obvious way in which language is foregrounded is in the paronomasic tendencies of the text. It exploits the technical functioning of punning to draw attention, not particularly to the humour of the pun (as the humour is largely removed by the heavy underscoring), but precisely to its technical functioning. For example in the description of the housing of Blenheim we read of '... houses ... those with new false bricks and real bricks over false bricks, and false iron and false wood, and various house-skins or "cladding" ' (p.57); the word 'cladding' is enclosed in inverted commas and so is drawn explicitly to the readers attention. It draws the attention of the reader to the way in which specific meaning is constructed in language, which is by the suppression of plurality. Cladding has become the signifier which refers to the idea of the artificial outside covering of a house, but it can also signify clothing. Placed in inverted commas and juxtaposed with house-skin, both signifieds attached to this signifier, as well as a combination of the two, are all simultaneously present.133 In the usual

133 The terms 'signifier', 'signified' and 'sign' as well as the concept of language as a signifying system have been circulating widely in the area of literary 
process of making sense of a phrase, there is of ten more than one possible signified for any signifier, and the selection of the appropriate one is performed by a reliance on context, but in Living in the Maniototo the text foregrounds multiple meanings and makes the selection of a single meaning problematic.

The forcing of multiple meanings on the reader can be seen again in the punning on the phrase 'New Zealand Bible Belt'. We are told that Brian 'was a product of the New Zealand Bible Belt where parents administer with equal tyranny and force both the Bible and the Belt' (p.91). Again, the reader's attention is explicitly drawn to the possible signifieds attached to the signifier 'belt'; the idea of a geographic area, the idea of a strip of leather used for holding up trousers and a form of the verb which signifies the idea of hitting or being hit. The pun is a construction where two or more possible signifieds are placed in a relation of co-existence where no signified can be excluded in favour of another. It is a structure of plurality, a structure which insists on multiple meaning, and this is its significance in Living in the Maniototo The puns in this text are more than just a self-indulgent form of humour. The problem of effaced or dis-allowed plurality, always possible but rarely allowed to be present, is an idea which is reiterated thematically and textually throughout the novel. 134

theory since Derrida's espousal and interrogation of them in the early 1960 s. They derive, of course, from Ferdinand de Saussure's Course in General Linguistics (1915), trans. W. Baskin (London: Fontana-Collins, 1974 ), pp.111-19, 120-21; rpt in Modern Literary Theory, ed. Philip Rice and Patricia Waugh, (London: Edward Arnold, 1989), pp. 8-15.

134 A similar process is carried out by the deployment of unfamiliar signifiers such as 'unsparkled' ( $p .120$ ), where the reader has no conventionally associated signified immediately to hand and can only supply one by actively and consciously participating in the production of linguistic meaning. A meaning for 'unsparkled' has to be produced by making new divisions among the similar and different terms in the conceptual realm. 
The text opens up the play of pluralities through particular terms: it discusses the way in which, through semantic shifts, the meanings of words which seem opposed to each other can transmute into one another:

I still marvel at the ... richness of meaning within the words 'guest' and 'host,' with a guest as originally a host, a stranger, hostis, an enemy, a host as a guest, an army, a multitude of men, women, angels; planets, stars; a guest as parasite sheltered by the host, the host a sacrifice and ultimately a blessed food (p.133)

At the same time as she ponders the relationship between the words guest and host, Mavis, who is a guest in the house of Irving and Trinity Garrett, is actually transformed into a host upon the arrival of the Garrett's guests, the Prestwicks and the Carltons, whilst still being a guest in the house herself. The meanings of terms becomes uncertain and unstable and unable to be linked unproblematically to the world of reference.

The whole condition of the metaphoric is exploited in the text's assault on mimetic presumptions. A prosaic and commonplace 'dead' metaphor is revivified by being extended and poeticised in a verse from the Manifold. When the narrator remarks of herself that she is 'going to seed' the phrase is identified as a cultural cliché which, because of its overfamiliarity, no longer has metaphorical play in it. The effect the verse has is to force the reader to attend to the metaphorical status of the phrase, and to the way in which the tenor has come to suppress the vehicle, to the way in which one signifier has been masked by another.

Yes, I am going to seed. I know it. 
After being eaten for so many years, cut, recut, forced to branch this way and that, I have grown tall, I have put forth small white flowers, I look over fences into people's faces.

Bees glance at me, the wind has taken me in hand.

My taste is too strong and sour, my growth is rank.

People frown to see me put down yet one more root (p.77).

After the poem, the phrase resounds with the metaphorical richness which had been suppressed by its apparent transparency in its prosaic context. The apparently unproblematic formal distinction between the literal and metaphoric is eroded throughout the text. The supposedly literal is shown to be metaphoric and metaphors become literalised. Shortly before the incident where Tommy is erased by the Blue Fury, Mavis comments on her response to Tommy and muses on the fate of the impoverished artist.

I smiled when he smiled and frowned when he frowned, trying to feel my way in step, as dancers and lovers do, but the agonizing tune was too much - another brilliant career gone, another mark on the world bleached out in the wash. There were so many of them. Already in my brief visit to California and New York I had seen them (emphasis added, p.37).

What initially seems to be a metaphor to describe the depredations of the material world on the hapless artist becomes literalised at the conclusion of Mavis's musings in the surreal but literal bleaching out of Tommy from the world of the novel. Again, through this process, the text forces the reader to look at language as an object and at its operations rather than simply through it.

Living in the Maniototo is a text which is rich in metaphorical resonances. However these resonances do not work to increase the effect of a sensual and complex reality which the reader can recognise 
and with which they can identify. The reality effect of the text is cut across by the repeated emphasis on the operation of language described above, by the constant shifts in tone and style of narration as well as shifts in the person of the narrator and by the fictional jokes of the text.

Particularly in the opening sections of the novel there are a series of metaphorical 'exchanges' through which different sets of ideas become interconnected and linked. For example not only is the investigation of emotion juxtaposed with the investigataion of consumer habits, but emotion is presented in terms usually marked out for the discussion of finance. 'I used to see market researchers writing down a citizen's preference for this or that brand of bedhead, mattress, house paint; social researchers exploring the emotional consumption by asking intimate questions from door to door' (emphasis added, p.23); What the metaphorical exchange emphasises is the comodification of emotion. It is similar to the comodification of loss which is associated with the growth of the modern city;

because if you take part, however remotely, in destruction, you also take pleasure in recreating what you have destroyed, there are many plant nurseries in Kaka Valley where you may buy all the native shrubs and trees .... A consumer's paradise ... where canaries and lovebirds sing, and fly in flashes of blue and yellow, an arrogant costly restoration and reminder, however, of the lost noise of the sun (p.22-23).

Material commodities are equated with emotional commodities and living is represented as a set of discursively constructed relationships. In each area that is linked by the series of metaphorical exchanges the personal or individual becomes indistinguishable from the social. Lance Halleton's desire to pay is described as financial patriotism, a 
natural symptom in a country where the body politic wore papermoney clothes and had kowhai gold in its two-cent eyes' (p.45). Both body and emotions become public and publicly produced. The complexity of this metaphorical play becomes such that the resonances begin to signify between the rhetorical figures of the text rather than effacing its textuality in an apparent reflection of the real.

The text's fictional jokes which preclude a mimetic approach are many and varied. Like the linguistic play, they serve to emphasise the self-reflexive nature of the text, its turning in upon itself, which again interrupts mimetic presumptions. The narrator is writing a book which never gets written, which is forestalled by all the other texts which come crowding in; the characters which are most fully achieved (Zita, Theo, Doris and Roger), are the ones which are dismissed as 'guests in the house of fiction' ( $p .133$ ), the characters who we are led to believe are dead make their return and the 'live' one about whom we are encouraged to forget is fictively assassinated, Lance Halleton suffers a 'death by language' and Lewis Barwell and Theo Cariton suffer a loss of language which prefigures their loss of life. There are parallels between the three locations which all begin with 'B,' and the whole text is crammed with twins, replicas and replication of all types and descriptions. The process of replication and correspondence within the text becomes so complex that the text becomes involutedly selfreferential.

The Blue Fury incident refered to above and these other similarly 'incredible' ones like the Garretts' return from their earthquake death serve to disallow the possibility of a realist reading of the text. In the ways discussed above the text contests the notion of mimeticism and 
through this, a reading wholly within the expectations of a realist framework.

Critics who do try to read the text implicitly within these conventions produce readings which are split against themselves. Patrick Evans pays lip-service to the 'game[s]' that the novel plays and asserts that 'anyone approaching it as a piece of slightly idiosyncratic realism will be puzzled and confused,' that it is 'driven not by experience but by the logic of language that is detached from experience,' but in his discussion of the text, he constantly points outwards to the world of reference, identifying aspects of the fiction with Frame's 'real' life and experience (Blenheim is Glenfield, Brian Wilford is Frame's professorial friend in Baltimore, John Money, and the poet who collapses and dies in the streets of Blenheim is James $\mathrm{K}$. Baxter), and he reiterates that the text is Frame's sharing of her personal vision with the reader. ${ }^{135}$ Robert Ross and Shona Smith also give a token acknowledgement to the text's anti-mimetic strategies but Ross returns to conclude that the novel is a failure in conventional terms and that what saves it is the author's talent to 'reflect ... the truths about the human condition' and Smith engages in a feminist reading within a realist framework which precludes paying any attention to the linguistic play of the text. ${ }^{136}$

135 Patrick Evans, 'Living and Writing in the Maniototo' Span 18 (1985) p.78, p.77, p. 84, pp 76-77.

136 Robert Ross, 'Linguistic Transformation and Reflection in Janet Frame's Living in the Maniototo', World Literature Written in English 27.2 (1987), p.325. and Shona Smith, 'Fixed Salt Beings: Isms and Living in the Maniotote Untold 5 (1986), pp.24-32. 
It would seem then that we need a new set of critical and taxonomic coordinates within which to read this text to take account of the parts of it which are made unavailable by the critical presumptions discussed above. I would suggest that some current discussions of postmodernism and postcolonialism can provide a productive critical access to the previously foreclosed aspects of Living in the Maniototo. 


\section{The dance of identity i) the death of the subject. ${ }^{137}$}

The features of the text which I have been outlining above, its ludic replications, its focus on representation, its undermining of the notion of individual identity are all features which come under the ægis of the term 'postmodern', and several fairly recent local critical accounts identify Living in the Maniototo as postmodern. Simon During's account of the text in his article 'Postmodernism or Postcolonialism' has been particularly influential in designating the text as participating in international postmodernism. During writes of place ('Baltimore, USA and Maniototo') entering 'into a dance of identity which denies autoaffection' (During, p.373).138 I would like to leave the question of 'autoaffection' to one side for the moment and explore in more detail here the way in which current discussions of postmodernism can help us to read the specific ways in which Living in the Maniototo represents identity.

I have suggested above that the multiple narrator, the pastiche in which the text engages, and the whole notion of replication in the text problematises and throws into question the viability of the concept of unique individual identity. Here Frame's text can be seen to be postmodern in so far as it is participating in what Frederic Jameson

137 The 'dance of identity' is taken from Simon During's 'Postmodernism or Postcolonialism?' (p.373) and 'the death of the subject' is taken from Jameson. 'Postmodernism,' p.17.

138 During's phrase is picked up by Linda Hardy in her remarks on the way in which Living in the Maniototo problematises relationships between 'lo]riginal and replica, fiction and reality, author and character' in 'The Ghost of Katherine Mansfield,' Landfall 172 (1989): p.424. The 'dance of identity' also hovers behind Mark Williams's account of During's argument in Leaving the Highway (pp.4546 ), though Williams is keen to emphasise the Platonic and Kantean antecedents of some postmodern notions ( $p p$.46-47). 
calls 'the death of the subject' or 'the end of individualism as such' where 'a unique self and private identity' is seen to be particular ideological production associated with 'classical modernism' and competitive capitalism and is therefore in the current state of late capitalism, 'a thing of the past' He asserts that

today, from any number of distinct perspectives, the social theorists, the psychoanalysts, even the linguists, not to speak of those of us who work in the area of culture and cultural and formal change, are all exploring the notion that that kind of individualism and personal identity is a thing of the past; that the old individual or the individualist subject is 'dead'; and that one might even describe the concept of the unique individual and the theoretical basis of individualism as ideological ('Postmodernism,' p.17).

According to Jameson this death of the subject leaves the artists and writers of the present period without a unique private world to express and 'all that is left is to imitate dead styles,' and hence pastiche becomes the predominant mode of cultural production. He suggests that postmodernist art is going to be about art itself in a new kind of way ... that one of its essential messages will involve the necessary failure of art and the aesthetic, the failure of the new, the imprisonment in the past' ('Postmodernism,' p.18).

Again, leaving aside the function of art and imprisonment in the past' for the moment, Living in the Maniototo can certainly be read productively in terms of Jameson's cultural analysis. Characters act in subservience to cultural and generic codes rather than in accordance with the internal forces of their own delineated psyches. It is constantly emphasised that the four house guests are not original or unique in any way, their dreams, aspirations, thoughts and emotions are immanent in their culture, not in their inner psyches. Brian 
Wilford acts out the discursively constructed role of parent (Maniototo pp.101-02), the Barwell family act out a travesty of conventional social relations where 'Lewis [the father] triles] to put his hand up young Edith's skirt' and even $\operatorname{tr}[$ ies] to seduce his son'(p.26).139 Even when the text presents a moment of domestic intimacy, such as that immediately before Lance Halleton's death, it is not a moment between two fully realised, psychologically complex, unique individuals.

He smiled gently. 'I might have dreamed it,' he said.

He got out of bed and went across to the dressing table and looked in the mirror. He traced with his hand the outline of his forehead and cheek and chin, and as he moved his arm forward, he tipped over the plate of ham sandwiches and they came unstuck and the ham fell out. Tongue-pink. I'd made them from a thick ' $n$ ' thin loaf, the thick end as the thin had already been used.

'It was a mistake,' I said. 'I shouldn't have made ham sandwiches.'

Lance returned to bed and we switched off the light.

'It's not the weather for ham sandwiches,' I said with a determination to be mundane. 'Why were you looking in the mirror?'

'Something I thought of,' he said.

We snuggled again. I could tell that he was smiling in the dark, a smile without hooks or traps.

'De chaque branche part une voix ...'

He completed the quotation, as he used to do, triumphantly as if to say, Ah what a memory!

Two hours later, in his sleep, he coughed violently, and died. They said it was an inexplicable spasm in his throat that choked him (Maniototo pp.63-64).

What is produced by this passage is not a sense of the unique essence of the interior being of Lance and Mavis and their complex psychological interaction, but a sense of an excess of surface. Yet the passage uses the conventions of realist fiction which classically depict

139 This dis-affected view of the nuclear family is radically different from Hyde's merely revisionist notion of 'man, woman, child.' 
the fully rounded, fully realised characters, the Dorothea Brookes and Maggie Tullivers. the Fanny Prices, the Lucy Snowes whose interior lives seems to live and breathe outside the pages of fiction. What the passages does is to overdo those conventions in a mimicry which again produces a blank pastiche, this time of the textual construction of subjectivity. The description of the characters gives no indication of their inner being. In this text the attention to material detail is devoid of emotional significance. One cannot convincingly say that the fate of the ham sandwiches functionsas a discrete objective correlative for the subsequent demise of Lance. What one can say with certainty though, is that one knows more about the constitution of the sandwiches than one does about the constitution of the characters. Where what seems to be the conventional language of affect is attached to the characters, it either regresses to the indecipherably neutral ('smiled gently'), or the cultural cliche ('as if to say, Ah what a memory!'), or departs in the other direction into a semi-surrealism reminiscent of Symbolist poetry ('a smile without hooks or traps'). At the same time the passage has a provoking excess of material detail. One can see here fun being had at the expense of the classic realist novel, (as in the digression about deal tables where an excess of bodily emotion is produced not in response to the dead Garretts, but in response to the representation of the material object in realist fiction). 140 But it is not that the information

140 The passage runs thus:

The Garretts had specified in their will a deal coffin and Julian Soule had thought that in the circumstances a deal table would account for their wishes. . . I suddenly felt the shivering ache of being in touch with fiction, a world at once vanished and newly imagined: Jane Austen, George Eliot, the Brontes, and all the deal tables that in memory were part of the furniture of the old houses in the kitchen at wering Heights, in the dining room at Lowwood school, the school at Brussels; the Mill on the Floss; the houses of Dickens. I felt then like breaking down and weeping ( $p .220$ ). 
that Mavis has made the sandwiches from 'a thick ' $n$ ' thin loaf, the thick end as the thin had already been used,' is irrelevant, so much as that all the information offered is given equal value. There is not, as in Middlemarch or Mansfield Park for example, the privileging of the moral and aesthetic organising consciousness of the protagonist. The most realised detail in this cameo of the domestic interior is the sensualised interior of the ham sandwich, 'the ham fell out. Tonguepink.'

What the text returns to is not a concern with the inner psychological dimensions of the characters' identities, but surfaces and the interactions of surfaces. Lance's interior thought remains absent for the reader, as it does for the narrator, and all that is told of him is the surface that is seen, the impersonalised contours of the surface of a face reflected in a mirror. What is substituted in the text for the concept of identity as the individual mind is a constant return to examining identity and consciousness as a marked interface or unstable and arbitrary boundary. Identity is marked out in a series of spatial metaphors.

Perhaps the most obvious of these are the ones which talk of the body as a house and of houses in terms of bodies. House-space is collapsed into bodily space.

He [Lance Halleton] measured the house, carefully working out ... the volume of each room, the amount of space each would need ... an activity to be commended in a new husband anxious to satisfy the ordinary human needs of his wife and himself and healthily curious about all kinds of space - outer, inner, nearer - that which rests on the skin and before the eyes and can be reached at little or no cost (p.42). 
In fact sensuality is reduced to a matter of surface and materiality, where 'passion was less between husband and wife than between person and furnishing - different models, textures, uses. Sex became a matter of interior gloss and washable surfaces' (p.58). The individual is no longer identified by a unique essence but is a series of socially defined and infinitely replicable spaces and surfaces. Irving Garrett, the town planner, produces not only simulacral cities (his model of his ideal city has no replica), but replicates the human subject, and in doing so, enacts its loss of individuality. 141 He has two photographs of his wife on his desk,

as if, confusing or enlarging upon his faculty for conjuring a city and its buildings, he had chosen to occupy desirable space with flesh and blood instead of with brick and concrete, creating for himself both a wife and a daughter (pp.16-17).

The individual is reduced to 'desirable space' and the bodily reproduction of a daughter is replaced by photographic replication. 142 The phrase 'human house' makes the textual concatenation of the two

141 In a later passage (which is reminiscent of the 'mighty heart' from Wordsworth's 'Lines Composed Upon Westminster Bridge,' and the 'human engine ... / Like a taxi throbbing, from Eliot's 'The Waste Land' yet without the emotional significance of either), the body and the city become completely interchanged:

And I dreamed of . . . the cabbage- and varnish-smelling bedsitter in London ... the soot-smelling rooms that were 'home,' the plastic slop and water buckets, the whistling kettles, the gas rings with the gas lingering at every joint, crevice, around the gas pipe, beneath the windowsill, and in the tenants too, in their joints and crevices, at their fingertips, on their skin, while their hearts must have surrendered their power of beating to the city traffic which, like a giant pacemaker, took over heart-duty, while the actual heart remained in its role of a tired bedsitter muscle, kin at last with the metal gas ring, the frayed linen, the thread-bleeding carpet .... (p.225).

142 This relationship between a husband and a wife who is also a daughter is subsequently replicated in that between Theo and Zita Cariton when Theo says Zita 'is often mistaken for [his] daughter' p.145). 
topologies explicit (p.16) and suggests that what was the individual subject is now a space, like the Garretts's house, not unique, but crammed with likenesses, of replicas, prints of paintings, prints of prints, genuine originals and genuine imitation originals, imitation sculptures and twin original sculptures' (p.17),143

At this juncture in the analysis of the text, it seems that identity becomes not a dance, but a nightmare. The figurative language of the text may redefine identity in terms of surface or boundary, but this boundary or surface is represented as always under threat. The threat to skin, barriers and identity are all linked in Doris's fears in the desert.

... her 'English' skin had been bred and blossomed in a temperate rain, sun, frost. She felt panic at the harsh way the heat of the California sun and the hot breath from the desert ... acted to melt important inner barriers. She was afraid that she too might change and not recognize herself (p.180).

The eradication of boundaries is continually present as a source of anxiety in the text. Brain Wilford's patients are described as being treated with 'wonderful perception and compassion' because they are 'not his opened wounds or memories' (p.102). Skin, surfaces, barriers and identity are all linked and their maintenance is under threat. Lonnie, the child from Palmerston North, who visits Baltimore is distressed at the difficulty of distinguishing between inside and outside in the city. He says

143 From this postmodern perspective the Yeatsless house of the Garretts could be taken to indicate the loss of that Modernist certainty that identity is a viable (if variable notion). In this postmodern space the question asked in response to the injunction to be true to thine own self would be not 'which self?' but 'what self?' 
But there's no real outside. Where's the outside like at home, with the lawn and all that? And there's no inside either; it's all dark. And you should be able to see the outside from inside.... (p.100).

The lack of a boundary is terrifying, as it makes impossible that differentiation between self and other, and in so doing annihilates the only marker of the self. Rupturing, or lesion is a constantly reiterated textual feature; ruptures of skins, shells, houses, laws of physics, 'reality' and of language occur within the text. Brian's anxiety about his precariously maintained identity is articulated in his string of references to ruptures and losses: 'Who- spilled, tipped, tore, split, left, dropped, lost, broke?' (p.104.). What is being articulated is the fear of 'an inevitable break in the surface of things' (p.38), which will annihilate the possibility of marking difference and hence identity. Of course Tommy's disappearance at the hands of the Blue Fury is described in the text as a shocking 'plague of unreality,' and explained by the narrator as the result of an inevitable break in the surface of things, as if a fire from the centre of the earth or a volcano beneath its skin had at last been forced through into an overtaking of the visible world' (p.38).

There is a marked difference between Brian's response to the Blue Fury incident and Mavis's which raises the question of the relationship between this postmodern view of identity and the function of the artist. Brian says 'Things like that don't happen,... I shan't mention it to anyone'(p.38). But Brian has also been represented as 'reluctant to be reminded of the necessary untidiness, the wilderness aspect, seen and unseen, of human life' (p.102). Mavis, the writer, however has a very different response to the epistemological, ontological and taxonomical problems which the Blue Fury presents. Although both 
characters are shaken, Mavis attempts no denial of the events. Her speech in the text links the incident specifically with forms of knowledge disallowed by the dominant discourse:

Those creatures and worlds that we know only in sleep and dream and mythology - of yesterday and today - the magical technology - are emerging as usual reality in the new dimension of living and dying. And when the unreal has been accepted and made real, new realities will present themselves, forces which become gentlenesses, gentlenesses which become forces(p.39).

Such a fluidity of boundaries, of categorisation which throws into question the whole notion of reality is untenable by the other characters. Mavis, the writer, is the only one who is frightened of neither the proscription of the boundary, nor the dangers inherent in lesion.

The skin riddle at the opening of the text represents the boundary of skin as a prison and a protection at the same time.

The sun has burned me. I bleed.

I break and mend. I knit.

I am a garment, a prison. I protect flower and seed.

I shrink and stretch, yet I always fit.

I'm a prison you must stay in.

What am I ?

I am your skin. (p.14.)

Unlike the 'false' artist, Howard Conway, Mavis is all too aware, and ready to accept the limitations of the boundaries that divide self from other, to work with the difficulty of the

separation between the "I" and the characters of the story, and the enormous burden upon the "I" to "tell all" while viewing through the narrow I-shaped windows that restricted the vision and allowed only occasional arrows to be 
fired with no guarantee that they would pierce the armour of 'otherness' worn by the characters of the book (p.61).144

Refusing this position is derided. The narrator is scornful about Howard Conway's prohibitions on the use of the first person,

'Never use it,' he said, and I might have been surprised by his tidy air of caution had I not realized that a skin-trapped ' $\mathrm{I}$ ' could have no place in the writing of such a roving omniscient as Conway (pp.61-62).

The artist figure, Mavis, undermines the notion of omniscience and claims to complete knowledge, particularly those which are articulated and assured through scientific taxonomies. What is emphasised are the possibilities for conceptualising existence and identity outside the conventional taxonomies:

I see now how close death is to the process of 'going to seed,' for both are merely an abundance of life which shocks and frightens by its untidiness, its lack of boundaries and the finality of its choice of a place to grow (p.78).

To think of death as 'merely an abundance of life' is to undo a binary opposition which is firmly grounded as a truth in western society. The function of the artist is to work across and through the boundaries through which meaning and identity are produced, with an awareness that both are relative and conventional, metaphysical rather than essential.

At this point I would like to return for a moment to one of the questions put aside earlier and to ask how useful Jameson's formulation of postmodern art is in relation to the way in which it is represented in Living in the Maniototo. Jameson's suggestion that postmodernist art is going to be about art itself in a new kind of way..

144 of course, the text is playing with this notion, as the ' $I$ ' of this narration is multiple and diffuse. 
that one of its essential messages will involve the necessary failure of art and the aesthetic, the failure of the new, only holds in part for this text. Certainly the absence of Yeats in the poem operates to indicate the failure of modernist art to hold its significance in a postmodern world, and the replication of other texts could be seen to represent the failure of the new and the consequent shift into pastiche, but I think that the text reassesses art and the function of the artist in a way slightly different to the one which Jameson outlines. The artist here is certainly not the Romantic artist, with a unique consciousness, but one who negotiates boundaries. The artist is organiser of the public and personal myths: 'By then I was in bed and asleep, drawing dreams from the manifold, but holding no responsibility for them until I could interfere with or change their shape and direction'(p.31).

Aesthetic judgement is still present in the text, but it is no longer concerned with the articulation of universal human truths, but with textuality, attendance and the production of meaning. The aesthetic code which Mavis propounds is one which is reinforced rather than undermined by the text as a whole.

- a prose sentence which touches like a branding iron is good. A sentence which keeps its feet clean from beginning to end is good. A sentence which, traveling [sic], looks out of portholes as far as horizons and beyond is good. A sentence which goes to sleep is good, if the season is winter; bad if it is early spring. A sentence which stumbles on useless objects instead of buried treasure is bad, worse if it illuminates useless objects with artificial light, but good if it casts a unique radiance upon them.

A word, which is exciting to look at and say and which doesn't slop its meaning over the side, is good; a word which comes up sparkling from the well is good; a word which clusters like last year's bee around last year's flower is bad, if the flower is already dead, but good if the flower is surviving, beautiful, and alone in a place where flowers have 
not been known to grow and where bees never swarmed before nor gathered nectar (Maniototo p.50).

In a series of ungrounded metaphors an aesthetic is produced which does not celebrate an accurate mimesis, but rather celebrates the act of paying attention. Textual production is envisaged here as a compulsive proliferation with no purpose and no end: 'there is no end to it in the literate world, explaining and telling, propagating and admiring the tongue blossom' (p.143). And attendance, we are told, is 'presence, being present, ... the payment for the dark debt of absence or death. Or ... a response to the Hypotenuse longing' ( $p .45)$. What underlies the compulsion to attend (and thereby to proliferate texts) is the 'yearning ... to identify the original as itself apart, not as real or unreal, or opposite or adjacent' (p.45).

What arises from this series of ideas which the text presents, but does not explicitly connect, is the desire for a space of alterity, for a 'form of otherness irreducible to and unable to be modelled on any form of projection of or identification with the subject. ... a notion of the other outside the binary opposition between self and other, an independent and autonomous other with its own qualities and attributes. ... outside of, ... and ontologically prior to the subject. ${ }^{145}$ This desire is for a space which is outside the series of boundaries and oppositions which simultaneously enable the production of meaning and identity and restrict and delimit them. This desire for a space of alterity, the Hypotenuse longing, is not however simply a version of the utopian postmodernism which imagines a liberated and egalitarian space created by the movement of culture and texts beyond oppressive

145 Elizabeth Grosz, Sexual Subversions, (Sydney: Allen \& Unwin, 1989), p.xiv. 
binary oppositions.'146 Beyond the restrictions of linguistic or conceptual markers of difference lies not only liberation but also annihilation. (The proliferating replications of the text, which lack identity, suggest the problematic other face of postmodernism, where the space beyond markers of difference is not so much achieved as thrust upon one.) This text positions itself in a more complex relationship to alterity. The Hypotenuse longing is connected with the 'dark debt of absence or death', it is recognised as an unfulfillable desire for the lost 'original which cannot be matched in value,' as an impossible desire to be free of both the fixity and the slippage of all meaning (p.45).

It is in this condition of loss or impossibility that the production of texts occurs; we are told by the voice of the Hypotenuse in a verse from the Manifold that to write you have to be at the terrible point of loss,' 'that life-dealing want' has to 'fill the world' for writing to proceed (p.72). In 'want' there is the collocation of absence and desire which suggests writing as the conscious filling of gap, of attempting to fill absence with the presence of the text. In Living in the Maniototo textual representation itself thus occupies a contradictory position; it is overtly located in a paradox where it simultaneously signifies loss and fills up that gap.

146 'utopian' is the name which E. Ann Kaplan gives to this version of postmodernism arising primarily out of the French feminist work on deconstruction. Although she does not use this term, Gina Mercer's analysis of Living in the Maniototo is one which sees it as a text which advocates and enacts a utopian postmodernism ( Gina Mercer, 'The Subversive Fiction of Janet Frame,' diss., U of Sydney, 1989, pp.226-254). Both the text's acknowledgement of the alignment between alterity and death and its participation in a co-opted postmodernism of the type described by Jameson prevents the text being read simply in terms of a utopian postmodernism. 


\section{The dance of identity: ii) No-one lives here?}

I would like here to return to two other issues which were put to one side earlier: the problem of 'auto-affection' which Simon During identifies and the problem of 'imprisonment in the past' which Jameson raises.

During's article, which has been influential locally, turns upon an impasse which besets current critical theory working at the intersection of postmodernism and postcolonialism. On the one hand ex-colonies are driven by the need to assert a distinct national identity to establish their independence and separation from the colonising power (their postcoloniality), whilst on the other hand the whole notion of identity, national or individual, is undermined by the condition of postmodernity. In this impasse, as During suggests, the question of reading becomes both crucial and highly politicised. Readings of the texts produced in postcolonial societies which do not take account of postmodernity and emphasise or celebrate representations of national identity risk mistaking the metaphysical for the essential (i.e. subscribing categories which are arbitrary and chimerical as if they had some substantive and natural status): readings of texts produced in postcolonial societies which do not take account of postcolonialism and emphasise the texts' postmodernity risk collusion in the neoimperialism with which postmodernity is associated. 147

147 The notion of the imperialist dynamics of co-opted postmodernism is fairly widespread. Here is a clear articulation of it from Seamus Deane: 'To remove ourselves from that condition ... in which the postmodernist simulacrum of pluralism supplants the search for a legitimating mode of nomination and origin, is surely to pass from one kind of colonizing experience into another. ... it is the concealed imperialism of the multinational .... ' (Deane, pp.18-19). 
There is, however, another impasse which is implicit in During's readings of Living in the Maniototo and Keri Hulme's The Bone People. ${ }^{148}$ During discusses the 'crisis of emptiness' which he claims besets Australian postcolonial discourse and claims that this stems from an imbalance in postcolonising and postcolonised voices and results in an 'auto-affective' talking to oneself. 149

Australia's distance from the centre, the voids of its deserts become metaphors of the emptiness of Australian autoaffective discourses. It need hardly be said that those deserts are only empty to those blind to the lives lived there: they are blank to the degree that the indigenous postcolonised voices are silent (During, p.371).

During clearly sees auto-affective discourse as form of 'consolatory nonsense' which stems from the need for self definition not only against the identity given . . . by [the] colonial past but also against international postmodernism' in the absence of 'effective postcolonised discourse' (p.371). It would seem to be implicit in his argument, then, that the presence of an effective postcolonised discourse prevents the slide into empty auto-affective discourse. However, in During's reading of the two New Zealand texts, what is located as preventing autoaffection is not actually the postcolonised voice but the entry into the postmodern 'dance of identity' (p.373).

His reading of The Bone People identifies the way in which the desired postcolonial identity in the text is articulated through connection with manifestations of precolonial culture, but that the whole text itself re-enacts a cultural colonisation where 'Maori culture

148 Keri Hulme, The Bone People (Auckland: Spiral-Hodder \& Stoughton, 1985).

149 During, (pp.369-70). 
is absorbed and controlled by its profoundly Occidental narratives' (p.374). The postcolonised voice is silenced by modernity in During's account of The Bone People and that same modernity also renders the text archaic. In his reading of Living in the Maniototo his account of the intersection of the postcolonial with the postmodern in the text leaves something of a gap.

Whereas During sees in The Bone People the subsumption of postcolonial cultural identity by a Western modernism, he reads in Living in the Maniototo the subsumption of postcolonial cultural identity by postmodernism. Whilst I concur broadly with the accounts which locate Living in the Maniototo as a postmodern text for reasons which I have outlined above, there is a blind spot at the very crux of During's argument where he sees the intersection of postmodernism and postcolonialism in Frame's text. During identifies the failure of the authenticating gestures made towards modernism and towards a New Zealand identity as the basis of the text's postmodernism and postcolonialism.

... both gestures fail. The novel itself ultimately works as a pastiche of the modernism it would like to recognise as expressing authenticity. ... And its very title Living in the Maniototo gives the other game away. No-one here lives in the Maniototo: and the Maniototo, a flat, characterless plain, was granted identity by its most famous inhabitant, a writer whose details replicate those of Ronald Hugh Morrieson. His texts, of course, owe more to international gothic than to postcolonialism. He has an alter ego in the book anyway: Frame supposes that Edgar Allen Poe is Baltimore's absent identity-giver. Thus Baltimore USA and the Maniototo enter into a dance of identity which denies auto-affection (p.373).

In his assertion that 'no-one here lives in the Maniototo' (emphasis added), During actually replicates the blind spot which he criticises in his account of the auto-affective discourse of the Australian 
postcolonisers. During's comment that it 'need hardly be said that those deserts are only empty to those blind to the lives lived there: they are blank to the degree that the indigenous postcolonised voices are silent' can be usefully applied to his own text. I do not mean to suggest that one should document how many people live in Patearoa but that the way in which the dynamics colonialism and postcolonialism are represented in Frame's text, and the way this intersects with that text's postmodernity, could perhaps bear a little more examination. Authenticating gestures towards New Zealand geography may fail, but there is still the presence of specifically colonial dynamics in the text.

I will argue that the text of Living in the Maniototo itself perhaps points to a way out of the theoretical impasse where, on the one hand to assert national identity is simultaneously naive and archaic, and on the other hand to relinquish the concept of national identity is to be subsumed by the simulacral culture of late consumer capitalism. What this theoretical impasse is structured around is a binary opposition between essentialism and anti-essentialism, so that any analysis in a text (whether fictional or critical) which asserts the value of the local is read as participating in constructing and perpetuating a myth of national identity and any text which is based on a premise of antiessentialism, and so participates in a postmodern cultural discourse, is seen to be rendered silent about the postcolonial grounds of its production. I would like to suggest that the local and specific can be invoked in a text without necessarily invoking the notions of presence and identity which would make them complicit in reproducing the myths of national identity which are based on false essentialisms; it is 
my contention that it is precisely this which Living in the Maniototo achieves.

I have already discussed above some specific representations to place and the way in which those representations work towards dismantling some myths of national identity. But the text makes itself specifically local in another way which creates a block to its complete subsumption by a co-opted postmodernism, but does not necessarily indicate its collusion in the production of essentialist identities. The text returns repeatedly to the history and dynamics of colonialism, imperialism and racism. The repetition of this history can be seen as productive. It stands in contrast to the disavowal of colonial history which was traced in the texts of Mansfield and Hyde.

Many of the references to colonialism, imperialism and racism seem to be parenthetical or incidental, sometimes consisting only of the metaphoric vehicle, but they are there as textual presences, not as textual aporia and their effect is cumulative. Blenheim is descibed as a 'disinherited suburb-city' (p.22), the children of which are not 'truly ... native' ( $p .21$ ), and the skulls in the gardens of this Auckland suburb are a sinister reminder that the comfortable suburban living in New Zealand is built on the history of colonial expansion and slaughter (p.23). The version of history in which the colonised is construed as an asocial, uncivilised force is critiqued by its comparison to an unhappy marriage:

Our marriage was not excessively happy. We plodded along because we'd been taught to, by the examples of our parents, in the same way that we'd been taught to think of our country, its peoples and history, as perfect except for the occasional characters who spoiled the picture ... Hone Heke who was 'bad' because he cut down the flagstaff three times (p.23). 
Stratford, Taranaki is described as a town full of 'bloody history' (p.77), and the expropriation of land is given a particular New Zealand context when the narrator asks rhetorically 'where else [but New Zealand] is there such critical judgement of land, its shape, color, texture, fertility, and such extraordinary yearning among those who took over the land for a plot or section that is flat ...' (pp.132-33), and comments that 'in New Zealand ... we insist that we have no partners when we exercise our presumed right to destroy [the land]' (p.131). The fact that New Zealand is a colonised country and that the act of colonisation has dislocated both colonised and colonising is reiterated throughout the text. Yet the dislocation registered here does not resolve itself either in the advocation of a cultural synthesis (in the attempt to produce a new national identity as discussed above), or in the reiteration of England as the ultimate home. Rather the text goes on to offer a wider ranging critique of the dynamics of imperialism.

Theo (who has already been likened to Balboa or Cortez 'planning possession') thinks of a geography of opinion which is part of the 'Empire of Prejudice.' The figurative langauge links imperialism with discrimination, and the importance of the metaphor is further emphasised by a self-conscious textuality which explicitly locates the metaphor as the narrator's - and the disavowal as Theo's - 'This habit of metaphor, by the way, is yours, Alice Thumb, Violet Pansy Proudlock, not mine' (p.144).

Roger's speech with its ' "marble-in-mouth" accent of some Englishmen,' is associated with 'past imperial domination,' again invoking the power dynamic that goes with the project of colonisation. The threat posed to imperial identity by the local variety of English 
and the imperial devaluation of the local because of this is humourously outlined in a simile which simultaneously suggest the domestic and the dangerously exotic: ' . . New Zealand English, as an offspring of "standard" English allied to other varieties and Polynesian intonation, had a pleasant neutrality, as if it had been suitably "fixed" or "altered" like a cat in danger of breeding a colony of cats' (p.191). The irony of this phrase indicates an awareness of the threat to metropolitan identity posed by the incipient nationalism of the excolonies. Linguistic identity is again linked explicitly to the dynamics of imperialism where the danger of Zita being colonised by the English language is likened to the imperialist conquest of nations,

had she gone beyond the learning of essential names, she might have been taken over by the English language as surely as the nations in the Wall Chart of the Condensed History of the World had been conquered and their tiny column of red or grey or blue or green erased (p.200),

and the erasure of linguistic and cultural identity which imperialism effects is repeated on a national scale in the legend of the chart itself .

This chart graphically represents the progress of man from the dawn of civilization to the present. Each nation or ethnic group is shown by a color [sic] band with dates of important events and persons to the right. Reading downward one may follow the rise and fall of empires, the emergence of new cultures and the migration of others. With a glance across the chart the reader can view the developments in all parts of the world at a particular moment in history. The relative expansion and decline in world powers is indicated by the width of the columns. Stripes of a different color show conquest or strong influence by an outside nation. When a nation loses its political identity the column merges into that of the conquering group (p.200).

The legend on the wall chart is quoted verbatim as it were, in a parenthesis, and the narrative moves straight on to other questions, 
thus this legend sits unexplicated in the text. What brings itself to the reader's attention however is the pomposity of the tone of the legend which goes hand in hand with its finality, its absoluteness, its totalising and hegemonic view of the world which places all nationalities and ethnic groups under its scopic control. The dynamics of imperial expansion are linked to conquest and assimilation. However the phrase 'the emergence of new cultures' is highly reminsicent of Mavis's explanation of the appearcince of the Blue Fury.

Those creatures and worlds that we know only in sleep and dream and mythology - of yesterday and today - the magical technology - are emerging as usual reality in the new dimension of living and dying. And when the unreal has been accepted and made real, new realities will present themselves, forces which become gentlenesses, gentlenesses which become forces(p.39).

As I suggested earlier, the notion that reality itself is conventional and therefore not able to be grasped through empirical knowledge challenges the possibility of hegemonic knowledge and this in turn has its place in undermining essentialisms, particularly those associated with identity. In this way, the eruption of the Blue Fury into the text can be seen as a particularly postmodern moment which represents all subjects as no more substantial (or three dimensional) than an advertising image from the television screen. This is the way in which the Blue Fury has been read in those critical acccounts which pay attention to it. 150

150 During comments that' [clonsumer goods - cleansing agents especially - are anthropomorphised in a chiasmic movement in which commodities are humanised while characters are fictionalised, dehumanised. And the characters ${ }^{t}$ lives are lived under the control of forces which are neither willed, nor ordered by any knowable rationalised frame. They live as products of and within postmodernity' ('Postmodernism or Postcolonialsim' p.373). Evans sees the Blue Fury more simply as the product of 'a writer determined to show how easily 
However, the Blue Fury is invoked elsewhere in the text and the context of this other reference has gone unremarked and the silence about this area of the text begs some questions. It is Mrs Tyndall, the black American cleaning woman in Brian Wilford's flat, who is likened to the Blue Fury.

It is in this section of the text that Living in the Maniototo most clearly articulates the problematic politics of postcolonialism. The description of Mrs Tyndall continues for three pages before it gives an indication of the racial difference between the narrator and Mrs Tyndall. However in this space what has been made clear in vivid detail is the economic and social gulf between Mrs Tyndall and her employer. The information about Mrs Tyndall's racial identity is introduced obliquely at first. It is presented in a conditional clause which makes it possible that Mrs Tyndall does not necessarily share the racial identity of the raiders who are clearly not white.

Because she was of an older generation, she had learned to suppress or dismiss the desire for a fair share of the world's goodies. Had she been younger she might have behaved like one of those who stormed down Fifth Avenue one evening, raiding the most exclusive shops for 'white man's sweaters' (p82).

What is clear is that she is old and economically deprived. However, the section very quickly becomes more explicit in its discussion of race relations.

'Dr Brian is very good to me,' she'd say as she was leaving, pointing to her bag of food. Yet there was a glitter of contempt in her dark eyes. We both knew she was too old and too tired to be slaving for Master Clean, Bright and White (p.83).

fictional characters can be scrubbed out' ('Living and Writing in the Maniototo.' in Span 18 (1984), p.77. 
The white, liberal benefactor, $\mathrm{Dr} \mathrm{Br}$ ian, who is so good to his black charwoman, is transposed in this last sentence to a 'White' 'Master' for whom she 'slave[s].' Legal slavery may have been abolished, but its legacy here is clearly traced in the relationship of economic slavery between Mrs Tyndall and Dr Brian. It is in this context that Mrs Tyndall is transformed into the Blue Fury.

... the bathroom was looked on as the white person's domain, for they, with their black skin, had always been encouraged to think that their skin was unclean (I had seen bottles of skin bleach still displayed in the drug stores); and by the time Mrs Tyndall had cleaned the bathroom and knelt at the tile-surrounded bath and the furred lavatory altar she came at last to life with a kind of whirling rage at the indignity her race had suffered, and in accordance with the role of the Blue Fury within the bottle of cleanser she erased all trace of Brian and me from the bathroom (p.86).

The Blue Fury is clearly associated with a break in 'reality', but its context here invites a reading with a slightly different emphasis from that which sees it as the signifier of a simulacral postmodernity. The Blue Fury can be read as that colonised presence which threatens to disrupt the structures of white Western postcolonising. This whitewashing does not work and difference reasserts itself. It is these moments of pure violence, of 'blue fury', in the text which cut across the neo-imperialism of postmodernity. The disruptive violence is that which can 'break' the 'pattern of the world' (Maniototo p.67). These moments do not seek to retrieve the notions of identity and presence, but neither are they completely subsumed within the operations of postmodernity. 


\title{
CONCLUSION
}

\section{Permanent nostalgia}

\author{
or \\ the conclusion in which \\ nothing is concluded.
}

\begin{abstract}
nostalgia, n. Home-sickness as a disease. [f. Gk nostos return home, Gk algos pain, -IA], (Concise Oxford Dictionary).
\end{abstract}

Homesickness as a disease permeates the texts of the colonising peoples. From the inconclusion of Johnson's Rasselas to Living in the Maniototo's refusal of closure, there is no satisfactory resolution to the problems of location and identity. 151

The texts of the colonising and postcolonising writers examined here are caught in a permanent nostalgia for which there is no alexipharmic. Loss of autochthonicity is the founding condition of coloniality. Anxiety about this loss is manifested in all the texts which have been discussed.

151 Samuel Johnson. 'The History of Rasselas, Prince of Abyssinia,' in Samuel Johnson (Oxford: Oxford UP, 1989) pp.335-418. 
Although this condition of coloniality is produced by a founding moment in history, the way in which that condition is manifested in the texts is not fixed and transhistorical. Coloniality is displayed differently in each of the three groups of texts.

In the Mansfield texts, which were mainly produced in the second decade of this century, coloniality is displayed in the strenuousness of the attempts to assert a position of European autochthonicity. There are two main strategies by which this assertion is carried out. Firstly, the colonising subject is presented in a series of stereotypes which attempt to fix and control the difference between the narrative's identification and its subject matter. This strategic disavowal is undermined by the signs of contiguity between the narrator and the discriminated colonial subjects. Secondly, identification is asserted with the cultural artefacts of European high culture. Autochthonous Europeans are produced as stereotypes and disassociated from European high culture. This allows the narrator to claim an autochthonous relationship to European high culture. The coloniality of the narrative voice is revealed by the strenuousness of its attempts to assert the European identification.

The Hyde texts all date from the 1930s. The explicit exploration of colonial dislocation in their narratives is mirrored in the fractured structures of their narratives. Their attempts to assert a national identity rather than a colonial one are effected by disavowal. National identity is characterised here by a libertarian ethos. However, the discriminated subjects produced in these texts are the colonised people rather than the colonising peoples. In these stereotyped figures the traces of racism return as a reminder of the conditions of coloniality. 
The one Frame text given detailed attention dates from the late 1970s. There are no discernible strategies of disavowal in this text. It constantly revisits the history of colonisation and charts the violence of its dynamics. At the same time, it renders problematic any assertion of fixed identity by its textual engagement with replication. Frame's text attempts to articulate the foundering moments of individual and national identity rather than their founding moments. At the same time the text marks and mourns the loss of these metaphysical categories.

Amongst the texts examined in this thesis, there is not a successful attempt to produce a national literature founded in national location. Nor can there be under the conditions of postcoloniality. All too of ten in writing about colonial literature, the production of national literature is envisaged as a biological or teleological progression. It is envisaged growing, organically, from a few embryonic settler scribblings, through a colonial and provincial adolescence, until it emerges as a fully fledged and adult national literature (which was always already its goal). Frederic Jameson suggests another model which can help to explain the absence of a secure national literature.

He argues that 'daily life and existential experience in the metropolis $\ldots$ is necessarily the very content of the national literature itself.' 152 He further suggests that, for the metropolis, the advent of colonialism

152 Frederic Jameson, 'Modernism and Imperialism,' in Terry Eagleton, Frederic Jameson, and Edward Said, Nationalism, Colonialism and Literature (Minneapolis: Minnesota UP, 1990), p.51. Further references to 'Modernism' in the text. 
meant that a 'significant structural segment of the economic system as a whole' was now 'located elsewhere ... outside of the daily life and existential experience of the home country' ('Modernism,' pp.50-51). Because of this, the 'very content of the national literature itself, can now no longer be grasped immanently; it no longer has meaning, its deeper reason for being, within itself' ('Modernism, 'p.51). He argues that colonialism removes the possibility of national literature for the imperial nation.

I suggest that it also removes the possibility of a national literature for the ex-colony. At the founding of the New Zealand colony, a significant structural section of its economic system was, of course, outside itself. Under the hegemony of multinational consumer capital it will remain so. Frame's text is hailed as postmodern (and by implication, therefore not provincial). I conclude that it is not New Zealand literature which has opened its horizons to international postmodernism, but that the permanent nostalgia, which is the condition of coloniality, has become, also, the condition of the world. 


\section{SELECTIVE BIBLIOGRAPHY}

\section{CONTENTS}

(i) EDITIONS OF PRIMARY TEXTS USED
(a) KATHERINE MANSFIELD
(b) ROBIN HYDE
(c) JANET FRAME

(ii) BOOKS AND MONOGRAPHS - CRITICISM
(a) KATHERINE MANSFIELD
(b) JANET FRAME

(iii) ARTICLES
(a) KATHERINE MANSFIELD
(b) ROBIN HYDE
(c) JANET FRAME

(iv) UNPUBLISHED THESES

(v) OTHER WORKS CONSULTED
(a) ARTICLES
(b) BOOKS AND MONOGRAPHS
(c) REFERENCE WORKS 
(i) EDITIONS OF PRIMARY TEXTS USED
(a) KATHERINE MANSFIELD

Mansfield, Katherine. The Aloe. London: Virago, 1985.

--- The Journal of Katherine Mansfield. Ed. J. Middleton Murry. London: Constable, 1929.

---. The Letters and Journals of Katherine Mansfield: A Selection.

Ed. C. K. Stead. Harmondsworth: Penguin, 1977 ed.

---. The Letters of Katherine Mansfield. Ed. J. Middleton Murry. Vol. 1. London: Constable, 1928.

---. The Scrapbook of Katherine Mansfield. Ed. J. M[iddleton] M[urry]. London: Constable, 1939.

--. The Stories of Katherine Mansfield. Ed. Antony Alpers. Auckland: Oxford UP. 1984.

(b) ROBIN HYDE

Hyde, Robin. Check To Your King: The Life History of Charles, Baron de THierry. King of Nukahiva. Sovereign Chief of New Zealand. London: Hurst, n.d.

---. Disputed Ground: Robin Hyde, Journalist. Comp. Gillian Boddy \& Jacqueline Matthews. Wellington: Victoria UP, 1991.

--- . The Godwits Fly. Ed. Gloria Rawlinson. Auckland: Auckland UP, 1980. 
--- A Home in This World. Auckland: Longman, 1984.

--- Nor The Years Condemn. Auckland: New Women's Press, 1986

--- Passport To Hell. Auckland: Auckland UP, 1986.

--- Selected Poems. Ed. Lydia Wevers. Auckland: Oxford UP, 1984.

---. Wednesday's Children. Auckland: New Women's, 1989.

---. Wednesday's Children B-15. ts. Manuscripts Collection, U of Auckland.

(c) JANET FRAME

Frame, Janet. A State of Siege.London: Allen, 1967.

--- An Angel At My Table: An Autobiography: Volume Two. Auckland: Century, 1985 ed.

--- The Carpathians. Auckland: Century,1988 ed.

---. Daughter Buffalo. Auckland: Century,1986 ed.

--- The Edge of the Alphabet. Christchurch: Pegasus, 1962.

--. The Envoy From The Mirror City: An Autobiography: Volume Three. Auckland: Hutchinson, $1986 \mathrm{ed}$. 
--. Faces in the Water. London: Women's, 1980.

--. Intensive Care. Auckland: Hutchinson, 1987 ed.

---. Living In The Maniototo. London: Women's, 1981.

---. Scented Gardens For The Blind. London: Women's, 1982.

(ii) BOOKS AND MONOGRAPHS

(a) KATHERINE MANSFIELD

Alpers, Antony. The Life of Katherine Mansfield. Oxford: Oxford UP, 1982.

Fullbrook, Kate. Katherine Mansfield. Key Women Writers Series. Brighton: Harvester, 1986.

Hanson, Claire., ed. The Critical writings of Katherine Mansfield. Houndmills, Basingstoke: Macmillan, 1987.

Tomalin, Claire. Katherine Mansfield: A Secret Life. London: Penguin, 1988 ed.

(b) JANET FRAME

Delbaere, Jeanne., ed. Bird. Hawk, Bogie: Essays on Janet Frame. Aarhus, Denmark: Dangaroo, 1978. 
Panny, Judith Dell. I Have What I Gave: The Fiction of Janet Frame. Wellington: Brasell, 1992.

(iii) ARTICLES

(a) KATHERINE MANSFIELD

Alcock, Peter. 'An Aloe in the Garden: Something Essentially New Zealand in Miss Mansfield.' Journal of Commonwealth Literature 11.3 (1977) 58-64.

Beachcroft, T. 0. 'Katherine Mansfield - Then and Now.' Modern Fiction Studies 24 (1978) 343-54.

Harding, Bruce. 'Mansfield, Misogyny and Murder: 'Ole Underwood', 'The Woman at the Store' and 'Millie' Revisited.' lournal of New Zealand Literature 6 (1988) 119-135.

Hardy, Linda. 'The Ghost of Katherine Mansfield. 'Landfall 43 (1989): 416-32.

Hankin, Cherry. 'Fantasy and the Sense of Ending in the Work of Katherine Mansfield.' Modern Fiction Studies 24 (1978): 465-74.

Justus, James H. 'Katherine Mansfield: The Triumph of Egoism' Mosaic 3 (1973): 13-26.

Nebeker, Helen E., 'The Pear Tree: Sexual Implications in Katherine Mansfield's 'Bliss'. Modern Fiction Studies 18 (197273): 545-551. 
Orr, Bridget. 'Reading with the taint of the pioneer: Katherine Mansfield and settler critcism.' Landfall 43 (1989): 447-61.

Wevers, Lydia. 'How Kathleen Beauchamp Was Kidnapped.' Women's Studies Journal 4.2 (1988): 5-17.

(b) ROBIN HYDE

Ash, Susan, Introduction and Afterword. Wednesday's Children. Auckland: New Women's 1989. 5-7, 289 - 95.

Birbalsingh, Frank. 'Robin Hyde, Landfall 31 (1977): 365-66.

Cox, Shelagh. 'Creating a Bearable World: Imaginative Transformation of an Alien Society in the Fiction of Robin Hyde \& Angela Carter.' Women's Studies Conference Papers 1982.11-18.

Sandbrook, Patrick. 'Two Responses to Armstrong's Hyde.' Landfall 36 (1982): 329-337.

(c) JANET FRAME

Calder, Alex. 'The Closure of Sense: Janet Frame, Language and the Body.' 
Evans, Patrick. ' "Farthest from the heart": the autobiographical parables of Janet Frame.' Modern Fiction Studies 27 (1981): 31-40.

---. 'Living and Writing in the Maniototo.' Span 18 (1985):76-88.

Ross, Robert. 'Linguistic Transformation and Reflection in Janet Frame's Living in the Maniototo.' World Literature Written in English 27.2 (1987):320-326.

Smith, Shona. 'Fixed Salt Beings: Isms and Living in the Maniototo.' Untold 5 (1986) 24-32.

Harris, Wilson. 'On the Beach.' Landfall 39 (1985): 335-41.

(iv) UNPUBLISHED THESES

Ash, Susan. 'Narrating a Female (Subject)ivity in the Works of Katherine Mansfield, Robin Hyde, Janet Frame and Keri Hulme.' Diss., U of Otago, 1990.

Mercer, Gina. 'The Subversive Fiction of Janet Frame' Diss. U of Sydney, 1989.

(vi) OTHER WORKS CONSULTED
(a) ARTICLES 
Bhabha, Homi K., 'Signs Taken for Wonders: Questions of Ambivalence and Authority Under a Tree Outside Delhi, May 1817.' Europe and its others: volume one Proceedings of the Essex Conference on the Sociology of Literature. July 1984 ed. Francis Barker, Peter Hulme. Margaret Iversen and Diana Loxley. (U of Essex: Colchester, 1985):89-106.

---. 'Of Mimicry and Man: The Ambivalence of Colonial Discourse.' October 28 (1984):125-33

---. The other question: difference, discrimination and the discourse of colonialism.' Literature. Politics and Theory: Papers from the Essex Conference 1976-84. Methuen: London(1986): 148-172.

Deane, Seamus. Introduction. Eagleton, Nationalism 3-19.

During, Simon. 'Postmodernism or Postcolonialism?' Landfall 39 (1985): 366-380.

Garrebian, Keith. "V. S. Naipaul's Negative Sense of Place.' Journal of Commonwealth Literature. 10.1 (1975): 23-35.

Ginsburg, Michal Peled. 'Pseudonym, Epigraphs, and Narrative Voice: Middlemarch and the Problem of Authorship. English Literary History 47 (1980): 550, 552. Baltimore: Johns Hopkins UP.

Gray, Stephen 'A Sense of Place in the New Literatures in English, Particularly South African,' A Sense of Place in the New Literatures in English. Ed. Peggy Nightingale. St Lucia: Queensland UP, 1986. 5-12. 
Huggan, Graham. 'Philomela' Retold Story: Silence, Music, and the Post-Colonial Text.' Journal of Commonwealth Literature 25.1 (1990): 12-23.

Jameson, Frederic. 'Modernism and Imperialism.' Eagleton, Nationalism 43-66.

----. 'Postmodernism and Consumer Society.' Postmodernism and Its Discontents (London: Verso-New Left Books, 1989.

Macciocchi, Maria-Antonietta. 'Female Sexuality in Fascist Ideology.' Feminist Review 1 (1979): 67-82.

Said, Edward. 'Yeats and Decolonization.' Eagleton, Nationalism 6995.

Tee, Garry J. 'Hildebrand Bowman in New Zealand'. Islands 3.2 (1974): 215-17.

Tiffin, Helen. 'Post-Colonialism, Post-Modernism and the Rehabilitation of Post-Colonial History.' Journal of Commonwealth Literature 23.1 (1988): 167-181.

Williams, Mark. Introduction. Journal of Commonwealth Literature 26.2 (1991): 112-120.

---. Leaving The Highway Auckland: Auckland UP1990, 11-29.

Wilcox, Leonard. 'Postmodernism or Antimodernism?' Landfall 39 (1985): 344-64. 
Yarwood, Vaughan. The Use of Paradigm: Classical Models of Empire in Early New Zealand Writing'. Journal of New Zealand Literature 4 (1986): 10-20.

(b) BOOKS AND MONOGRAPHS

Eagleton, Terry, Frederic Jameson, and Edward Said. Nationalism. Colonialism and Literature. Minneapolis: Minnesota UP, 1990.

Gibbs, Philip The Romance of Empire. London: Hutchinson, n.d.

Hulme, Keri. The Bone People. Auckland: Spiral-Hodder. 1985

Jones, Lawrence. Barbed Wire and Mirrors:Essays on New Zealand Prose Dunedin: Otago UP, 1987.

--. 'The Novel.' The Oxford History of New Zealand Literature ed. Terry Sturm. Auckland: Oxford U P, 1991.

Koonz, Claudia Mothers in the Fatherland. London: Methuen, 1988.

Lee, John, A., Soldier. Wellington: Reed, 1976.

Moi, Toril, Sexual/Textual Politics: Feminist Literary Theory. London: Methuen, 1988. 
Smith, E. M., A History of New Zealand Fiction. Dunedin: Reed, 1939.

Oliver, W. H. The Story of New Zealand. Wellington: Oxford UP, 1981.

Said, Edward. Orientalism. Harmondsworth: Penguin,1978.

Sinclair, Keith. A History of New Zealand.London: Allen LanePenguin 1980.

Stead, C. K. In the Glass Case: Essays on New Zealand Literature Auckland: Auckland UP, 1981.

Southey, Robert. Joan of Arc: Ballads. Lyrics, and Minor Poems. London: Routledge, 1894.

Wilson, George H. Ena, or the Ancient Maori. London: Smith, 1874.

Wood, F. L. W. New Zealand in the World Wellington: Dept of Internal Affairs, 1940.

Woolf, Virginia. The Death of the Moth and Other Essays New York: Harcourt, 1942

(c) REFERENCE WORKS

Oxford English Dictionary. Glasgow: Oxford University Press, 1971.

A Feminist Dictionary. London: Pandora Press-Routledge, 1985. 